University of Louisville

ThinkIR: The University of Louisville's Institutional Repository

Electronic Theses and Dissertations

8-2010

\title{
Temporal environmental traffic capacity for urban streets.
}

Yu Xia 1980-

University of Louisville

Follow this and additional works at: https://ir.library.louisville.edu/etd

\section{Recommended Citation}

Xia, Yu 1980-, "Temporal environmental traffic capacity for urban streets." (2010). Electronic Theses and Dissertations. Paper 1600.

https://doi.org/10.18297/etd/1600

This Doctoral Dissertation is brought to you for free and open access by ThinkIR: The University of Louisville's Institutional Repository. It has been accepted for inclusion in Electronic Theses and Dissertations by an authorized administrator of ThinkIR: The University of Louisville's Institutional Repository. This title appears here courtesy of the author, who has retained all other copyrights. For more information, please contact thinkir@louisville.edu. 
TEMPORAL ENVIRONMENTAL TRAFFIC CAPACITY FOR URBAN STREETS

By

Yu Xia

B. S., Southeast University, 2002

M. S., Southeast University, 2006

\author{
A Dissertation \\ Submitted to the Faculty of the \\ Graduate School of the University of Louisville \\ in Partial Fulfillment of the Requirements \\ for the Degree of
}

\title{
Doctor of Philosophy
}

Department of Civil and Environmental Engineering University of Louisville

Louisville, Kentucky

August 2010 
Copyright 2010 by Yu Xia

All rights reserved 

TEMPORAL ENVIRONMENTAL TRAFFIC CAPACITY FOR URBAN STREETS

\author{
By
}

\title{
Yu Xia
}

B. S., Southeast University, 2002

M. S. Southeast University, 2006

A Dissertation Approved on

July 31,2010

by the following Dissertation Committee:

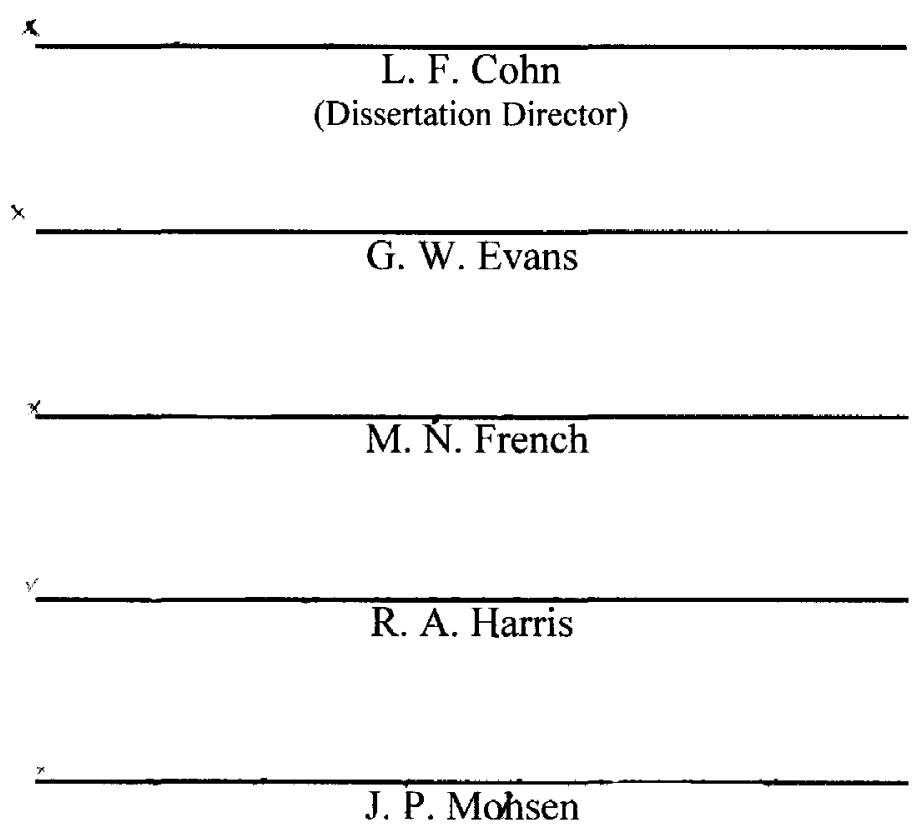




\section{DEDICATION}

This dissertation is dedicated to

my parents

for their invaluable love 


\section{ACKNOWLEDGMENTS}

I am grateful to many people who have contributed to make this dissertation possible.

First of all, I would like to extend my most sincere gratitude to my advisor, Dr. Louis F. Cohn, for his guidance, support and inspiration during my four years at the University of Louisville. I truly admire his enthusiasm, patience, and generosity.

My sincere appreciation goes to Dr. Evans, Dr. French, Dr. Harris, and Dr. Mohsen, for their advising on my work, and for their serving on the committee.

Particular recognition goes to Prof. Tiezhu Li from Southeast University, for providing the equipment and tools, more importantly, for his advice on this research.

Thanks to Arnold Sherwood from the Southern California Association of Governments, for his guidance on emission models and suggestion on research ideas.

My special thanks go to Hao Cheng and Yan Jiang, for their precious friendship.

Thanks to many others who have ever been helpful.

In the end, I would like to express my most genuine gratitude to my parents, for their years of support, encouragement and love.

Thank you. 


\begin{abstract}
TEMPORAL ENVIRONMENTAL TRAFFIC CAPACITY FOR URBAN STREETS
\end{abstract}

Yu Xia

July 15,2010

The purpose of this dissertation is to develop a methodology to estimate the temporal Environmental Traffic Capacity (ETC) for urban streets. The approach constitutes the main procedure of ETC calculation and an experimental process of developing an emission inventory. The major contribution of this study includes results that support the development of traffic control policies to alleviate the negative impacts of on-road emission sources, and suggestions for future research to optimize road capacity with respect to air quality.

A framework is proposed for the combination of the traffic volume model developed in this dissertation with the Danish OSPM (Operational Street Pollution Model), a dispersion model, to calculate the ETC. The time-dependent traffic volume is connected with the time-dependent ETC via the average speed generated by a traffic speed-flow model. The basis for estimating the ETC is an inverse modeling of the OSPM. This method is improved by a further inverse modeling of the traffic volume model, which was developed in this research, to obtain the values of ETC for each hour under 
consideration.

An experimental process is designed for the development of a weight-based emission inventory. A probability approach is applied to calculate the emission factors based on speed and acceleration variations. This method results in a weighted-emission inventory by a series of speed-acceleration combinations, for each of three categories of test vehicles, of $\mathrm{CO}_{2}, \mathrm{CO}, \mathrm{HC}$, and $\mathrm{NO}_{\mathrm{x}}$ emissions. Using a real-site case study, the implementation of the methodology to estimate the ETC of a road section in a congested area for ten consecutive hours on a regular weekday is demonstrated.

It has shown that the ETC is closely related to the joint effects of meteorology and traffic conditions. Two options of improvements using the ETC to relieve the traffic pollution are also presented at the end of the case study. The result indicates that increasing the speed limit of the whole area has better effect on reducing the traffic pollution than reconfiguring the physical dimension of the road section. 


\section{TABLE OF CONTENTS}

PAGE

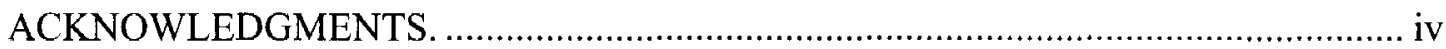

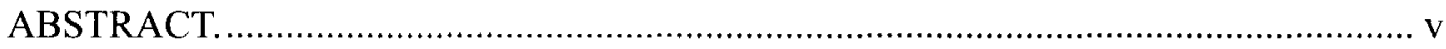

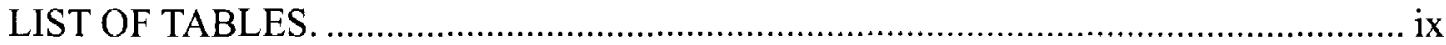

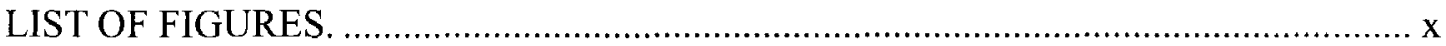

Chapter 1 Introduction ....................................................................................... 1

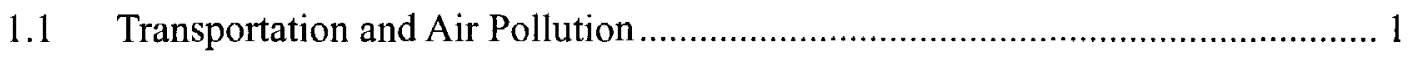

1.2 Environmental Traffic Capacity .................................................................. 3

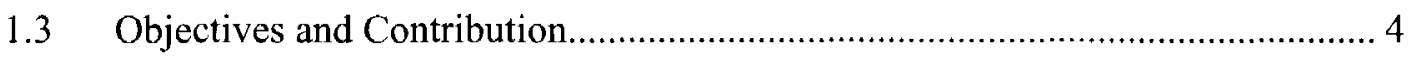

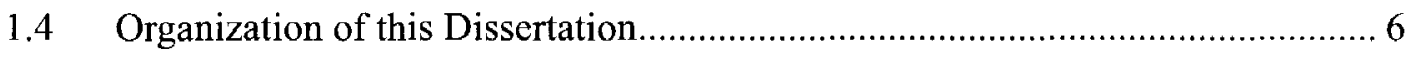

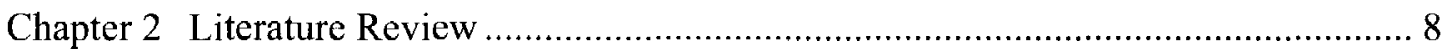

2.1 Dispersion Models for Traffic-Related Air Pollutants .................................... 8

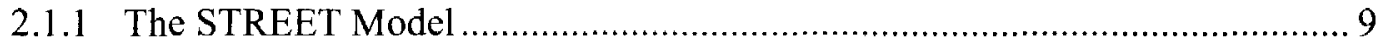

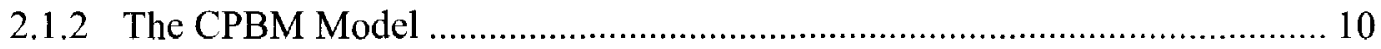

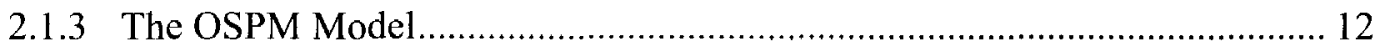

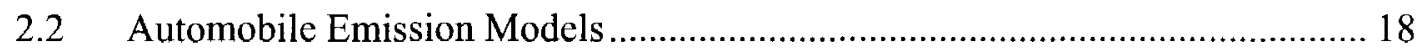

2.2.1 Parameters of Emission Modeling ....................................................... 19

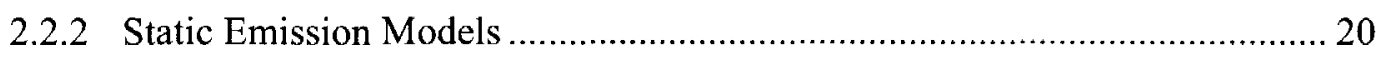

2.2.3 Dynamic Emission Models......................................................................... 20

2.2.4 Modal Emission Model ........................................................................... 25

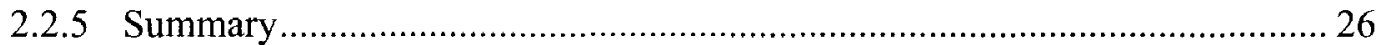

2.3 Environmental Capacity (EC): Concept and Approaches ............................. 26

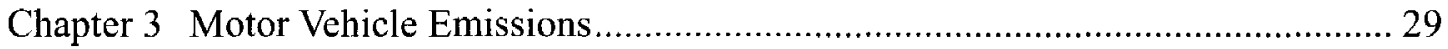

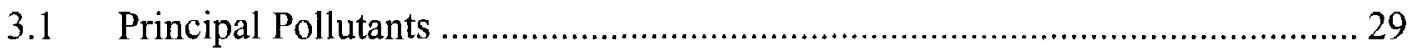

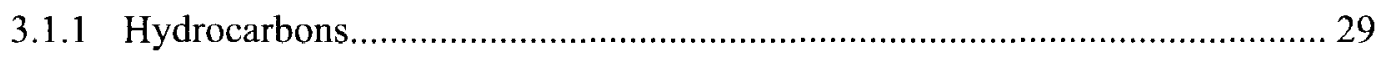

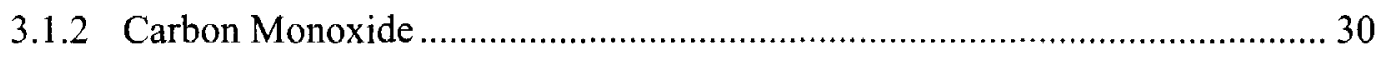

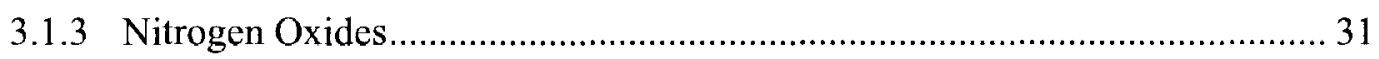




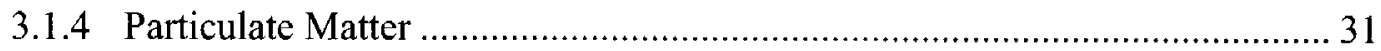

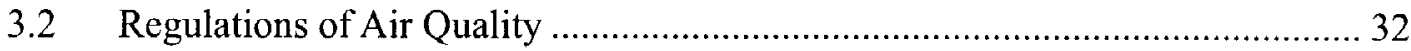

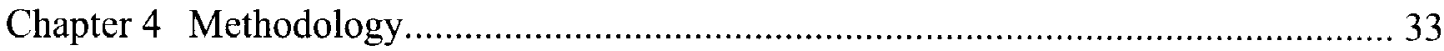

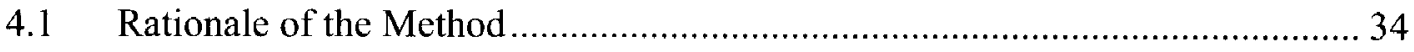

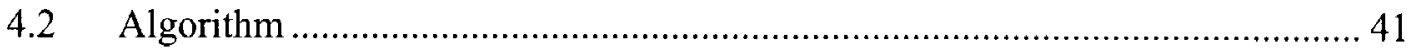

4.2.1 Dilution Factor and Concentration ......................................................... 41

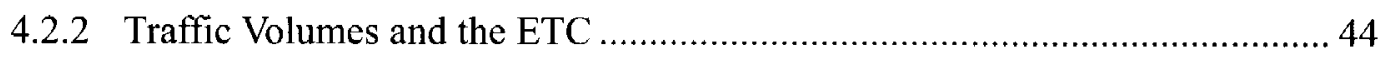

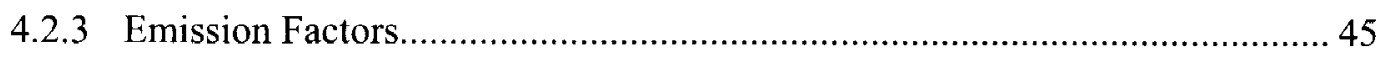

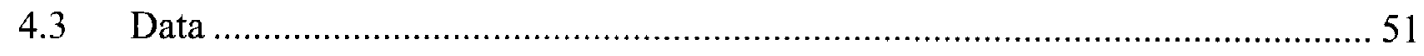

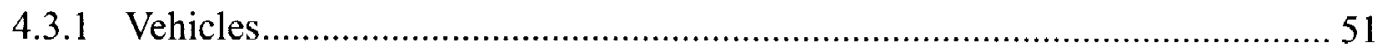

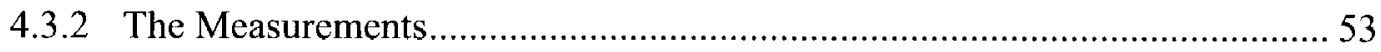

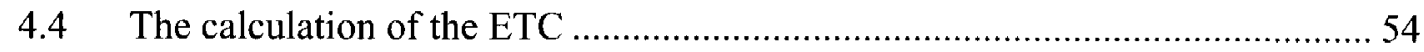

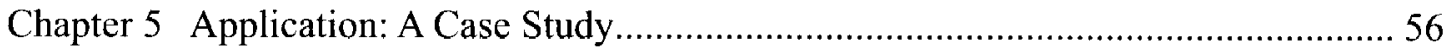

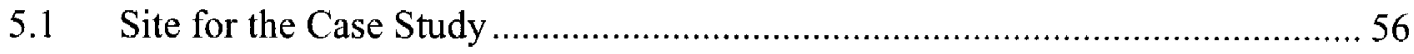

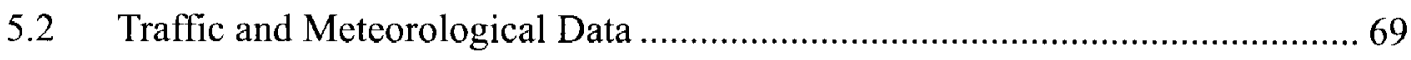

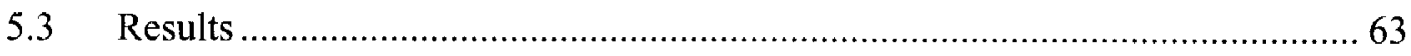

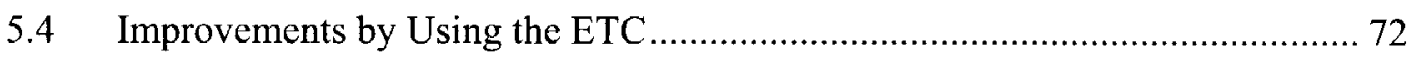

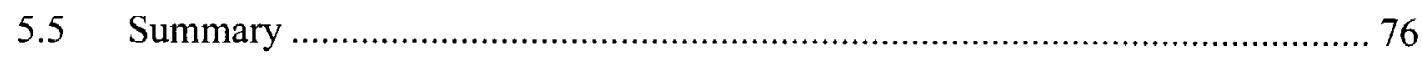

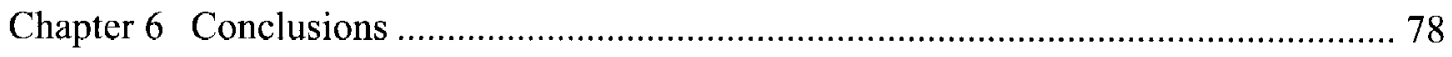

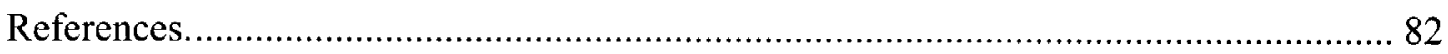

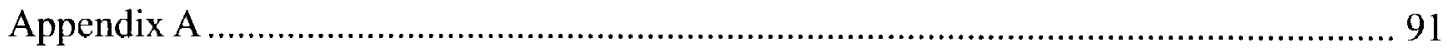

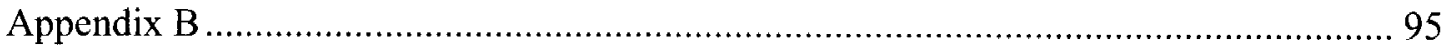

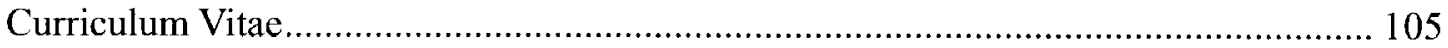




\section{LIST OF TABLES}

TABLE

PAGE

TABLE 4-1

TABLE 4-2 .

TABLE 4-3

TABLE 4-4

TABLE 4-5 ……

TABLE 4-6

TABLE 4-7 ...

TABLE 4-8

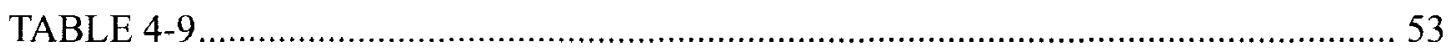

TABLE 5-1 .

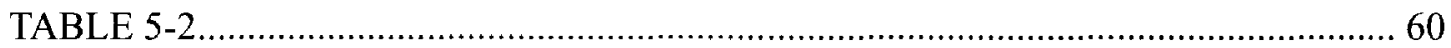

TABLE 5-3

TABLE 5-4

TABLE 5-5

TABLE 5-6

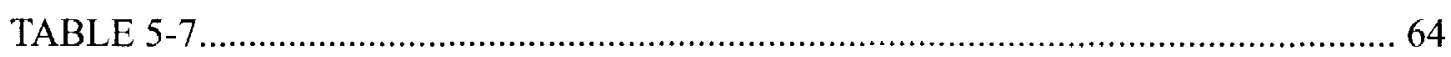

TABLE 5-8

TABLE 5-9

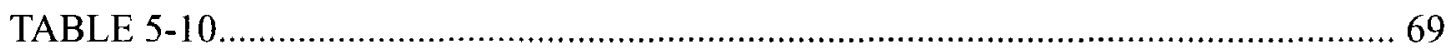

TABLE 5-11 ...

TABLE 5-12

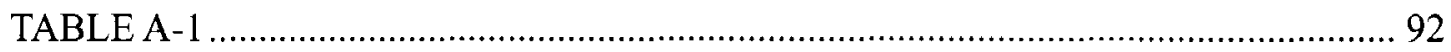

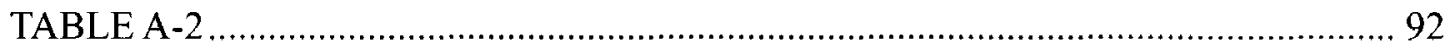

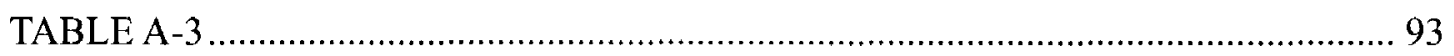

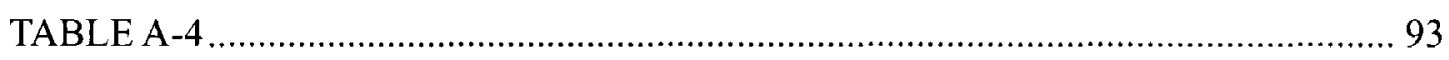

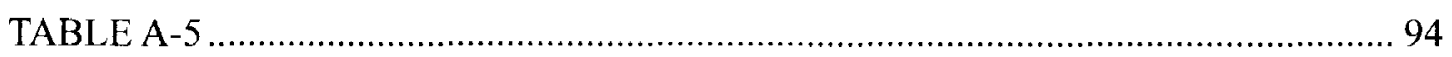

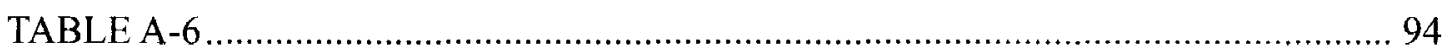




\section{LIST OF FIGURES}

FIGURE

PAGE

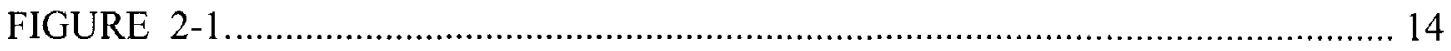

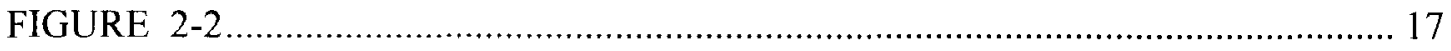

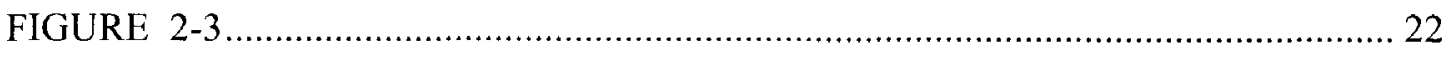

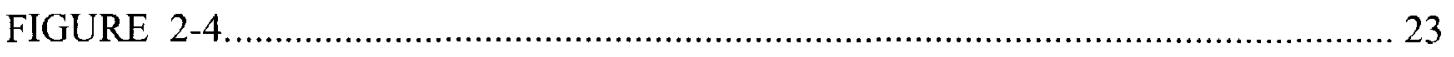

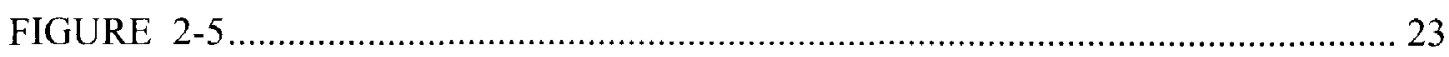

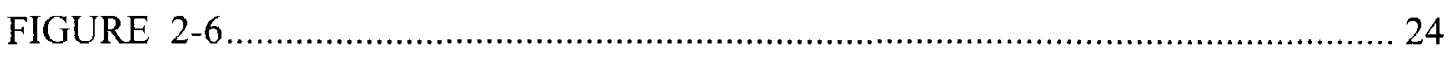

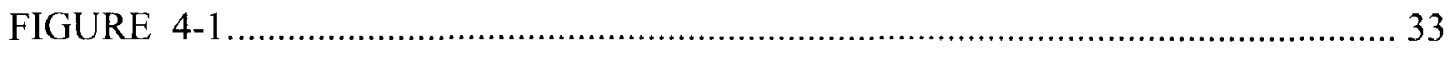

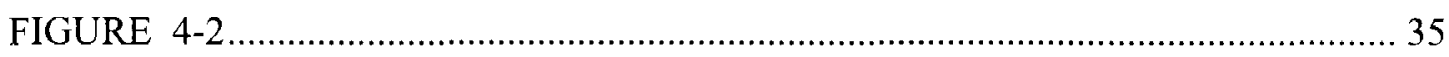

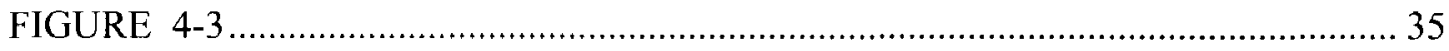

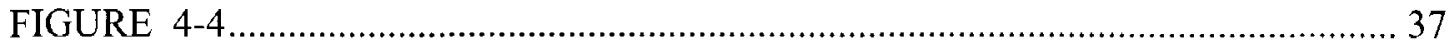

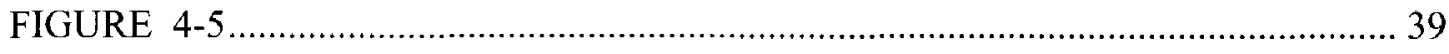

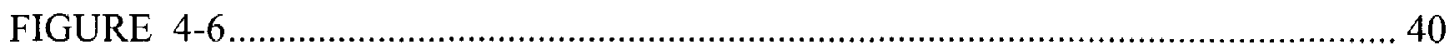

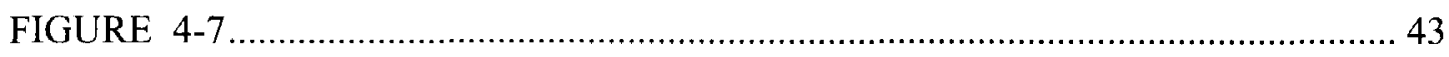

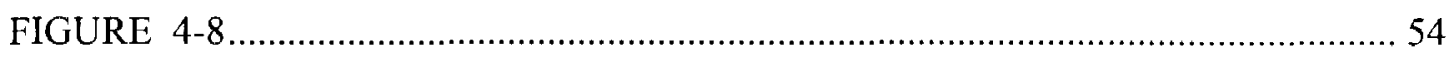

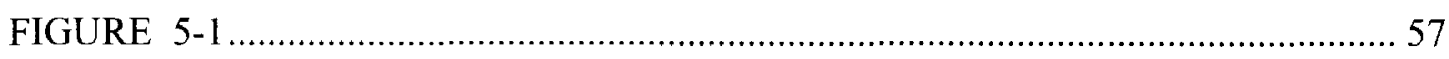

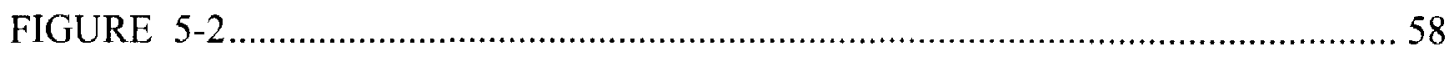

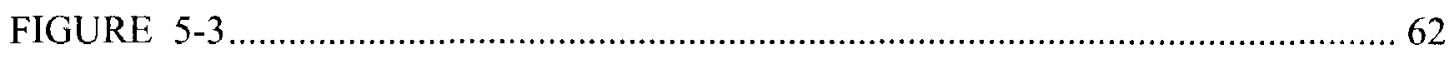

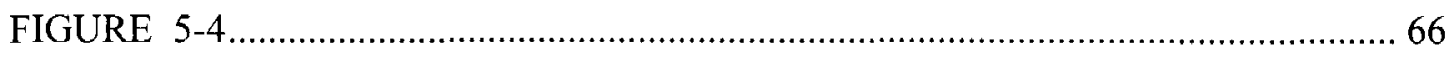

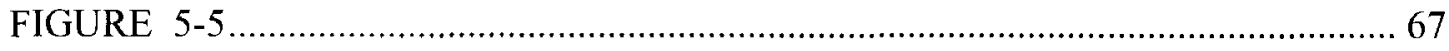

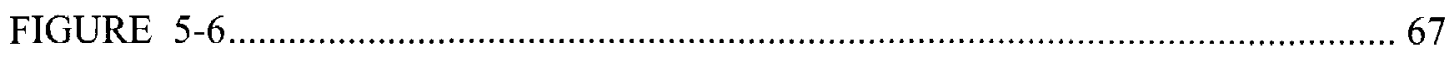

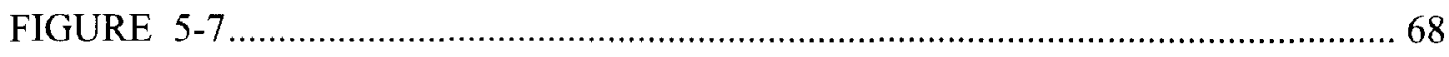

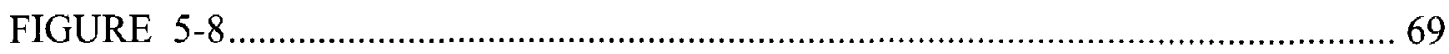

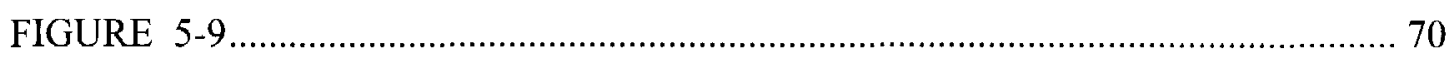

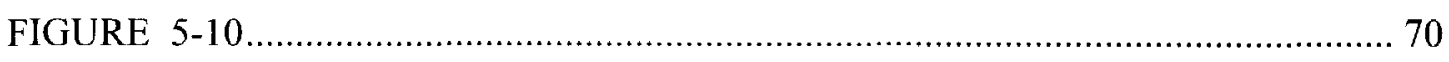

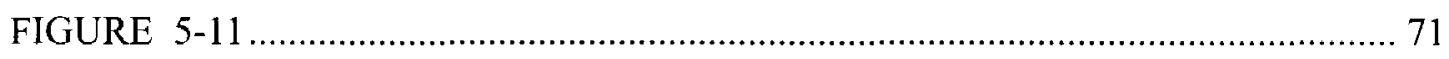

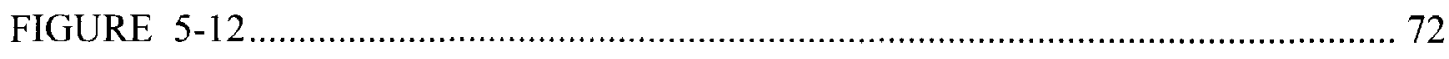

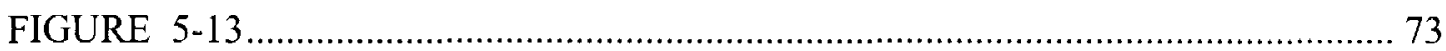




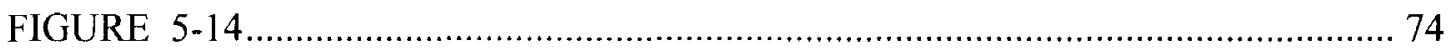

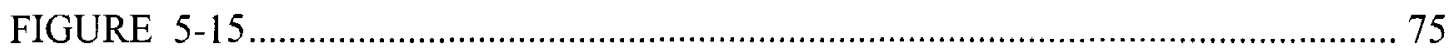

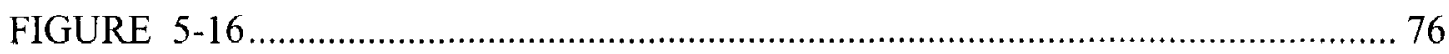

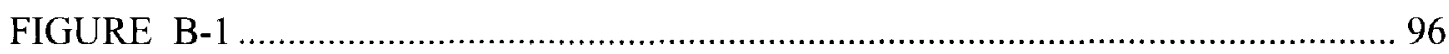

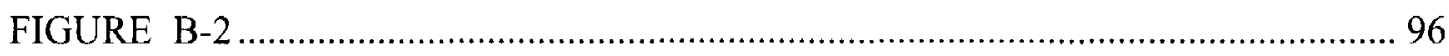

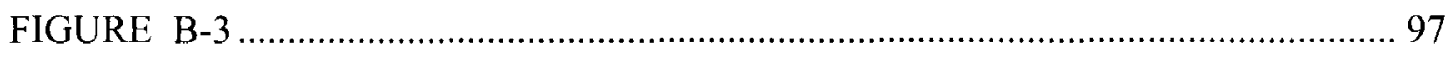

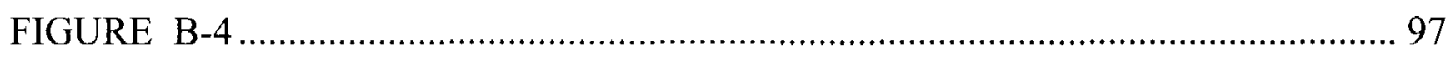

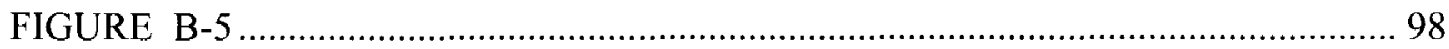

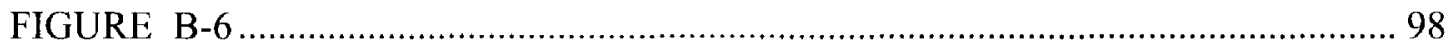

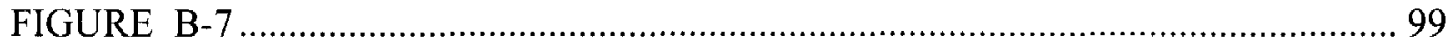

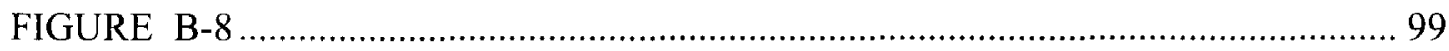

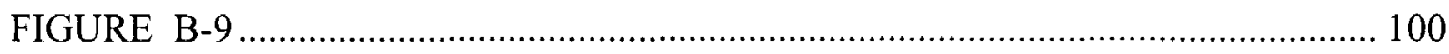

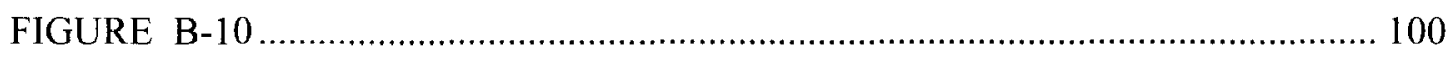

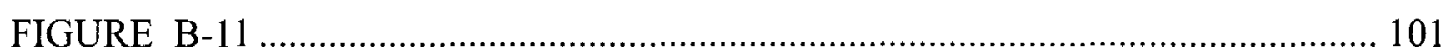

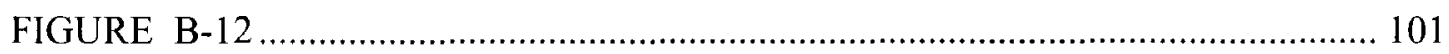

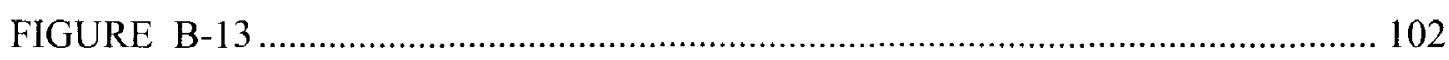

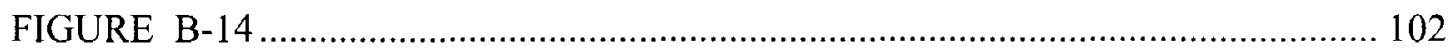

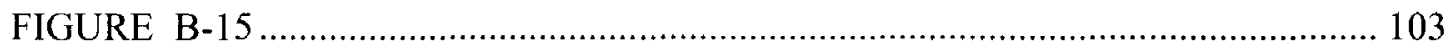

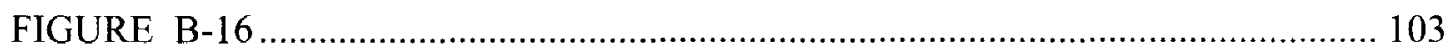

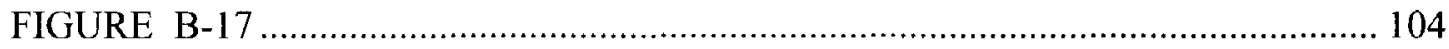

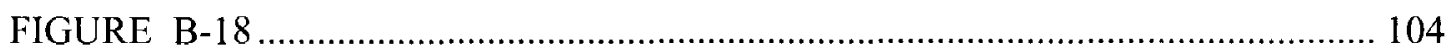




\section{CHAPTER 1 INTRODUCTION}

This dissertation develops a methodology to estimate the Environmental Traffic Capacity (ETC) for roads or streets carrying heavy traffic in urban areas. In this study, the ETC is concerned with the traffic capacity by deploying criteria of air quality. The final capacity of a road or street for traffic, with respect to air quality, is presented for each of the featured hours (am/pm peak hours, daytime hours, business hours) of a weekday, to determine the appropriate time-dependent traffic volumes in the concerned area. The results are expected to help supplement traffic policy designed to reduce ambient air pollution in communities adjacent to streets in urban areas.

This chapter introduces the concept of the ETC and the context in which the temporal ETC needs to be studied, and presents the objectives, contributions and organization of the dissertation.

\subsection{Transportation and Air Pollution}

Transportation provides basic mobility for the movement of people and goods as well as accessibility from residences to workplaces, schools, business, recreation, and other social and economic events (Ritchie, 1987). However, the price of this benefit is the deterioration of the environment, especially the degradation of air quality around the world. In recent decades, road transportation has been one of the major contributors to the 
emission of air pollutants, such as hydrocarbons, carbon monoxide, carbon dioxide, and particulate matters (WBCSD, 2001). According to a study by the United States Environmental Protection Agency (EPA), 50\% of the carbon monoxide in typical U.S. cities comes from mobile sources, and $32 \%$ of the nitrogen oxides come from on-road mobile sources (EPA, 2009). In Europe, road traffic is a major contributor to the "greenhouse" gas, Carbon Dioxide $\left(\mathrm{CO}_{2}\right)$; these emissions are expected to increase steadily with the increasing amount of traffic.

In developing countries, the situation has been worse. A study by Asian Development Bank (2003) presented that SPM (suspended particulate matter) concentrations in Shanghai, Calcutta, and Bangkok reached a level of $270\left(\mu \mathrm{g} / \mathrm{m}^{3}\right), 360\left(\mu \mathrm{g} / \mathrm{m}^{3}\right), 180\left(\mu \mathrm{g} / \mathrm{m}^{3}\right)$ respectively, which exceeded the World Health Organization's (WHO) limit of $90\left(\mu \mathrm{g} / \mathrm{m}^{3}\right)$. Gaseous pollutants from motor vehicles have adverse effects on health, which are believed to be associated with cardio-respiratory mortality and morbidity (Hoek, 2002; Hoffman, 2007). According to Air Pollution Control (2007), air pollution and fuel consumption caused by on-road transportation has been considered one of the essential topics addressed by national and local regulations as well as international agreements (IGES, 2007).

For gasoline-fueled motor vehicles, the efficient fuel consumption and low exhaust emission occur in the speed range of $50-70 \mathrm{~km} / \mathrm{hr}(\mathrm{Li}, 2001)$. However, impacts of population growth, industrialization and motorization have led to an increase in the number of personal vehicles. An increase in urban sprawl has also resulted in more overall mileage, heavy traffic congestion, and hence, higher levels of air pollution (Shiran, 1997).

It is believed that emissions and fuel consumption are closely related to congestion 
(Colornie, 1999). Congestion corresponds to increases in the traffic density, as well as in the frequency of accelerations and decelerations, which are believed to lead to higher fuel consumption and more emissions. Since speeds over $70 \mathrm{~km} / \mathrm{hr}$ usually lead to high emissions (Li, 2001; Zhu, 2008), and favorable traffic conditions may encourage more frequent and longer trips (Litman, 2001) which consequently cause more fuel consumption and emissions, reduction in congestion, however, may not always help decrease the total emissions. In other words, emissions may not be reduced by relieving the congestion itself. Therefore, it is necessary to consider emissions and congestion with a variety of criteria, seeking a balance between the benefits of transportation and the protection of the environment.

\subsection{Environmental Traffic Capacity}

In environmental science and engineering, the notion of Environmental Capacity (EC) has been defined as the maximum amount of pollutants that is allowed into the ambient air with respect to air quality regulations and standards (Shiran, 1997). For the transportation sector, the notion of EC was introduced by Colin Buchanan in 1963. In his book Traffic in Towns, Buchanan defined EC as the capacity of a street or an area to accommodate moving and stationary vehicles with regard to environmental standards. He used the delay time of pedestrians crossing the streets as the estimating criterion. Later, air pollution was introduced to calculate EC for a set of road links based upon the living standards of residents in the concerned neighborhoods (Sharpe \& Maxman, 1973). Considering the traffic capacity itself, this term has been defined in the Highway Capacity Manual as the "maximum hourly rate that persons or vehicles can reasonably be expected to traverse a point or uniform section of a lane or roadway during a given time period under 
prevailing roadway, traffic and control conditions" (Transportation Research Board [TRB], 2000, p 2-2).

The main purpose of this study is to relate transportation activities to environmental impact using air quality as the applicable criterion. This requires one terminology to differentiate the definitions in both environmental and transportation sectors. The question is how to control the traffic-generated air pollution by determining the appropriate traffic capacity with respect to air quality standards. First, the standards or regulated concentration of pollutants from traffic within a given area during a given period of time must be appropriately addressed. Secondly, a limitation must be set for the amount of traffic in order to keep the emissions under the regulated level. The upper limit of traffic volume is defined as the ETC ( $\mathrm{Li} \& \mathrm{Lin}, 2009$ ). This dissertation is designated to study the ETC of urban streets under temporal traffic and meteorological conditions.

\subsection{Objectives and Contribution}

The scope of this study is to develop a methodology to estimate the traffic capacity of urban streets during different hours with respect to air quality considerations.

Speed has been used in air quality models as an important indicator to estimate vehicle emissions (Margiotta, 1996). Since the variance in the speed of vehicles follows a time-dependent pattern, with low speeds in heavy hours and high speeds in hours with less traffic, the emissions are also time-related and should have time-dependent characteristics. The traffic emission studies are based on the local environment, which means that the configuration of streets, time-varying traffic conditions, and weather conditions should be included in the analysis.

The first step of this study is to determine the framework of the ETC model, which 
consists of a model of pollutant concentrations and a model of emission factors. The ETC is calculated by a process of inverse modeling of existing concentration models with inputs of emission factors and meteorological data.

The second step is to determine the emission status of vehicles during different time periods. For example, operating in peak hours or non-peak hours will have a significantly different influence on the vehicles' energy consumption and emissions. The hourly volume on a lane or road varies over time, which results in the fluctuation of speed. It is reasonable to conclude that there will be a connection between the emission factors of the vehicles and the hourly traffic volume on a street.

In the third step, the ETC model and emission factors model will be combined to calculate the traffic volumes with respect to air quality considerations.

In summary, the objectives of this study include:

1. To develop a new ETC model by inverse modeling of an existing dispersion model.

2. To integrate emission factors and traffic volumes, in order to develop the timedependent emission factors as a function of the volume.

3. To determine how ETC varies over time by combining the ETC model and emission factors model.

This study provides answers to the objectives presented above. Its contribution to the sum of knowledge includes the following:

1. Some of the limitations of the existing ETC models are improved by considering instantaneous emission factors of vehicles (light-duty gasoline vehicles and diesel buses). 
2. A methodology is developed to calculate ETC by inverse modeling of existing concentration models.

3. An inventory of emission factors is developed by integration with traffic data to calculate time-dependent emissions from on-road vehicles.

4. The process is applied to a typical road section in a medium-sized city (Nanjing, China), and the ETC of selected featured hours is calculated, which can be of reference for policy makers.

5. Limitations of the study and recommendations are made for further studies.

Since the primary objective of this study is to provide a method for the more general purpose of calculating the ETC, it is dedicated to developing a methodology for estimating the ETC, rather than introducing new emission and/or dispersion models.

\subsection{Organization of this Dissertation}

Chapter Two presents a literature review of studies related to ETC, such as the dispersion model, motor vehicle emission model, and ETC studies that have been done by others.

Chapter Three provides a summary of primary emissions from on-road motor vehicles. The regulations on air quality in the United States are also described.

Chapter Four describes the methodology developed to calculate the ETC. It also describes the measurement of instantaneous emissions and provides an inventory of weighted emission factors, which is used as inputs to estimate the ETC of a road section in a case study presented in the following chapter. 
Chapter Five describes the application of the approach presented in Chapter Four. The method is used for a typical congested road section in the downtown area of Nanjing, a medium-sized city with a population of six million in southeast China. The ETC is presented for each of the ten consecutive hours of a regular weekday in the winter.

Chapter Six presents the conclusions of this dissertation. The contributions and limitations of this study are also discussed. Future research is recommended at the end of this chapter. 


\section{CHAPTER 2 LITERATURE REVIEW}

In this chapter, a comprehensive literature review is presented. Three main areas related to the study of Environmental Traffic Capacity (ETC) are included. They are dispersion modeling, on-road emission modeling, and the methodologies that have been developed for the ETC studies by others.

Section 2.1 discusses the dispersion models developed and used since early 1970s. Section 2.2 introduces and compares the existing mobile source emission models. Section 2.3 presents a brief introduction of the environmental capacity for transportation and the development of the approaches to calculate the environmental capacity.

\subsection{Dispersion Models for Traffic-Related Air Pollutants}

The mathematical principles of dispersion modeling are basically derived from those of wind flow modeling. The equations work as the steady state mass conservation equation for a scalar (Berkowicz, 1997):

$$
u_{j} \frac{\partial c}{\partial x_{j}}=-\frac{\partial \overline{\bar{c}^{\prime u_{j}^{\prime}}}}{\partial x_{j}}+S
$$

where,

$u_{j}$ - mean velocity of wind field at coordinates $x, y, z$;

$u_{j}^{\prime}-$ turbulent fluctuation components (the deviations of the mean velocity);

$c$ - mean concentration; 
$c^{\prime}$ - deviation of the mean value of $c$;

$S$ - possible sources and sink terms;

$\overline{c^{\prime} u_{j}^{\prime}}$ - turbulent flux term;

The turbulent flux term in Equation 2-1 can be calculated by using the eddy diffusivity concept (Sievers, 1986), where K denotes the eddy diffusivity coefficient,

$$
\overline{c^{\prime} u_{j}^{\prime}}=-K \frac{\partial c}{\partial x_{j}}
$$

The following sections introduce some existing dispersion models designed to calculate traffic pollution for roads.

\subsubsection{The STREET Model}

The STREET model was developed by Johnson et al. in 1973. The model was developed based on the data of pollution collected in St. Louis and San Jose. The model defined the concentration of pollution on street sides as the summation of the local contribution $C_{t}$ from traffic and the background contribution $C_{b}$ from sources other than motor vehicles (Berkowicz, 1997).

$$
c=c_{t}+c_{b}
$$

For the windward side,

$$
c_{t}=\frac{K}{\left(u+u_{t}\right)} \frac{H-z}{H} \sum_{\mathrm{i}} \frac{\mathrm{Q}_{\mathrm{i}}}{\mathrm{W}}
$$

For the leeward side,

$$
c_{t}=\frac{K}{u+u_{t}} \sum_{\mathrm{i}} \frac{\mathrm{Q}_{\mathrm{i}}}{\left[\left(\mathrm{x}_{\mathrm{i}}{ }^{2}+\mathrm{z}^{2}\right)^{0.5}+\mathrm{h}_{0}\right]}
$$

where, 
$H$ - height of the street;

$W$ - width of the street;

$Q_{i}$ - emission strength of the $i$-th lane;

$K$ - empirical constant;

$u_{t}-$ air movement caused by traffic;

$h_{0}$-initial mixing height of pollutants;

$x_{i}$ - horizontal distance between axis of the $i$-th lane and the receptor point;

$z$ - vertical distance between axis of the $i$-th lane and the receptor point;

It should be mentioned that the previous equations are for situations in which the direction of wind is at an angle of more than 30 degrees with the axis of the street. The STREET model is not designed for wind blowing at an angle less than 30 degrees (Berkowicz, 1997).

\subsubsection{The CPBM Model}

In Yamartino et al. (1986), the Canyon Plume-Box Model (CPBM) was developed by combining a plume model with a box model. The plume is assumed to follow the Gaussian plume dispersion theory. The box model is used to compute additional contributions generated by recirculation in the street (Berkowicz, 1997). The vertical dispersion parameter for CPBM is given by,

$$
\sigma_{t}(t)=H_{1} / \sqrt{2 \pi}+\sigma_{w} \cdot t
$$

where,

$H_{I}$ - initial plume dispersion;

$\sigma_{w}$ - height of effective source (set as half of vehicle height); 
The concentrations caused by the recirculation can be calculated by Equation 2-7, which is based upon the considerations of the mass budget in the street (Yamartino et al, 1986):

$$
C_{R}=\frac{Q}{v_{c}(W / 2)} \frac{F}{(1-F)}
$$

where,

$Q$ - emission rate per unit length of street;

W - width of the street;

F - fraction of recirculated material, which can be given by:

$$
\begin{gathered}
F=\exp \left(-t_{s} / \tau\right) \\
t_{s}=2 H / u_{b}
\end{gathered}
$$

where,

$t_{s}-$ vortex recirculation time scale;

The street canyon ventilation speed is determined by the life time, $\tau$ :

$$
\tau^{-1}=\tau_{a}^{-1}+\tau_{d}^{-1}
$$

where,

$\tau_{a}$ - advective component;

$\tau_{d}$ - diffusive component;

and,

$$
\begin{gathered}
\tau_{a}^{-1}=\frac{\sqrt{2 \pi} \sigma_{j} w_{j}}{H \cdot W} \\
\tau_{d}^{-1}=\left(W-2 \sqrt{2 \pi} \sigma_{j}\right) \sigma_{w t} /(\sqrt{2 \pi} H \cdot W)
\end{gathered}
$$


where,

$\sigma_{j}-$ size of the fresh air plume;

$w_{j}$ - speed of the fresh air plume;

$\sigma_{\mathrm{wt}}-$ turbulent velocity;

In the CPBM model, $w_{j}$ is calculated by the method developed by Hotchkiss and Harlow (1973); $\sigma_{j}$ can be empirically set as 0.25 meter (Hertel et. al, 1989).

\subsubsection{The OSPM Model}

Based on similar principles to the CPBM introduced by Yamartino and Wiegand (1986), the Operational Street Pollution Model (OSPM) was initially developed in 1989 by Hertel and Berkowicz. The OSPM simplified the parameterization of flow and dispersion conditions in a street canyon, which was derived from extensive model tests and data analysis. By using the results of these tests, the model performance was remarkably improved, especially for scenarios with various meteorological and traffic conditions (Berkowicz et al., 1995).

The OSPM uses a simple plume model for the direct contribution and a box model for the contribution of recirculation. The total concentration of emissions from traffic is calculated as the sum of the direct and recirculation contributions:

$$
C=C_{d}+C_{r}
$$

where $C_{d}$ is the concentration directly contributed by wind at street level, and $C_{r}$ is the concentration contributed by the recirculation in the canyon.

\subsubsection{The Direct Contribution}

A basic assumption of the OSPM is that the traffic emissions are distributed evenly 
along the street. Each lane of the roadway is treated as an "infinitesimal line source of emissions" (Berkowicz et al., 1997, p. 26). The density of emissions for such a line source is:

$$
d Q=\frac{Q}{W} d x
$$

where,

$W$ - width of the street;

$Q$ - emission rate of the line source $(\mathrm{g} / \mathrm{m} / \mathrm{s})$;

The contribution to the concentration at a point located at a distance $x$ from the line source is given by,

$$
d C_{d}=\sqrt{\frac{2}{\pi}} \frac{d x}{u_{b} \sigma_{z}(x)}
$$

Where,

$d C_{d}-$ direct contribution from the line source;

$\sigma_{z}(x)$ - vertical dispersion parameter at downwind distance $x$;

$u_{b}-$ wind speed at the street level;

Equation 2-15 is integrated along the wind path at the street level, which depends on the street length, the wind direction, and the extension of the recirculation zone (Berkowicz et al., 1997). The integration path for Equation 2-14 is illustrated in Figure 2-1. If the wind blows at an angle $\theta$ compared to the street axis, the street level wind in the recirculation zone also forms an angle $\theta$ with the street axis. The wind direction outside the recirculation zone is the same as roof-level wind.

Equation 2-14 is integrated along the wind path on the street level. The length of the integration path is the same as the length of the vortex $\left(L_{v o r t e x}\right)$, which is estimated as 
twice the height of the upwind building $H_{u}$. It is assumed that $L_{v o r t e x}$ decreases with wind speed linearly for roof-level wind speeds less than $2 \mathrm{~m} / \mathrm{s}$ (Berkowicz et al., 1997). For an oblique wind blowing at an angle $\theta$ with the street axis, and $\mathrm{L}_{\text {vortex }}>\mathrm{W}$, the width of the recirculation zone can be presented by:

$$
L_{r}=\min \left(W, L_{\text {vortex }} \cdot \sin (\theta)\right)=\min \left(W, 2 H_{u} \cdot \sin (\theta)\right)
$$

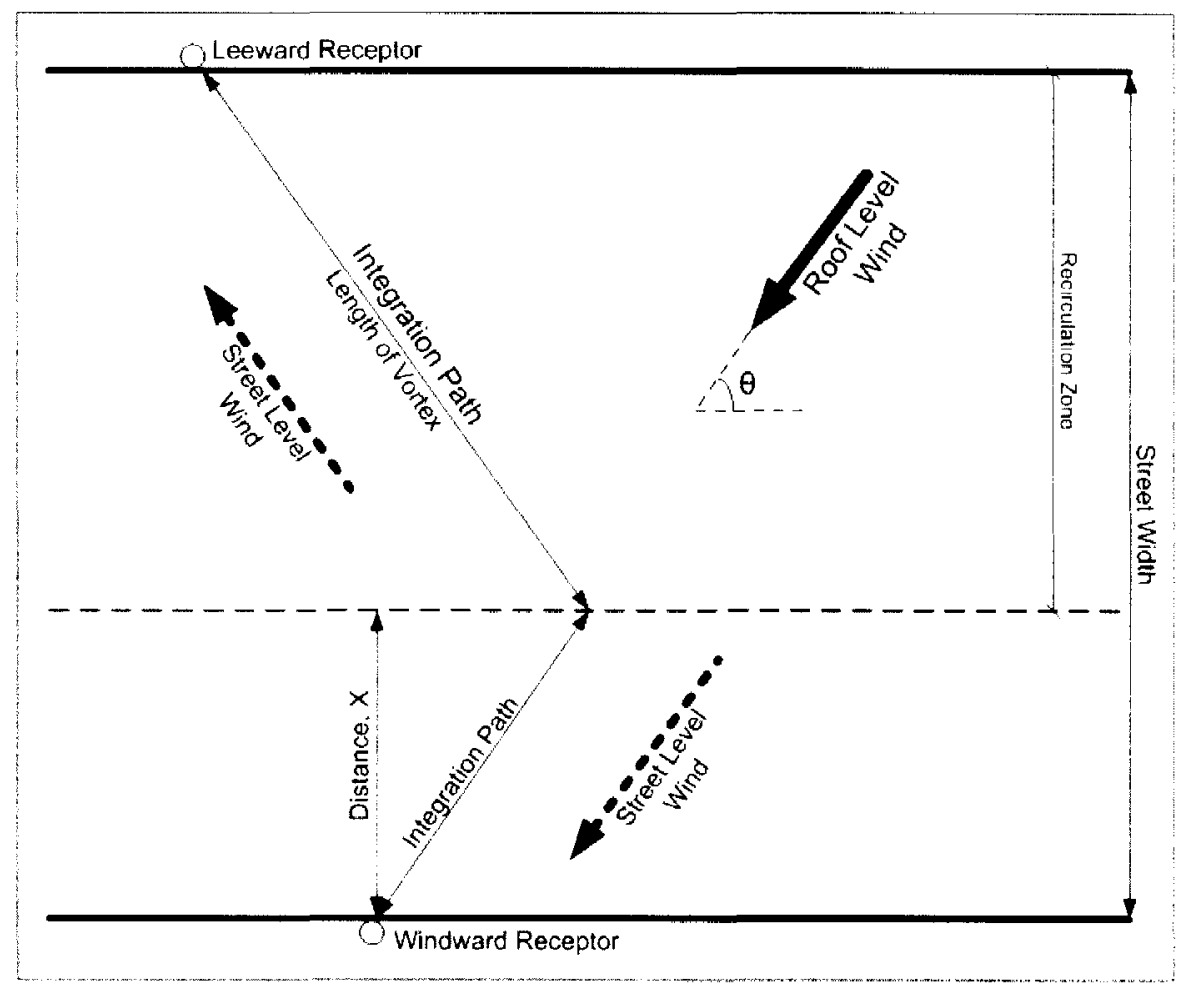

Figure 2-1: Wind directions and recirculation zone in a street canyon

It is assumed that the dispersion of the plume is determined by the vertical turbulence fluctuation, $\sigma_{w}$, which is generated by two mechanisms: 1) wind-induced turbulence, and 2) traffic-induced turbulence:

$$
\sigma_{w}=\left(\left(\alpha u_{b}\right)^{2}+\sigma_{t}^{2}\right)^{0.5}
$$

where,

$\alpha$ - empirical constant; 
$\sigma_{t}-$ turbulence induced by traffic;

The constant $\alpha$ is given a value of 0.1 by Hertel et al. (1994). The dispersion parameter of the plume at a distance $x$ is given by the following equation:

$$
\sigma_{z}(x)=\sigma_{w} \frac{x}{u_{b}}+h_{0}
$$

The parameter $h_{0}$ is the height of the immediate dispersion in traffic. It can be assumed that $h_{0}=2(\mathrm{~m})(\mathrm{Zhu}, 2008)$.

Consequently, the direct contribution is obtained by integrating Equation 2-14 along the integration path. Combined with Equations 2-15, 2-16, and 2-17, the result is:

$$
C_{d}=\sqrt{\frac{2}{\pi}} \frac{Q}{W \sqrt{\left.\left(\alpha u_{b}\right)^{2}+\sigma_{t}^{2}\right)}} \ln \left(1+\frac{\sqrt{\left(\alpha u_{b}\right)^{2}+\sigma_{t}^{2}} L_{r}}{u_{b} h_{0}}\right)
$$

where,

$Q-$ Emission rate, $\mathrm{g} / \mathrm{m} / \mathrm{s}$

$W$ - Width of the street, $\mathrm{m}$;

$u_{b}-$ Wind speed at street level, $\mathrm{m} / \mathrm{s}$;

$L_{r}-$ Length of recirculation zone, $\mathrm{m}$;

$h_{0}$ - Initial dispersion parameter, set as $2 \mathrm{~m}$;

$\alpha$ - Empirical constant, set as 0.1 ;

$\sigma_{t}-$ traffic-induced turbulence, set as $0.1 \mathrm{~m} / \mathrm{s}$ ( $\left.\mathrm{Zhu}, 2008\right)$;

\subsubsection{Recirculation Contribution}

For the OSPM, a box model has been applied to calculate the contribution from the recirculation component. Ventilation of the recirculation zone takes place through the edges of the box, which is assumed to have the shape of a trapezoid (Berkowicz et al., 
1997). The inflow rate per unit length is given by:

$$
I N F L O W=\frac{Q}{W} L_{r}
$$

The outflow rate through the top and side edges is given by:

$$
\text { OUTFLOW }=C_{r}\left(\sigma_{w t} L_{t}+v_{u} L_{s 1}+v_{l} L_{s 2}\right)
$$

where,

$\sigma_{w t}-$ flux velocity through the top edge of the box;

$v_{u}$ - flux velocity through the upper half of the side edge;

$v_{l}$ - flux velocity through the lower half of the side edge;

$L_{t}, L_{s l}, L_{s 2}-$ street canyon geometry parameters (see Figure 2-2);

To calculate the dispersion from the box, it is assumed that the canyon vortex is in the shape of a trapezoid, with the length of the upper edge being $0.5 L_{\text {vortex }}$, or the height of the side building $H\left(L_{\text {vortex }}=2 H\right)$, and the outflow rate of the pollutants into the recirculation zone is equal to the outflow rate, and the pollutants are well mixed inside the box (Hertel et al., 1994). According to Equations 2-19 and 2-20, it is given that:

$$
C_{r}\left(\sigma_{w t} L_{t}+v_{u} L_{s 1}+v_{l} L_{s 2}\right)=\frac{Q}{w} L_{r}
$$

In this study of ETC, the process of the box modeling is simplified by assuming that the flux velocities through the upper and lower half of the side edge are equal, and are given by:

$$
v_{u}=v_{l}=u_{d}
$$

where, $u_{d}$ is defined as speed of convection $(\mathrm{Fu}, 1998), u_{d}=\sqrt{u_{b}^{2}+\sigma_{t}^{2}}, u_{b}$ is the wind speed at street level, and $\sigma_{t}$ is the turbulence induced by traffic. The concentration 
brought by the effects of recirculation can be calculated by combining Equations 2-19 through 2-22. The result is given by:

$$
C_{r}=\frac{(Q / W) L_{r}}{\sigma_{w t} L_{t}+u_{d} L_{s}}=\frac{(Q / W) \min (W, 2 H \cdot \sin (\theta))}{\sigma_{w t} \cdot H+u_{d} L_{s}}
$$

where,

$Q$ - emission rate in the street canyon;

$W$ - width of the street;

$\theta$ - angle of wind direction and street axis;

$H$ - average height of the side buildings;

$\sigma_{w t}-$ flux velocity through the top edge of the box;

$L_{r}$ - length of the recirculation zone (the bottom edge, see Figure 2-2);

$L_{t}$ - length of the top edge of the recirculation zone;

$L_{s}$ - length of the side edge of the recirculation zone, $\mathrm{L}_{\mathrm{s}}=\mathrm{L}_{\mathrm{s} 1}+\mathrm{L}_{\mathrm{s} 2}$;

(Since $L_{t}=H, L_{s}=\sqrt{\left(L_{r}-H\right)^{2}+H^{2}}$ )

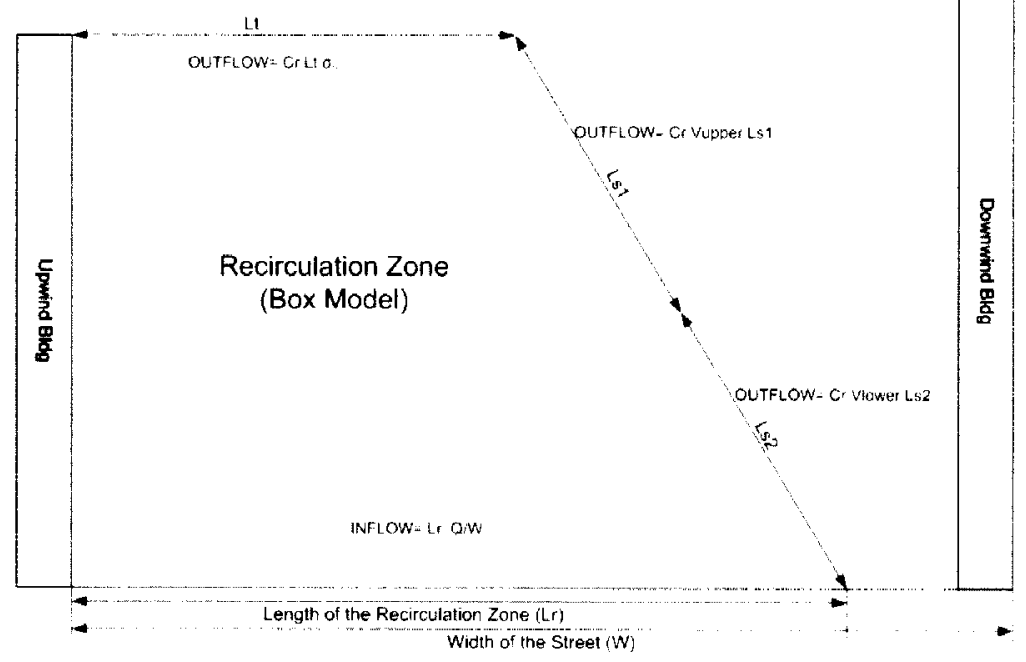

Figure 2-2: Geometry of the Recirculation Zone and the Box Model

Using the OSPM model, the concentration at the street side can be obtained as the sum of Equations 2-18 and 2-22, which is: 


$$
C=\sqrt{\frac{2}{\pi}} \frac{Q}{W \sqrt{\left.\left(\alpha u_{b}\right)^{2}+\sigma_{t}^{2}\right)}} \ln \left(1+\frac{\sqrt{\left(\alpha u_{b}\right)^{2}+\sigma_{t}^{2}} L_{r}}{u_{b} h_{0}}\right)+\frac{(Q / W) L_{r}}{\sigma_{w t} L_{t}+u_{d} L_{s}}
$$

where,

$Q$ - pollution line-density $(\mathrm{g} / \mathrm{m} / \mathrm{s})$

$W$ - width of the street $(\mathrm{m})$;

$u_{b}-$ wind speed at street level $(\mathrm{m} / \mathrm{s})$

$u_{d}-$ speed of convection, $u_{\mathrm{d}}=\sqrt{\mathrm{u}_{\mathrm{b}}^{2}+\sigma_{\mathrm{t}}^{2}}(\mathrm{~m} / \mathrm{s})$;

$h_{0}-$ initial dispersion parameter, set as $2 \mathrm{~m}$;

$\alpha$ - empirical constant, set as 0.1 (Berkowicz, 1996);

$\sigma_{t}-$ traffic-induced turbulence;

$\theta$ - angle of wind direction and street axis;

$\sigma_{w t}-$ flux velocity through the top edge of the box;

$L_{r}$ - length of recirculation zone $(\mathrm{m}), \operatorname{Lr}=\min (W, 2 H \cdot \sin (\theta))$;

$L_{t}-$ length of the top edge of the recirculation zone $(\mathrm{m})$;

$L_{s}$ - length of the side edge of the recirculation zone $(\mathrm{m}), L_{s}=\sqrt{\left(L_{r}-H\right)^{2}+H^{2}}$, see Figure 2-2;

$H$-average height of the buildings on the upper wind side of the street;

Equation 2-24 is used as part of the inverse modeling in later steps of the study of ETC.

\subsection{Automobile Emission Models}

In this section, various approaches provided in the literature to model automobile emission are presented. First is the introduction of the variables and parameters which have influences on vehicle emission modeling. Second, the existing emission models are 
divided into two classes: static and dynamic models.

\subsubsection{Parameters of Emission Modeling}

The parameters and variables of vehicle emission models can be grouped into three categories:

1. vehicle design

2. vehicle condition

3. operating status

The vehicle design parameters usually include those characteristics of an automobile, such as power-train design, fuel type, emission control equipment, aerodynamic efficiency, etc. The parameters representing vehicle conditions commonly include the mileage, year, and mechanical conditions of the vehicle. Vehicle operating status includes the en-

gine speed, power demand, air-to-fuel ratio, running speed, acceleration/deceleration, and sometimes the driving patterns of individual drivers (Chan et al., 2004).

Since vehicle designs and conditions have significant effects on the generation of gaseous pollutants, emission models are generally calibrated individually for each vehicle make and model (Cappiello, 2002). The operating status of the vehicle is usually the principal input to the models, such as speed and acceleration. Generally, engine/chassis dynamometer measurements are used to calibrate emission models (EPA, 1993): the wheels of a vehicle are allowed to spin on the dynamometer while inertial weights at various horsepower settings are loaded to simulate real-world conditions. The data are recorded by measurement equipment attached to the tailpipe. 


\subsubsection{Static Emission Models}

Static emission models, or average speed-based emission models, are normally fed with the total vehicle miles traveled (VMT) estimated by static traffic models (Cappiello, 2002), which are generally applied in large-scale analyses such as regional transportation planning. Applications of static emission models usually include the conditions of steady average speed of traffic, which adequately presents the status of vehicle flow. Static models can only determine the average emissions as a function of the average speed of a running cycle. The outputs of static models are usually emission inventories.

The following static models have been widely used in transportation conformity practice:

COPERT III - Computer Program to Calculate Emissions from Road Transport (Ntziachristos and Samaras 2000), is a part of the CORINAIR program, sponsored by the European Environmental Agency. The program developed several suites of software for European countries to compile annual air emission inventories.

Mobile6 - An emission factor model developed by the EPA for predicting emissions of hydrocarbons ( $\mathrm{HC})$, carbon monoxide (CO), nitrogen oxides (NOx), particulate matter (PM), and toxics from cars, trucks, and motorcycles under various conditions (EPA, 2003).

EMFAC - Emission Factors Model, issued by the California Air Resources Board for forecasting criteria pollutant emissions of a regional transportation plan (CARB, 2007).

\subsubsection{Dynamic Emission Models}

Dynamic emission models are based on instantaneous measurements made for emissions by chassis dynamometer tests. To develop dynamic models, speed and acceleration 
are recorded simultaneously with the emissions, second-by-second. If $E_{i}(t)$ denotes the emissions of pollutant $i$ generated at time $t$ by vehicles in a given network, the total amount of pollutant $i$ can be calculated by (Cappiello, 2002):

$$
E_{i}(t)=\sum_{n} e_{i}\left(c_{n}, v a_{n}(t)\right)
$$

where,

$n$-vehicle ID;

$c_{n}$ - category of vehicle $n$;

$v a_{n}(t)$ - variables of vehicle type $n$ at time moment $t$, which usually uses instantaneous speed and/or acceleration;

$e_{i}\left(c_{n}, v a_{n}(t)\right)-$ emission of pollutant $i$ for vehicle $n$ at time $t$;

The dynamic models can be used to estimate the emissions for an individual vehicle or overall emissions for a network. However, due to the amount of information and data required to model the traffic emissions, the measurements and tests may become expensive and impractical (Esteves-Booth et al., 2002).

The following sections will introduce several internationally-used dynamic models.

\subsubsection{Comprehensive Modal Emissions Model}

The Comprehensive Modal Emission Model, also known as CMEM, is a load-based ${ }^{1}$ emission model developed at the University of Michigan and the University of California at Riverside (Barth et al., 2000). The model was calibrated by using FTP and MEC01 data (Schultz et al., 2001), which include measurements of second-by-second emission rates

\footnotetext{
'Load-base models: composed of modules that simulate single steps of the process, each calibrated with laboratory measurements and vehicle specifications data (Goodwin, 1996).
} 
of $\mathrm{HC}, \mathrm{NO}_{x}, \mathrm{CO}$, and $\mathrm{CO}_{2}$ on three driving cycles: (i) the FTP cycle ${ }^{2}$ (Figure 2-4); (ii) the US06 cycle $^{3}$ (Figure 2-5); and (iii) the MEC01 cycle $^{4}$ (Figure 2-6).

The CMEM is composed of six components (see Figure 2-3): (i) power demand, (ii) engine speed, (iii) air-to-fuel ratio, (iv) fuel rate, (v) engine-out emissions, and (vi) catalyst-pass fraction. The model uses vehicle speed and acceleration (operation variables) as inputs. The outputs contain second-by-second tailpipe emission rates of $\mathrm{HC}, \mathrm{NO}_{\mathrm{x}}, \mathrm{CO}$, and $\mathrm{CO}_{2}$ (Barth et al., 2000).

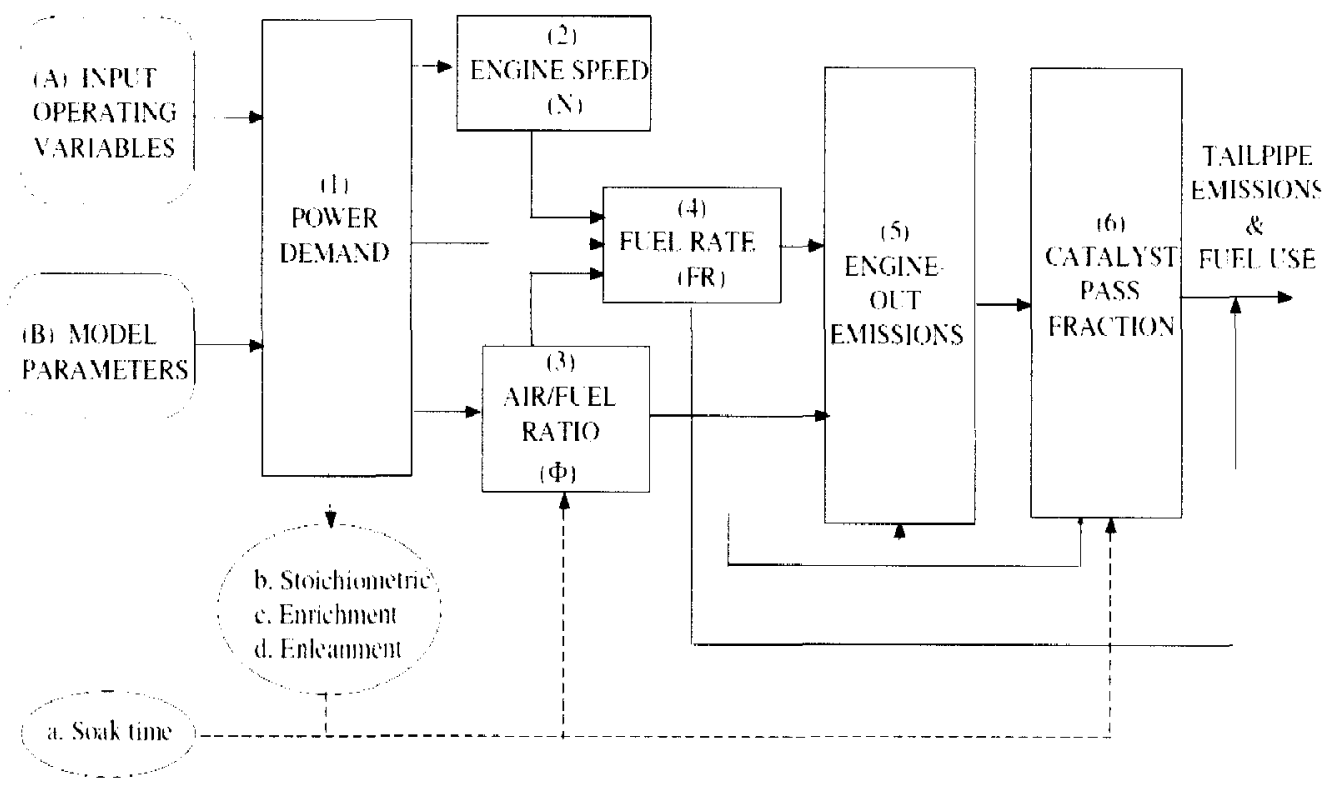

Figure 2-3: The Structure of the CMEM Model (Barth et al., 2000)

\footnotetext{
${ }^{2}$ FTP cycle: standard testing cycle in the United States (EPA), which is composed a 505-second cold-start phase, an 870-second hot-transient phase, and a 505-second hot-start phase.

${ }^{3}$ US06 cycle: a hot-start testing cycle simulating hard accelerations and high speed $(80.3 \mathrm{mph})$. The total time for US06 is 10 minutes (600 seconds). (http://www,epa.gov/OMS/sftp.htm)

${ }^{4} \mathrm{MEC} 01$ cycle: Consists of 5 sections- stoichiometric cruise, constant power, constant acceleration, scrambled cruise, and air conditioning. Total time is 32 minutes (1920 seconds), with a speed range of $10 \mathrm{mph} \sim 80 \mathrm{mph}$. The cycle represents driving conditions with higher speeds and harder accelerations than the FTP cycle.
} 


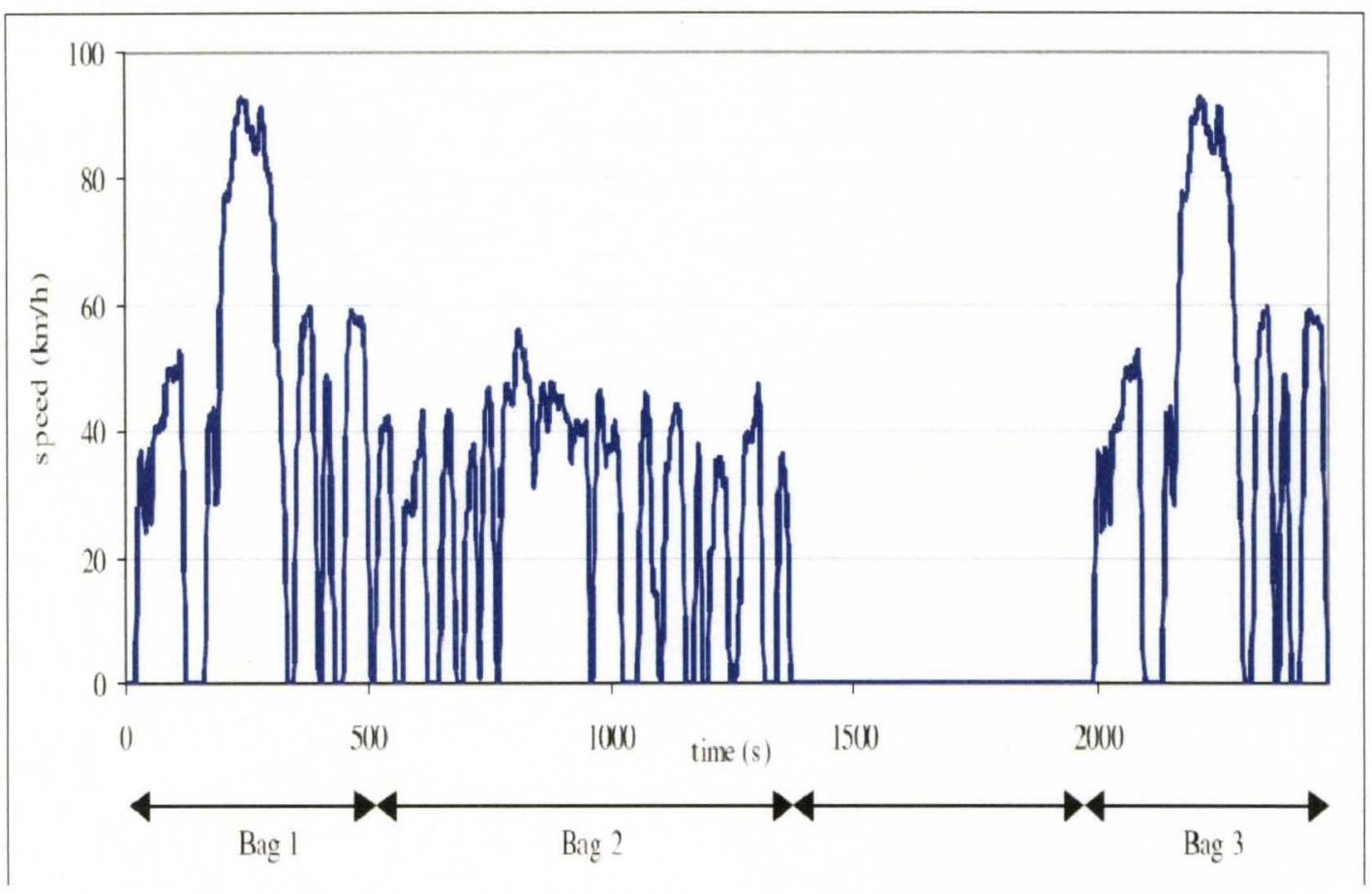

Figure 2-4: An FTP Cycle (Cappiello, 2002)

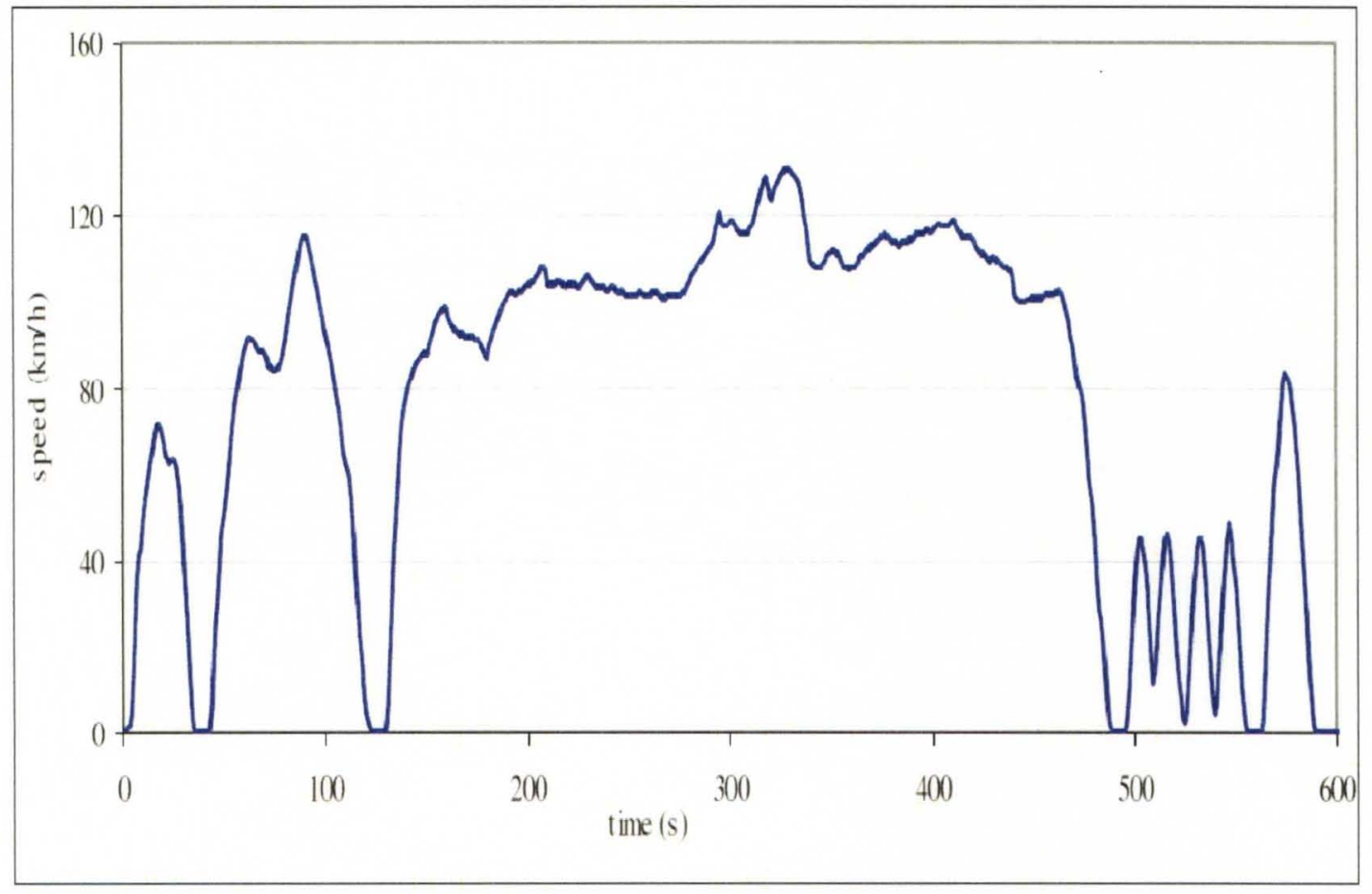

Figure 2-5: A US06 Cycle (Cappiello, 2002) 


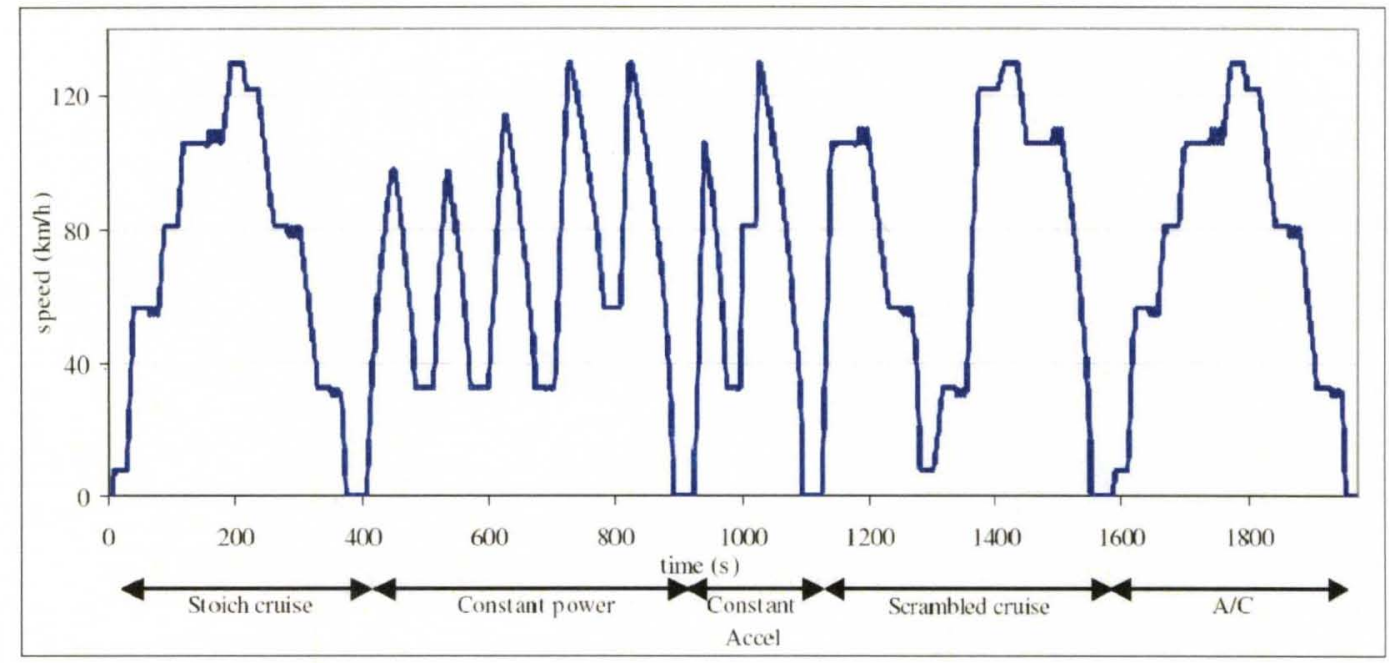

Figure 2-6: The MEC01 Cycle (Cappiello, 2002)

\subsubsection{POLY Model}

The POLY model was developed by the Polytechnic University and Texas Southern University. It was calibrated by the FTP data and validated by data of MEC01 and US06. It is one of the internationally-used regression-based models of mobile source emissions. Different from the load-based models, the POLY model utilizes a linear least squares regression that adopts the instantaneous speed and acceleration in addition to past accelerations and road grade (Teng et al., 2002).

The regression is presented by:

$$
\begin{aligned}
e_{i}(c, t)= & \beta_{0}+\beta_{1} v(t)+\beta_{2} v^{2}(t)+\beta_{3} v^{3}(t)+\beta_{T^{\prime}} T^{\prime}(t)+\beta_{T^{\prime \prime}} T^{\prime \prime}(t)+\beta_{A_{t}} A(t)+ \\
& \ldots+\beta_{A_{t-9}} A(t-9)+\beta_{W} W(t)
\end{aligned}
$$

where,

$e_{i}(c, t)-$ emission rate for species $i$, that depends on vehicle category $c$ and time $t$;

$v(t)$ - speed at time $t$;

$T(t)$ - duration of acceleration since its inception up to the current time $t$; 
$T^{\prime}(t)$ - duration of deceleration since its inception up to the current time $t$;

$A(t-\tau)$ - combined acceleration/deceleration at time $t-\tau(t=0,1, \ldots, 9)$, calculated from the acceleration $a(t)$ and the grade $g(t)($ in $\%$ ) as follows:

$$
A(t-\tau)=a(t-\tau)+9.81 \cdot\left(\frac{g(t-\tau)}{\sqrt{1+g(t-\tau)}}\right)
$$

$W(t)=v(t) \cdot A(t)$, and $\beta$ s are vehicle category parameters.

The regression-based models are usually linear regressions that use instantaneous speed and acceleration as the variables. The strengths of the regression-based models are generally the continuity of the computing capability which overcomes the discrete inventory of the static models (Cappiello, 2002). However, they usually give unpredictable results if applied to situations not covered by the calibration data. And in most practical cases, the regression models are actually unable to be calibrated easily, and the regressions usually differ on a case by case basis, since they are calibrated by the specific data collected from the each measurement. In other words, one cannot find a universal regression for all situations ( $\mathrm{Wu}, 2009)$.

\subsubsection{Modal Emission Model}

The United States Environmental Protection Agency issued the latest mobile source emission model in 2009 (EPA, 2010), which is called MOVES (Motor Vehicle Emission Simulator). This new generation of emission model is for the purpose of creating a more comprehensive range of applications than could be appropriately addressed by the traditional models (EPA, 2001b). Unlike Mobile6 and EMFAC, the MOVES estimates emissions based on modal analysis instead of inputting average speed. It uses second-by- 
second vehicle performance data for various driving conditions to more accurately estimate emissions at scales ranging from individual project level to large regional level. It will serve as the model for estimating on-road emissions and regional conformity analyses (Bai et. al, 2009).

\subsubsection{Summary}

The static models contain a wide range of speed-emission relationships. But they usually lack the instantaneous records of emissions and only use average speed as the input, so they may lead to underestimates or overestimates, depending on the speed range. The dynamic models are generally calibrated using second-by-second data. Due to the lack of physical interpretation of the model's development (eg. coefficients calibrated by regression), the dynamic models may result in non-desirable estimates for situations other than those where the calibrating data are collected. Moreover, it takes a lot of time and work to recalibrate the regressions.

In order to develop a method to estimate the environmental traffic capacity for different roads or areas, there is a need to find more efficiency, and more importantly a standard procedure, to estimate the emission rates/factors. In Chapter 4, a simpler but more practical method to estimate the emission rates/factors by speed/acceleration weightedcategorizing is introduced.

\subsection{Environmental Capacity (EC): Concept and Approaches}

Back in the 1960 s, the concept of environmental capacity was initially introduced by Sir Colin Buchanan. In his report the Traffic in Towns, he defined the environmental capacity as the capacity of a street or an area to accommodate moving and stationary ve- 
hicles with respect to the environmental standards (Buchanan, 1963). The calculation of EC was based on the delay for pedestrians crossing the streets.

In 1979 and 1980, Holdsworth and Singleton developed an approach of specifying an environmentally-based capacity for streets, which was composed of three aspects of traffic movement: 1) road traffic noise, 2) pedestrian safety, and 3) pedestrian delay. In their studies, EC was related to pavement widths, building configuration, land-use type, and traffic conditions. It was also assumed that by controlling vehicle speeds and models, noise and air pollution could also be controlled.

In the late 1980 s and early 1990 s, the environmental capacity was calculated also by using the risk analysis for pedestrians crossing the streets who may be under the impact of traffic. Song, Dunne, and Black presented their research in 1993, revealing that, given an acceptable risk level, and assuming that a negative exponential distribution describes the vehicular headway distribution, the EC can be yielded by solving the following equation, in which EC was represented by Q:

$$
R=\left(1-e^{-\alpha Q}\right) \times 1.85 Q^{0.713} \times S^{0.733} \times T^{0.523} \times 10^{-6}
$$

where, $\alpha$ is critical gap or mean gap acceptance, $S$ is the mean vehicle speed $(\mathrm{km} / \mathrm{hr})$ and $T$ is the duration of crossing an exposure distance $L$ in seconds. Song et al. used the risk criteria to calculate the EC of streets by the above model, and details can be found in their case study (Song et al., 1993).

The concept of air pollution-related environmental capacity was emphasized recently by a few studies. Cheng (2004) introduced an approach to estimate the area capacity of personal cars by calculating the average $\mathrm{NO}_{x}$ per vehicle. Lin (2008) developed a model using a matrix of dilution factors to estimate the optimum amount of vehicles under the 
conformity of gaseous pollutant levels. Zhu (2008) developed a methodology using the emission factors as one of the impedances of trip distribution, with regard to controlling the emission level. Although there have not been many studies of environmental capacity for air pollution considerations, the existing research has indicated a new criterion for determining the amount of vehicles in addition to the capacity of road network itself, which results in the concept of environmental traffic capacity (ETC) related to emission control. 


\section{CHAPTER 3 MOTOR VEHICLE EMISSIONS}

The previous two chapters have introduced the general concepts and addressed the major problems of traffic emissions. This chapter will continue to present a description of the principal vehicle emissions as well as their negative effects on health and the environment. The chapter also contains a summary of policies of air quality in the United States.

The organization of this chapter is as follows. Section 3.1 describes the generation and dispersion of the principal gaseous pollution produced by motor vehicles. Section 3.2 summarizes the regulations and policies of air quality in the United States.

\subsection{Principal Pollutants}

Motor vehicles produce various types of pollutants. The principal pollutants are defined as those that have been demonstrated to have significant effects on human health and environmental welfare. The Clean Air Act Amendments of 1990 established emission standards for on-road motor vehicles, which control total hydrocarbons (HC), carbon monoxides (CO), nitrogen oxides $\left(\mathrm{NO}_{\mathrm{x}}\right)$ and particulate matter (PM) (CAAA, 1990).

\subsubsection{Hydrocarbons}

It has been estimated that $29 \%$ of the total hydrocarbons emitted in the United States 
are contributed by on-road mobile sources (EPA, 2001a). Hydrocarbons are a major contributor to smog, which has negative effects on health, perhaps including liver or kidney damages (Klaassen et al., 1965). The hydrocarbons are a result of incomplete combustion in motor vehicle engines or evaporative emission from the engine and exhaust. The incomplete combustion in engines may be caused by a lack of oxygen, or by higher burning temperatures of some fuel species. An et al. (1998) stated that hydrocarbons can escape during enleanment conditions ${ }^{5}$, which may occur in periods of long time deceleration.

\subsubsection{Carbon Monoxide}

The EPA estimates that on-road sources contribute $50 \%$ of the carbon monoxide emissions in the United States. However, the percentage can be even higher in urban areas (EPA, 2009).

Carbon monoxide is produced from the partial oxidation of carbon-containing compounds. It forms when there is not enough oxygen to produce carbon dioxide $\left(\mathrm{CO}_{2}\right)$. In motor vehicles, carbon monoxide forms when there is an incomplete combustion of fuel, which usually occurs when there are low air-to-fuel ratios in the engine. These conditions are most likely to occur when the vehicle is started, when oxygen supply is restricted, or at high altitude, where thin air reduces the availability of oxygen for engines (EPA, 1993).

Carbon Monoxide is colorless and odorless, but is highly toxic. It combines with hemoglobin to produce carboxyhemoglobin, causing ineffective delivery of oxygen to bodily tissues, which is also known as anoxemia (Omaye, 2002).

\footnotetext{
${ }^{5}$ Enleanment is an engine-malfunction which is typically caused by hard deceleration or load reduction. Incomplete combustion or misfire occurs under enleanment conditions (An, 1998).
} 


\subsubsection{Nitrogen Oxides}

The EPA has estimated that one third of the total nitrogen oxides in the United States are produced by on-road vehicles, $42 \%$ of which is emitted by diesel engines (EPA, 2009).

Nitrogen oxides are a class of highly reactive gases which are generated from fuel burned at high temperature and pressure. The primary sources of nitrogen oxides are motor vehicles, industrial, and commercial facilities where fuel is burned (http://www.arb.ca.gov/html/gloss.htm\#N). The major nitrogen oxides produced by combustion in motor engines are composed of nitrogen monoxide (NO) and nitrogen dioxide $\left(\mathrm{NO}_{2}\right)$. The following formulas describe the reactions:

$$
\begin{aligned}
\mathrm{N}_{2}+\mathrm{O}_{2} & \rightarrow 2 \mathrm{NO} \\
2 \mathrm{NO}+\mathrm{O}_{2} & \rightarrow 2 \mathrm{NO}_{2} \\
\text { or, } \mathrm{N}_{2}+2 \mathrm{O}_{2} & \rightarrow 2 \mathrm{NO}_{2}
\end{aligned}
$$

Due to the excess oxygen, more $\mathrm{NO}_{\mathrm{x}}$ tends to be formed under enleanment conditions (An et al., 1998). $\mathrm{NO}_{\mathrm{x}}$ is also a precursor to the formation of ground level ozone. It reacts with moisture and other gaseous compounds to form nitric acid which may cause respiratory symptoms (Saldiva et al., 1994).

\subsubsection{Particulate Matter}

Particulate matter is a complex mixture of extremely small particles and liquid droplets suspended in the air. Particulate matter includes particles with diameters larger than 2.5 micrometers and smaller than 10 micrometers and "fine particles," with diameters that are 2.5 micrometers and smaller (http://www.epa.gov/air/particlepollution/basic.html).

Particles are generated from a variety of sources such as construction sites, power 
plants, etc. The EPA estimates that $4.5 \%$ of the total $\mathrm{PM}_{2.5}$ in the United States is contributed by motor vehicles (EPA, 2009). Particulate matter contains micro solids and/or liquid droplets that can get into the lungs of humans and cause health damages (http://www.epa.gov/pm/health.html).

\subsection{Regulations of Air Quality}

The Clean Air Act Amendments of 1990 (CAAA90) mandate that air quality standards for six pollutants must be met everywhere in the United States: carbon monoxide $(\mathrm{CO})$, nitrogen dioxide $\left(\mathrm{NO}_{2}\right)$, lead $(\mathrm{Pb})$, ozone $\left(\mathrm{O}_{3}\right)$, sulfur dioxide $\left(\mathrm{SO}_{2}\right)$, and particulate

matter with a diameter less than 10 microns $\left(\mathrm{PM}_{10}\right)$. The standards are defined in terms of concentration of the pollutant in ambient air with respect to various temporal aggregations.

The National Ambient Air Quality Standards (NAAQS) of the United States were established by the EPA, under the requirements of the Clean Air Act. The six principal pollutants set forth in CAAA90 were used as "criteria" pollutants for the development of the NAAQS. Units of measure for the standards are parts per million (ppm) by volume, parts per billion ( $\mathrm{ppb}$ ) by volume, milligrams per cubic meter of air $\left(\mathrm{mg} / \mathrm{m}^{3}\right)$, and micrograms per cubic meter of air $\left(\mu \mathrm{g} / \mathrm{m}^{3}\right)$. The standards state that the 1-hour average concentration of carbon monoxide, nitrogen dioxide, ozone, and sulfur dioxide should not exceed 35 ppm, $100 \mathrm{ppb}, 0.12 \mathrm{ppm}, 75 \mathrm{ppb}$, respectively. More specific data and notes are available at EPA's official website (http://www.epa.gov/air/criteria.html).

The next chapter develops a methodology to estimate a 1-hour environmental traffic capacity, using selected "criteria" pollutants. 


\section{CHAPTER 4 METHODOLOGY}

The development of the methodology for estimating temporal environmental traffic capacity is presented in this chapter. The basis of the method is derived from the relationships between speed, flow, and emissions. The process of calculating environmental traffic capacity is the inverse of determining the contribution of pollutants from traffic. The dilution factor is attained by deploying OSPM. By using the regulated pollution level as the maximum amount of pollutants allowed from the traffic, the traffic volume is obtained under an environment-friendly condition. See Figure 4-1.

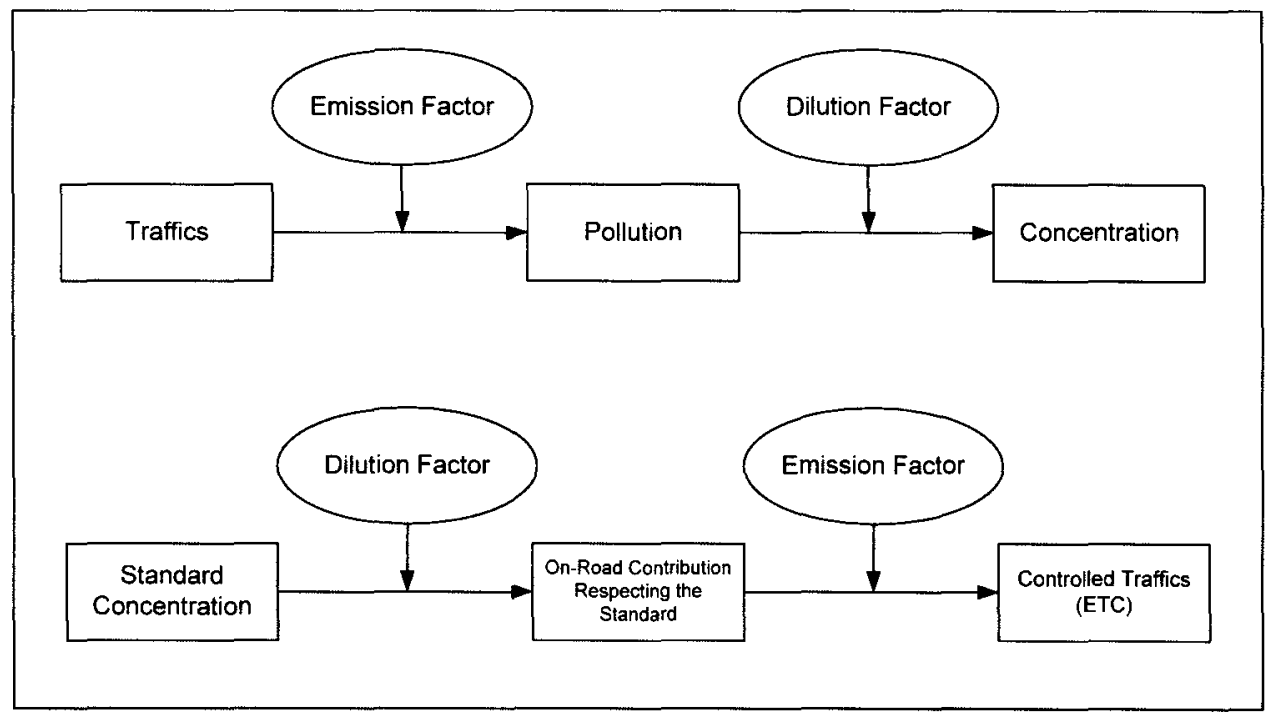

Figure 4-1: The comparison of calculating the concentration and the ETC

The main component of the algorithm is based on three parts which are developed to determine: 1) the dilution factor; 2) the emission factor; and 3) the traffic pollution. Data were collected to estimate the emission factors under the effects of speed and acceleration. 
This chapter is organized as follows. Section 4.1 describes the rationale of the method. Section 4.2 presents the algorithm. Section 4.3 introduces the process of data collection to estimate the emission factors. Section 4.4 summarizes the process of calculation for the environmental traffic capacity.

\subsection{Rationale of the Method}

As indicated in the literature review (see Chapter 2), pollutant emissions are closely related to the operating conditions of vehicles. The traffic emission studies usually involve evaluating the relationship between the operating status and the emission rates and factors. The emission rate is measured in the unit of $\mathrm{g} / \mathrm{veh} / \mathrm{sec}$. The emission factor, in the unit of $\mathrm{g} / \mathrm{veh} / \mathrm{km}$, is derived from the emission rate by:

$$
\text { Emission Factor }=\frac{\text { Emission Rate } \times 3600}{S p e e d(\mathrm{~km} / \mathrm{h})}
$$

In general, the emission rate increases as the engine produces more power and burns more fuel. The emission factor usually stays at a high level for the vehicle in the low speed range $(0-10 \mathrm{kph}$ or $0-7 \mathrm{mph})$. As the vehicle speeds up, the emission factor starts to decrease because of the derivative relationship with the emission rate and vehicle speed.

According to the data obtained by the United Kingdom Highway Agency (2005), the low emission factor occurs at a speed range of $50-80 \mathrm{kph}$ or $30-50 \mathrm{mph}$ (see Figures 4-2 and 4-3). In the following sections, the range of $50-80 \mathrm{kph}$ is referred to the "low emission zone", while the "high emission zone" is identified as the range of $0-30 \mathrm{kph}$. 


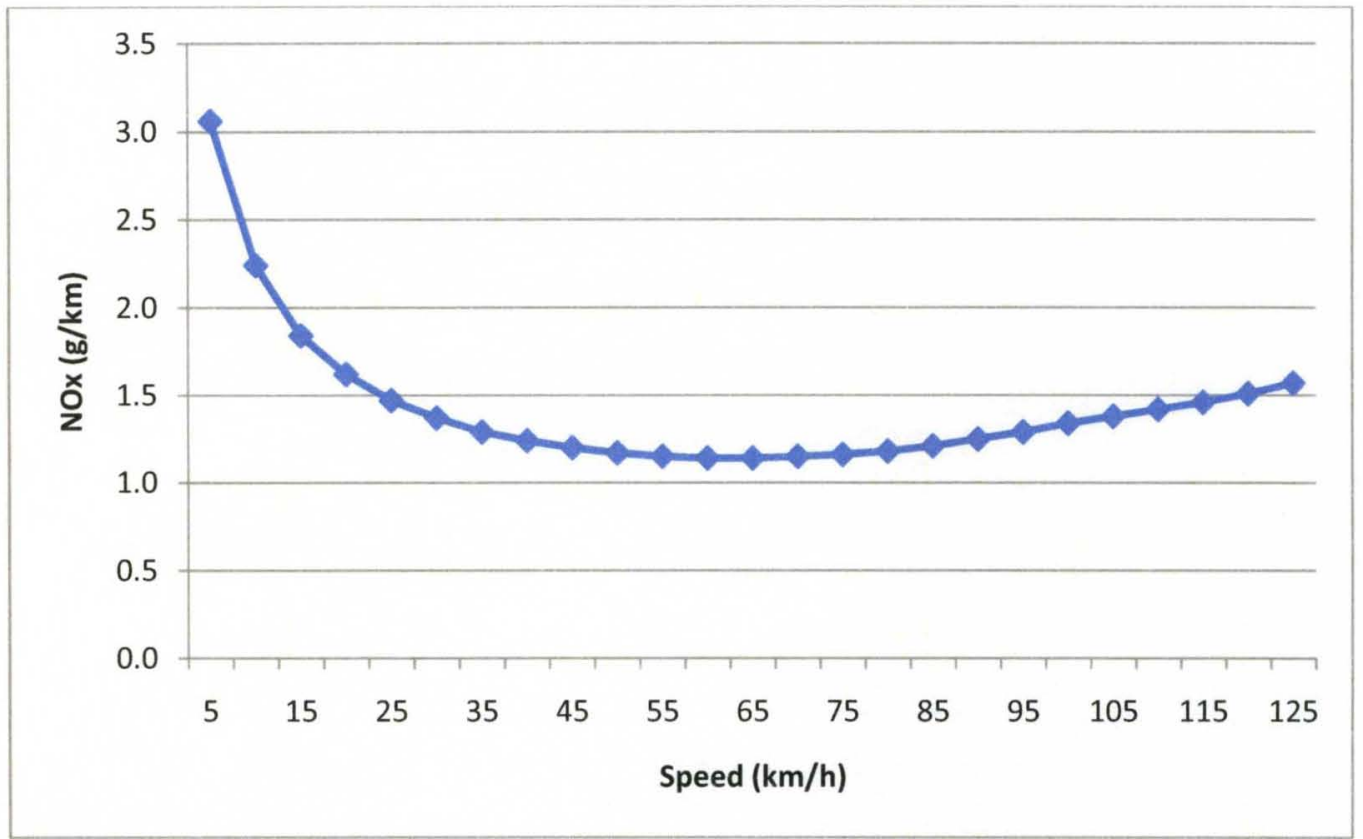

Figure 4-2: $\mathrm{NO}_{\mathrm{x}}$ emission factors vs. speed (UK Highways Agency, 2005)

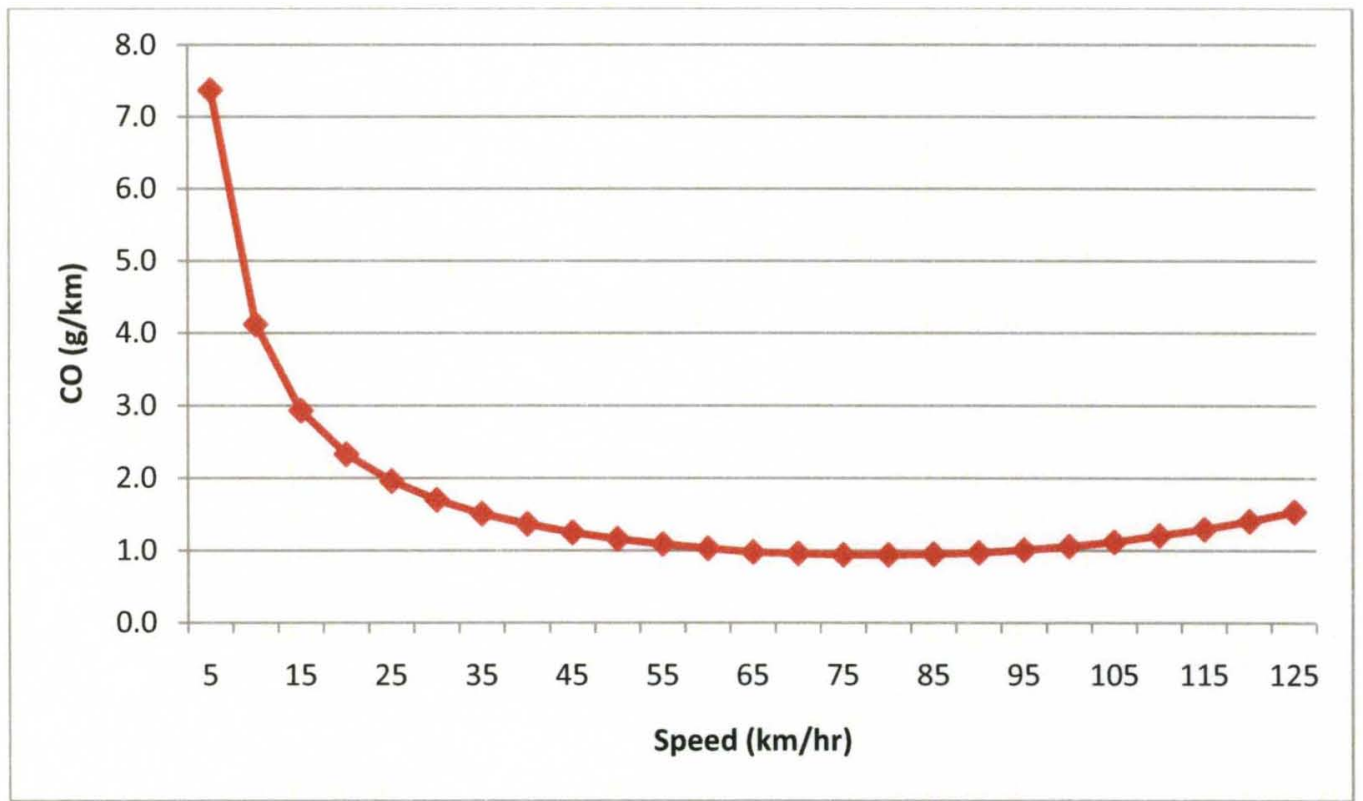

Figure 4-3: CO emission factors vs. speed (UK Highways Agency, 2005)

\section{Speed vs. Flow Rate}

In this dissertation, the Greenshield's model is applied as the part for the traffic model. The theory of Greenshield's model was based on the assumption that the speed and density of the flow are linearly related (Garber \& Hoel, 2001). One issue of this theory is 
that it was derived empirically from the observed data and lacks theoretical explanations for situations on the microscopic level (Hall, 1992). However, the purpose of this dissertation is to present a procedure to estimate the ETC. The Greenshield's model provides a clear speed-flow relationship for addressing the connections between speed, flow and ETC. For further studies, it is recommended to apply other traffic models for more specific scenarios. The methodology developed in the following sections is postulated with respect to the Greenshield's curve depicting the relationship between speed and flow (see Figure 4-4).

According to the Greenshield's speed-flow model, the flow rate is a function of the space mean speed, which is the harmonic mean of the speeds of vehicles passing a point on a highway during an interval of time (Garber \& Hoel, 2001):

$$
q=k_{j}\left(u-\frac{u^{2}}{u_{f}}\right)
$$

where,

$q$ - flow rate on the concerned section of $\mathrm{road}(\mathrm{veh} / \mathrm{lane} / \mathrm{hr}) ;$

$k_{j}-$ congestion density (veh/lane/km);

$u_{f}-$ free flow speed $(\mathrm{km} / \mathrm{hr})$

$u$ - space mean speed $(\mathrm{km} / \mathrm{hr})$;

By Equation 4-1, $u$ can be derived as:

$$
u=u_{f}\left(\frac{1}{2}+\sqrt{\frac{1}{4}-\frac{q}{u_{f} k_{j}}}\right)
$$

Figure 4-4 indicates that the maximum flow rate occurs at the point at which the vehicles on the section of road are operating at a space mean speed of $u_{m}$. The free-flow 
speed $u_{f}$ occurs as the flow rate closes back to $0(\mathrm{veh} / \mathrm{hr})$. The left half of the area within the curve shows the speed/flow range when congestion occurs. When the congestion starts to dissolve, the space mean speed increases towards the value of $u_{m}$. It continues to increase as congestion gradually dissipates so as the flow rate per hour decreases. An important parameter for this function is the congestion density $k_{j}$, which is the number of vehicles per unit length of the road when congestion has formed. The congestion density is determined by the physical characteristics of the road and the traffic control scenarios (TRB, 2000).

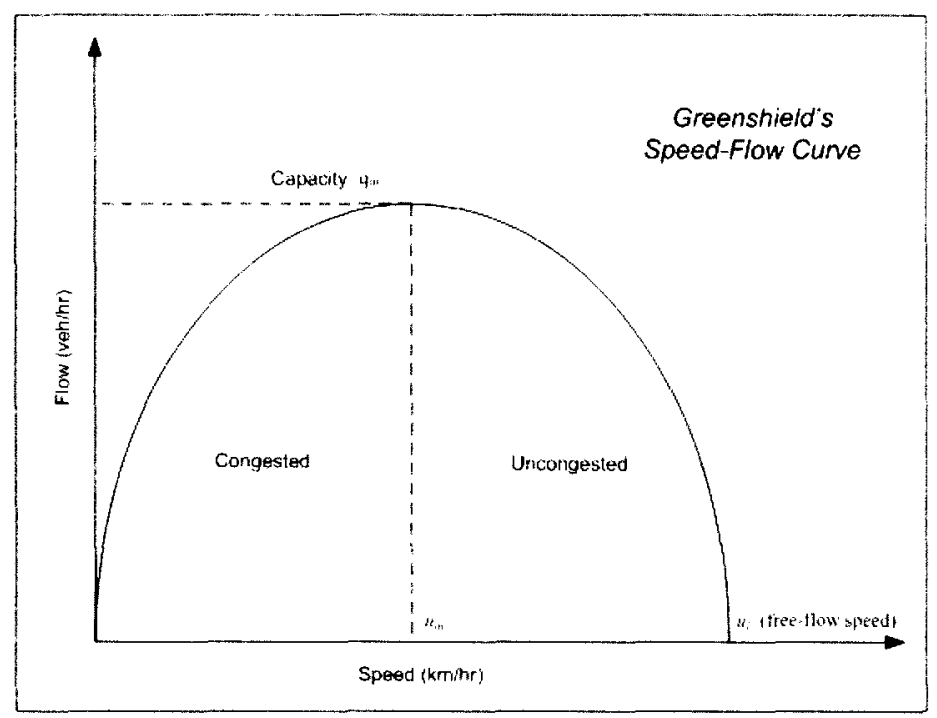

Figure 4-4: Flow rate vs. speed (Garber \& Hoel, 2001, p 179)

\section{Basics of Environmental Traffic Capacity}

The basic theory of Environmental Traffic Capacity (ETC) is to estimate the capacity of a road link or network which is able to accommodate traffic that produces pollutant emissions that are below the regulated level ( $\mathrm{Li} \& \mathrm{Lin}, 2009$ ). If the regulated concentration of pollutant $\mathrm{k}$, by that street or area, is denoted by $Q_{k}$, and the average emission rate of $\mathrm{k}$ for each vehicle is $e_{k}$, then the capacity to hold the traffic without breaking the permitted emissions level can be presented as (Lin, 2008; Li \& Lin, 2009): 


$$
E T C=\frac{Q_{k}}{e_{k}}
$$

Referring to the relationship between speed and emissions, illustrated in Figures 4-2 through 4-3, it can be assumed that there is also a connection between speed and the ETC.

As speed goes up into the range best for emissions and fuel economy, the ETC should also increase because the emission factor decreases. If speed continues to increase, the emission factor would somewhat rise so that the ETC decreases simultaneously as a result. See Figure 4-5.

\section{Speed vs. ETC}

This dissertation postulates that, theoretically, if $u_{m}$ falls to the "low emission zone" $(50-80 \mathrm{kph})$, the peak flow rate would also correspond to the best condition for emissions and fuel economy. ${ }^{6}$ However in real situations, the free-flow speed $u_{f}$ is usually set as the speed limit on road, which is commonly $55-60 \mathrm{kph}(35-40 \mathrm{mph})$ on urban/rural highways, and $100-110 \mathrm{kph}(65-70 \mathrm{mph})$ on urban/rural freeways. Since $u_{m}$ is less than $u_{f}$, it can be assumed that the peak flow rate usually corresponds to a speed below the "low emission zone" $(50-80 \mathrm{kph})$, and, as a result, vehicles under the speed limit $\left(u_{f}\right)$ are operating in "high emission zone".

Shown in Figure 4-5, the two curves cross over at point $\left(u_{x}, q_{x}\right)$, which means if there exists a speed $u_{x}$ that is associated with an hourly flow rate $q_{x}$, according to the Greenshield's model, the ETC value that keeps the emissions below the regulated level should equal $q_{x}$. When speed falls to $u_{x}^{-}$, flow rate should be above the ETC; and speeds in the range $u_{x}^{+}$should keep the emissions below the permitted level. If the point $\left(u_{x}, q_{x}\right)$ does not exist, the speed-flow rate curve should only be covered by the speed-ETC curve, a

\footnotetext{
${ }^{6}$ From this part on, this dissertation essentially reflects original work by the author.
} 
situation that takes place when the ETC is always larger than the flow rate; such a situation could not be consistent with reality.

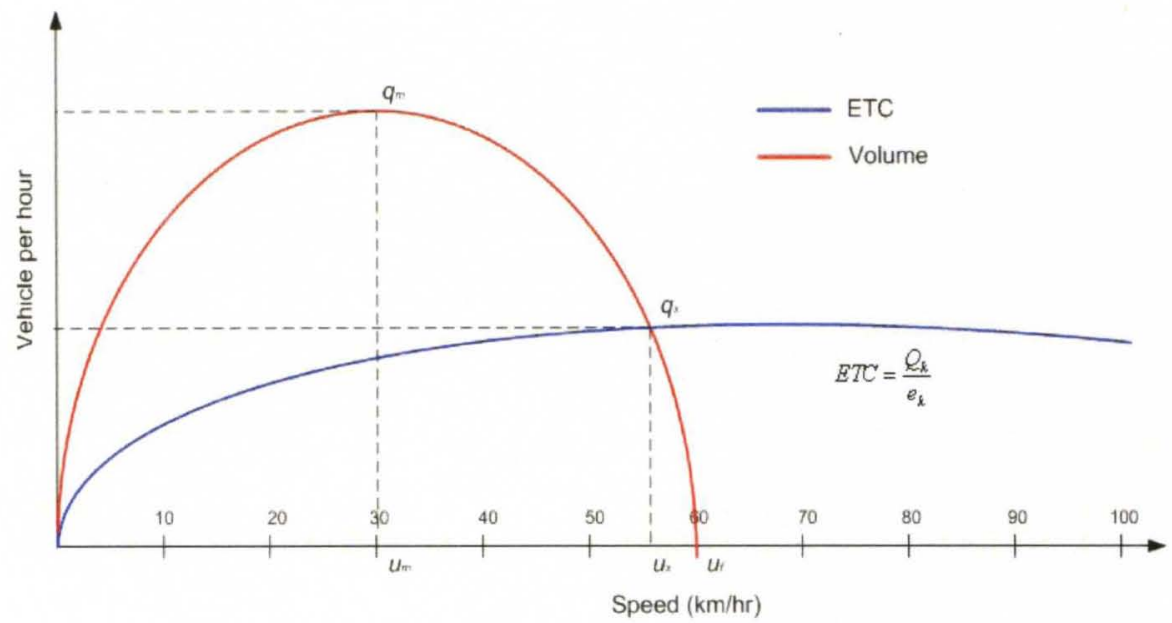

Figure 4-5: ETC and flow rate against speed

\section{$\underline{\text { ETC vs. Time }}$}

The traffic volume on a road section is calculated by multiplying the flow rate times the number of lanes on the road during a given time interval.

where,

$$
V=q \cdot n \cdot T
$$

$V$ - volume (veh/hr);

q- flow rate (veh/lane/hr);

$n$ - number of lanes;

$T$ - time interval;

The volume varies by different time period of the day, such that the highest rate is during rush hour and the lowest rate is from midnight through the early morning (see Figure 4-6). The fluctuation of volume induces the change of a vehicle's running condition. In time intervals of heavy volume, speeds range at lower levels and more frequent acceleration and deceleration would occur. Accordingly, the ETC has a time-dependent 
feature like volume does. Since the environmental capacity for pollutants varies with the temporal traffic volumes, it is important to compare the ETC with the volume; therefore the questions are:

1. Is the ETC over or under the volume?

2. How close they are? (the ratio, ETC : volume)

3. How is the ETC affected by controlling the volume?

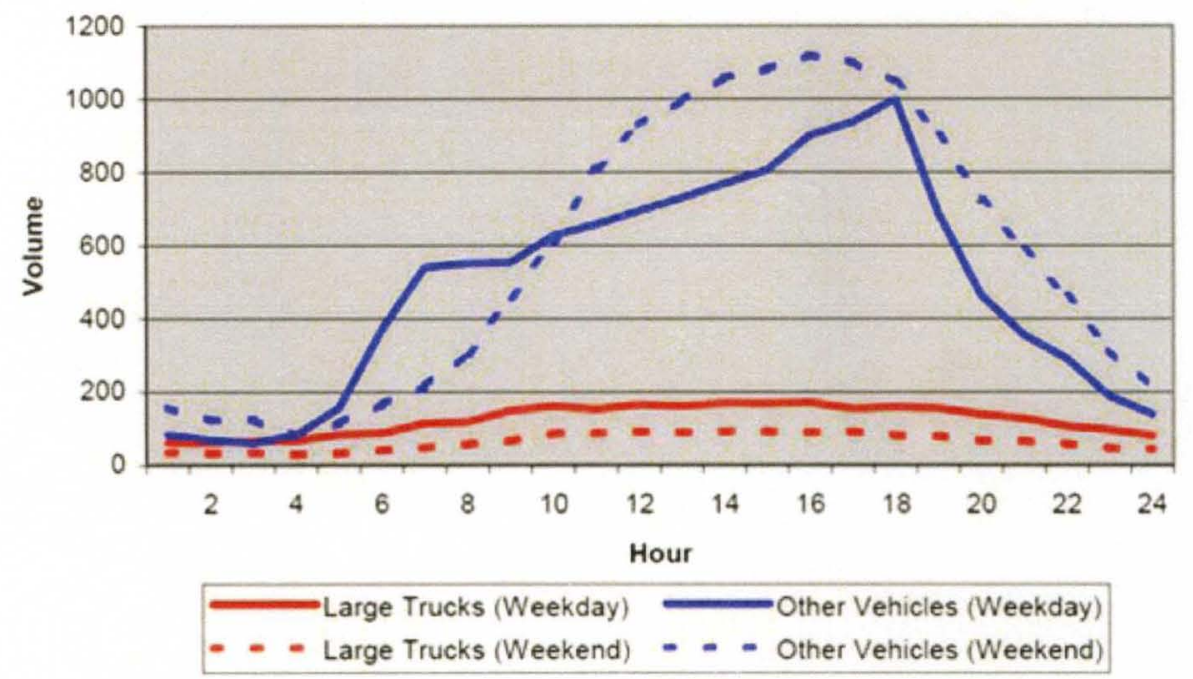

Figure 4-6: Daily volume distribution on a section of Interstate 82 (WSDOT, 2003)

Commonly the worst instances of emission occur when congestion increases because the speed slows down into the high-emission zone. The density (veh/lane/km) is maintained as high as the congestion level until the end of the heavy traffic hours. The ETC itself is a parameter with respect to air quality for these congestion situations. In most cases the volume per hour is much higher than the capacity for the ETC to hold, considering the actual emission levels around the world, especially in developing countries. Numerous traffic control efforts have been developed as part of urban planning studies and transportation research. However, it is very difficult to control the number of vehicles in an urban area, especially during rush hours. In other words, if the flow rate (veh/lane $/ \mathrm{km}$ ) 
must be kept constant, the way to reduce the volume is to physically reconfigure the roads, which means physically reducing the capacity of the road network, or, increase the speed limit $u_{f}$ so that $u_{m}$ would become closer to the "low emission zone". For such a purpose, the ETC provides a reference of the capacity that a road/network is assumed to accommodate for traffic during different time intervals. More details are presented in Chapter 5.

\subsection{Algorithm}

This portion of Chapter 4 introduces the algorithm and its equations used to calculate the Environmental Traffic Capacity. The second subsection imports a probabilistic modeling of acceleration distributions (Abou Zeid et al., 2002) to estimate the emissions under different operating conditions.

\subsubsection{Dilution Factor and Concentration}

To calculate the impact of traffic emissions on objects adjacent to the road under study, the Danish Operational Street Pollution Model (OSPM) is used in this dissertation to determine the dilution factor. The OPSM model has demonstrated a satisfactory description of the air pollutant dispersion in urban streets (Berkowicz et al., 1996). Using the geometrical configuration, traffic and meteorological conditions as inputs, the model calculates the dilution factor taking effect during the movement of pollutants from the source to the concerned object (details are introduced in Section 2.1). Equation 2-24 can be expressed as:

$$
C_{d}=Q \cdot f
$$


where,

$C_{d}$ - direct contribution of pollutants from the traffic,

$Q$ - concentration of pollutants on street,

$f$-dilution factor.

According to the OSPM model (see Chapter 2),

$$
f=\left(\sqrt{\frac{2}{\pi}}\right) \frac{1}{w \sqrt{\left.\left(\alpha u_{b}\right)^{2}+\sigma_{t}^{2}\right)}} \ln \left(1+\frac{\sqrt{\left(\alpha u_{b}\right)^{2}+\sigma_{t}^{2}} L_{r}}{u_{b} h_{0}}\right)+\frac{L_{r}}{W\left(\sigma_{w t} L_{t}+u_{d} L_{s}\right)}
$$

where,

$W$ - width of the street (m);

$u_{b}$ - wind speed at street level $(\mathrm{m} / \mathrm{s})$

$u_{d}-$ speed of convection, $u_{d}=\sqrt{u_{b}^{2}+\sigma_{t}^{2}}(\mathrm{~m} / \mathrm{s})$;

$h_{0}-$ initial dispersion parameter, set as $2 \mathrm{~m}$;

$\alpha$-empirical constant, set as 0.1 (Berkowicz, 1996);

$\sigma_{t}-$ traffic-induced turbulence;

$\theta-$ angle of wind direction and street axis;

$\sigma_{w t}-$ flux velocity through the top edge of the box;

$L_{r}$ - length of recirculation zone $(\mathrm{m}), \operatorname{Lr}=\min (W, 2 H \cdot \sin (\theta))$;

$L_{t}$ - length of the top edge of the recirculation zone (m);

$L_{s}$ - length of the side edge of the recirculation zone $(\mathrm{m}), L_{s}=\sqrt{\left(L_{r}-H\right)^{2}+H^{2}}$, (see Figure 2-2);

For calculation purposes, the emission line density $q(\mathrm{~g} / \mathrm{m} / \mathrm{s})$ is defined as:

$$
d=\frac{Q}{T \cdot L}
$$


where, $T$ is the time period in which the pollution is produced, and $L$ is the length of the concerned street.

The line density is the emission strength within a thin strip of area on the road, which is defined here as a width of 1 meter. See Figure 4-7.

If the permitted level of pollutant $k$ is denoted by $C_{k}$, then the direct contribution of $k$, $C_{d, k}$, should not exceed $C_{k}$, which is presented as:

$$
C_{d, k}=Q \cdot f \leq C_{k}
$$

Therefore, it is possible to calculate the $Q$ by the targeted level of emission and dilution factor, which is by:

$$
\begin{gathered}
Q \leq \frac{C_{k}}{f} \\
d \leq \frac{C_{k}}{f \cdot T \cdot L}
\end{gathered}
$$

This procedure (Equations 4-4 through 4-9) originated from a method that is often referred to as inverse simulation (Palmgren et al., 1999). In Palmgren's study, the inverse modeling was used to calculate the on-street emission strength, which is referred to in this dissertation as $Q$ in Equations 4-8 and 4-9.

The following subsection continues to describe the process of calculating the ETC by inverse modeling with $Q$.

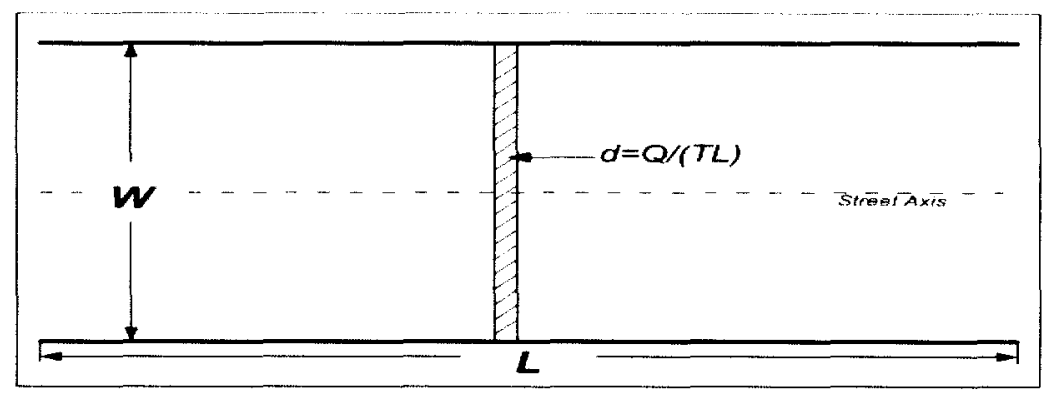

Figure 4-7: Line Density of Emissions (Berkowicz et al., 1997) 


\subsubsection{Traffic Volumes and the ETC}

In this section, a traffic volume model is developed to calculate the ETC, based on the consideration of emissions.

It is assumed that a road link $j$ has a uniform volume $V_{j}(t)(\mathrm{veh} / \mathrm{sec})$ of vehicles, which is a function of time $t(\mathrm{sec})$ at any location on this link. During elapsed time $T$ (usually in hours), the number of vehicles passing through link $j$ could be determined by:

$$
N_{j, T}=\int_{0}^{T} V_{j}(t) d t
$$

If the accumulated amount of pollutant $k$ from traffic on link $j$ during time period $T$ is denoted by $Q_{j, k}(T)$, the following equation represents the emission $k$ from the vehicles on link $j$ during $T$ :

$$
Q_{j, T, k}=N_{j, T} \sum_{i=1}^{r} \alpha_{i} \int_{0}^{L_{j}} e_{i, j, k}(u) d l
$$

where,

$r$-vehicle types;

$\alpha_{i}-$ ratio of vehicle of type $i$;

$e_{i, j, k}(u)-$ emission factor $(\mathrm{g} / \mathrm{veh} / \mathrm{km})$ of pollutant $k$ by vehicle type $i$ at speed $u(\mathrm{~km} / \mathrm{hr})$, on link $j$;

$L_{j}-$ length of link $j$;

Since $d l$ can be represented as $u \cdot d t$, combining Equations 4-10 and 4-11, the accumulation of pollutant $k$ over time $T$ is calculated by:

$$
Q_{j, T, k}=\alpha_{i} \int_{0}^{T} V_{j}(t) d t \cdot\left(\sum_{i=1}^{r} \int_{0}^{T} e_{i, j, k}(u) u d t\right)
$$

In realistic cases, when it is difficult to collect the data for a continuous integration, 
Equation 4-12 can be converted into a form of discrete summation, which is,

$$
Q_{j, T, k}=\alpha_{i}\left(\sum_{T} V_{j}(t) \cdot \Delta t\right) \cdot\left(\sum_{i=1}^{r} \sum_{T} e_{i, j, k}(u) u \cdot \Delta t\right)
$$

where, $V_{j}$ is the traffic volume on link $j$, and the other components are the same as defined earlier. If Equations 4-9 and 4-13 are combined, the time-dependent traffic volume $V_{j}(t)$, which is also the temporal ETC, can be determined by the inverse processing of Equation 4-13, assuming that $Q_{j, T, k}$ equals the standard concentration of pollutant $k$. This can be represented by the following equations:

$$
\begin{gathered}
\alpha_{i}\left(\sum_{T} V_{j}(t) \cdot \Delta t\right) \cdot\left(\sum_{i=1}^{r} \sum_{T} e_{i, j, k}(u) u \cdot \Delta t\right) \leq \frac{c_{k} T L_{j}}{f} \\
\sum_{T} V_{j}(t) \cdot \Delta t \leq \frac{c_{k} T L_{j}}{\alpha_{i} \cdot f \cdot\left(\sum_{i=1}^{r} \sum_{T} e_{i, j, k}(u) u \cdot \Delta t\right)}
\end{gathered}
$$

The hourly volume $V_{j}$ is calculated as the ETC that meets the standard established for pollutant $k$. Therefore, for several types of pollutants, the ETC that satisfies all the standards should be:

$$
E T C=\min \left(V_{j, k}\right)
$$

In next subsection, the last component of determining the ETC, which is denoted as $e_{i, j, k}(u)$ in Equation 4-15 is discussed.

\subsubsection{Emission Factors}

As discussed in Chapter 2, several emission models have been widely used to evaluate the impact of mobile-source pollution on air quality. The Mobile6, CMEM, and EMFAC are among the most popular emission models that have been applied by governments and researchers for quite some time. However, these models require average 
speed as the sole descriptor of a vehicle's modal events and driving conditions, and are not sensitive to events such as idling, cruising, acceleration, and deceleration. In this chapter, a procedure to estimate the emission factor based on instant speed and acceleration is developed. But different from a dynamic model that records the emission rate second-by-second, what has been built up here is still an emissions inventory. The improvement that has been achieved in this section is that the emission rates $(\mathrm{g} / \mathrm{s})$ and factors $(\mathrm{g} / \mathrm{km})$ are estimated and categorized for each combination of speed and acceleration. A probability approach has been applied for the calculation.

\section{Weighting Factor}

In Abou Zeid et al. (2002), acceleration is defined as a random variable for a given speed range, such as intervals of $10 \mathrm{~km} / \mathrm{hr}$. A probability distribution was calibrated on the frequency of acceleration/deceleration observed in the records. Several probability distributions were calibrated and two half-normal distributions were found to best simulate the real situations, which are expressed by the following:

$$
f_{r, u}^{*}(a)=\left\{\begin{array}{cl}
f_{r, u}^{-}(a)=\frac{2}{\sqrt{2 \pi} \sigma_{u}^{-}} e^{-\frac{1}{2}\left(\frac{a}{\sigma_{u}^{-}}\right)^{2}} & a \leq 0 \\
f_{r, u}^{+}(a)=\frac{2}{\sqrt{2 \pi} \sigma_{u}^{+}} e^{-\frac{1}{2}\left(\frac{a}{\sigma_{u}^{+}}\right)^{2}} & a>0
\end{array}\right.
$$

where $f_{r, u}^{-}(a)$ and $f_{r, u}^{+}(a)$ are the density functions of deceleration and acceleration distributions, respectively; $u$ denotes the speed range, $a$ represents the acceleration; $\sigma_{u}{ }^{-}$and $\sigma_{u}{ }^{+}$are the standard deviations of the distributions of $a$, given $a \leq 0$ and $a>0$ respectively.

Cappiello (2002) has applied a probability model with EMIT, a regression-based emission model, to estimate the average emission rate in a hypothetical network. However, the data used to calibrate the regression model may vary by locations and vehicles, 
which means it is difficult to set up a regression that is universal for all scenarios, and it needs to repeat the calibration to adjust to new scenarios. Later in this chapter, an emissions inventory based on speed and acceleration combinations is introduced. The emissions inventory is also an equivalent look-up table, which is faster to use and more importantly, easier to adjust.

\section{Emissions Inventory}

In Cappiello (2002), the emission rate $e(u, a)$ is a function of speed range $v$ and acceleration $a$. Equation 4-18 denotes the expected emission rate for pollutant $k$ as $\bar{e}_{k, i, u}$ $(\mathrm{g} / \mathrm{veh} / \mathrm{s})$, for vehicle type $i$ at speed range $v$. In each range of speed, the acceleration varies within a certain range $\left[a_{1}, a_{2}\right]$. The expected emission rate for pollutant $k$, vehicle type $i$ at speed range $v$ can be calculated by:

$$
\bar{e}_{k, i, u}=\int_{a_{1}}^{a_{2}} e_{i, k}(u, a) f_{r, u}^{*}(a) d a
$$

In this dissertation, the probability density $f_{r, u}^{*}(a)$ is defined as a weighting factor, which is integrated with the emission rates/factors to develop the weighted emissions inventory. Therefore, the expectation $\bar{e}_{k, i, u}$ is applied as the weighted emission rate for each speed range (see Tables 4-1 through 4-6). The improvement of applying the weighting factor at this point is that it takes into consideration of speed and acceleration. The weighted emission rate gives more consideration to the variation of speed and acceleration than the average emission rate (arithmetic mean). The calculation details are shown in Section 4.3.

The emission factor $e f(u, a)(\mathrm{g} / \mathrm{veh} / \mathrm{km})$, is given in the following equation, where $u$ denotes the speed of vehicle $(\mathrm{km} / \mathrm{s})$ : 


$$
\overline{e f}_{k, i, u}=\int_{a_{1}}^{a_{2}} \frac{e_{i, k}(u, a)}{u} f_{r, u}^{*}(a) d a
$$

Based on the data collected for this study, it has been found that the variation of average emission rate is significant with a $10 \mathrm{~km} / \mathrm{hr}$ speed interval. Therefore, the emission rate $(\mathrm{g} / \mathrm{veh} / \mathrm{s})$ and emission factor $(\mathrm{g} / \mathrm{veh} / \mathrm{km})$ are calculated for each speed range at $10 \mathrm{~km} / \mathrm{hr}$ intervals. For example, the weighted emission rates are grouped along with the speed ranges of $0-10 \mathrm{~km} / \mathrm{hr}, 11-20 \mathrm{~km} / \mathrm{hr}, 21-30 \mathrm{~km} / \mathrm{hr}$, etc.

The calculation is performed by using Microsoft Excel $2007^{\mathcal{C}}$ and Matlab $7.0^{\mathcal{C}}$. Tables 4-1 through 4-6 list the weighted emission rates (g/veh/s) and emission factors $(\mathrm{g} / \mathrm{veh} / \mathrm{km})$ of $\mathrm{CO}_{2}, \mathrm{CO}, \mathrm{HC}$, and $\mathrm{NO}_{\mathrm{x}}$, separately. The weighted values are also compared with the average (arithmetic mean) on the left.

Table 4-1: Category (I) vehicle emission rate (g/s), average vs. weighted

\begin{tabular}{c|cccc|cccc}
\hline \multirow{2}{*}{$\begin{array}{c}\text { Speed Range } \\
(\mathrm{km} / \mathrm{hr})\end{array}$} & \multicolumn{4}{|c|}{ Average Emission Rate $(\mathrm{g} / \mathrm{s})$} & \multicolumn{4}{c}{ Weighted Emission Rate $(\mathrm{g} / \mathrm{s})$} \\
\hline $0-10$ & $\mathrm{CO}_{2}$ & $\mathrm{CO}$ & $\mathrm{HC}$ & $\mathrm{NO}_{x}$ & $\mathrm{CO}_{2}$ & $\mathrm{CO}$ & $\mathrm{HC}$ & $\mathrm{NO}_{\mathrm{x}}$ \\
$11-20$ & 0.775765 & 0.005421 & 0.000134 & 0.000183 & 1.139872 & 0.007591 & 0.000174 & 0.000194 \\
$21-30$ & 1.734069 & 0.013069 & 0.000344 & 0.001147 & 1.416823 & 0.010589 & 0.000253 & 0.000778 \\
$31-40$ & 1.739340 & 0.012025 & 0.000274 & 0.001072 & 1.592594 & 0.010704 & 0.000232 & 0.000826 \\
$41-50$ & 1.362616 & 0.009996 & 0.000186 & 0.001205 & 1.606765 & 0.011384 & 0.000290 & 0.001147 \\
$51-60$ & 1.414308 & 0.009632 & 0.000163 & 0.001262 & 2.196521 & 0.013827 & 0.000316 & 0.001637 \\
$60+$ & 1.550002 & 0.010977 & 0.000162 & 0.001065 & 2.471933 & 0.016179 & 0.000320 & 0.001449 \\
\hline
\end{tabular}

Table 4-2: Category (I) vehicle emission factor $(\mathrm{g} / \mathrm{km})$, average vs. weighted

\begin{tabular}{c|cccc|cccc}
\hline \multirow{2}{*}{$\begin{array}{c}\text { Speed Range } \\
(\mathrm{km} / \mathrm{hr})\end{array}$} & \multicolumn{3}{|c|}{ Average Emission Factor $(\mathrm{g} / \mathrm{veh} / \mathrm{km})$} & \multicolumn{4}{c}{ Weighted Emission Factor $(\mathrm{g} / \mathrm{veh} / \mathrm{km})$} \\
& $\mathrm{CO}_{2}$ & $\mathrm{CO}$ & $\mathrm{HC}$ & $\mathrm{NO}_{\mathrm{x}}$ & $\mathrm{CO}_{2}$ & $\mathrm{CO}$ & $\mathrm{HC}$ & $\mathrm{NO}_{\mathrm{x}}$ \\
\hline $0-10$ & 1776.597 & 12.757 & 0.095 & 0.044 & 1895.155 & 31.486 & 0.195 & 0.084 \\
$11-20$ & 408.335 & 3.112 & 0.046 & 0.027 & 328.182 & 12.466 & 0.059 & 0.038 \\
$21-30$ & 232.603 & 3.037 & 0.025 & 0.014 & 214.202 & 9.796 & 0.041 & 0.033 \\
$31-40$ & 141.771 & 1.041 & 0.012 & 0.012 & 166.630 & 6.184 & 0.020 & 0.022 \\
$41-50$ & 114.61 & 0.784 & 0.009 & 0.010 & 177.924 & 5.124 & 0.018 & 0.013 \\
$51-60$ & 103.013 & 0.727 & 0.008 & 0.007 & 164.186 & 3.071 & 0.015 & 0.010 \\
$60+$ & 88.447 & 0.596 & 0.010 & 0.006 & 228.215 & 3.508 & 0.024 & 0.015 \\
\hline
\end{tabular}


Table 4-3: Category (II) vehicle emission rate (g/s), average vs. weighted

\begin{tabular}{c|cccc|cccc}
\hline \multirow{2}{*}{$\begin{array}{c}\text { Speed Range } \\
(\mathrm{km} / \mathrm{hr})\end{array}$} & \multicolumn{4}{|c|}{ Average Emission Rate $(\mathrm{g} / \mathrm{s})$} & \multicolumn{4}{c}{ Weighted Emission Rate $(\mathrm{g} / \mathrm{s})$} \\
& $\mathrm{CO}_{2}$ & $\mathrm{CO}$ & $\mathrm{HC}$ & $\mathrm{NO}_{\mathrm{x}}$ & $\mathrm{CO}_{2}$ & $\mathrm{CO}$ & $\mathrm{HC}$ & $\mathrm{NO}_{\mathrm{x}}$ \\
\hline $0-10$ & 0.817209 & 0.008588 & 0.002183 & 0.003425 & 1.139367 & 0.011119 & 0.003187 & 0.005005 \\
$11-20$ & 1.400635 & 0.031871 & 0.003078 & 0.007081 & 1.744160 & 0.021413 & 0.004219 & 0.009815 \\
$21-30$ & 1.815307 & 0.029494 & 0.004697 & 0.014031 & 2.069661 & 0.024032 & 0.005884 & 0.01116 \\
$31-40$ & 1.978246 & 0.035661 & 0.003879 & 0.013622 & 2.519966 & 0.033557 & 0.005954 & 0.016139 \\
$41-50$ & 2.182384 & 0.035466 & 0.003641 & 0.012986 & 2.962424 & 0.041041 & 0.005841 & 0.017318 \\
$51-60$ & 2.094701 & 0.017016 & 0.002537 & 0.009541 & 3.241014 & 0.044659 & 0.005423 & 0.016528 \\
$60+$ & 2.768864 & 0.010311 & 0.007007 & 0.029987 & 4.437508 & 0.049944 & 0.006222 & 0.016616 \\
\hline
\end{tabular}

Table 4-4: Category (II) vehicle emission factor $(\mathrm{g} / \mathrm{km})$, average vs. weighted

\begin{tabular}{c|cccc|cccc}
\hline \multirow{2}{*}{$\begin{array}{c}\text { Speed Range } \\
(\mathrm{km} / \mathrm{hr})\end{array}$} & \multicolumn{3}{|c|}{ Average Emission Factor $(\mathrm{g} / \mathrm{veh} / \mathrm{km})$} & \multicolumn{3}{c}{ Weighted Emission Factor $(\mathrm{g} /$ veh/km) } \\
& $\mathrm{CO}_{2}$ & $\mathrm{CO}$ & $\mathrm{HC}$ & $\mathrm{NO}_{\mathrm{x}}$ & $\mathrm{CO}_{2}$ & $\mathrm{CO}$ & $\mathrm{HC}$ & $\mathrm{NO}_{x}$ \\
\hline $0-10$ & 2455.374 & 6.772 & 0.302 & 0.583 & 2656.676 & 34.822 & 1.251 & 1.031 \\
$11-20$ & 340.087 & 3.905 & 0.103 & 0.166 & 424.633 & 17.930 & 0.368 & 0.830 \\
$21-30$ & 263.774 & 4.308 & 0.117 & 0.205 & 301.454 & 11.515 & 0.164 & 0.652 \\
$31-40$ & 205.715 & 4.198 & 0.037 & 0.141 & 261.726 & 9.466 & 0.125 & 0.277 \\
$41-50$ & 175.165 & 1.362 & 0.039 & 0.106 & 237.226 & 3.303 & 0.120 & 0.133 \\
$51-60$ & 140.63 & 1.13 & 0.029 & 0.064 & 218.527 & 3.636 & 0.070 & 0.078 \\
$60+$ & 157.321 & 0.585 & 0.014 & 0.069 & 252.964 & 3.337 & 0.073 & 0.163 \\
\hline
\end{tabular}

Table 4-5: Category (III) vehicle emission rate (g/s), average vs. weighted

\begin{tabular}{c|cccc|cccc}
\hline $\begin{array}{c}\text { Speed } \\
\text { Range } \\
(\mathrm{km} / \mathrm{hr})\end{array}$ & \multicolumn{4}{|c|}{ Average Emission Rate $(\mathrm{g} / \mathrm{s})$} & \multicolumn{4}{c}{ Weighted Emission Rate $(\mathrm{g} / \mathrm{s})$} \\
\hline $0-10$ & $\mathrm{CO}_{2}$ & $\mathrm{CO}$ & $\mathrm{HC}$ & $\mathrm{NO}_{\mathrm{x}}$ & $\mathrm{CO}_{2}$ & $\mathrm{CO}$ & $\mathrm{HC}$ & $\mathrm{NO}_{\mathrm{x}}$ \\
$11-20$ & 2.500471 & 0.013747 & 0.000927 & 0.027603 & 3.227037 & 0.017645 & 0.001071 & 0.034325 \\
$21-30$ & 4.490278 & 0.027068 & 0.001201 & 0.046767 & 4.023979 & 0.018478 & 0.001158 & 0.035689 \\
$31-40$ & 4.942459 & 0.032289 & 0.001131 & 0.048977 & 4.852190 & 0.032764 & 0.001309 & 0.046057 \\
$41-50$ & 5.506646 & 0.027289 & 0.001045 & 0.046221 & 5.091863 & 0.031078 & 0.001202 & 0.051476 \\
$51-60$ & 4.567279 & 0.019058 & 0.001057 & 0.057602 & 4.461820 & 0.039916 & 0.001561 & 0.072388 \\
$60+$ & 5.724302 & 0.006273 & 0.000714 & 0.035280 & 5.548974 & 0.042002 & 0.002027 & 0.081494 \\
\hline
\end{tabular}


Table 4-6: Category (III) vehicle emission factor $(\mathrm{g} / \mathrm{km})$, average vs. weighted

\begin{tabular}{c|cccc|cccc}
\hline \multirow{2}{*}{$\begin{array}{c}\text { Speed range } \\
(\mathrm{km} / \mathrm{hr})\end{array}$} & \multicolumn{3}{|c|}{ Average Emission Factor $(\mathrm{g} / \mathrm{veh} / \mathrm{km})$} & \multicolumn{3}{c}{ Weighted Emission Factor $(\mathrm{g} / \mathrm{veh} / \mathrm{km})$} \\
& $\mathrm{CO}_{2}$ & $\mathrm{CO}$ & $\mathrm{HC}$ & $\mathrm{NO}_{\mathrm{x}}$ & $\mathrm{CO}_{2}$ & $\mathrm{CO}$ & $\mathrm{HC}$ & $\mathrm{NO}_{\mathrm{x}}$ \\
\hline $0-10$ & 3722.29 & 21.942 & 1.269 & 1.943 & 3218.457 & 43.669 & 3.279 & 6.964 \\
$11-20$ & 1120.012 & 12.703 & 0.729 & 2.067 & 1002.668 & 16.066 & 0.997 & 2.986 \\
$21-30$ & 732.938 & 8.788 & 0.696 & 1.718 & 721.303 & 14.865 & 0.877 & 1.677 \\
$31-40$ & 471.859 & 2.877 & 0.403 & 0.483 & 532.607 & 7.271 & 0.514 & 0.937 \\
$41-50$ & 409.715 & 2.225 & 0.293 & 0.474 & 477.098 & 2.738 & 0.388 & 0.555 \\
$51-60$ & 299.144 & 1.244 & 0.275 & 0.379 & 291.132 & 1.298 & 0.231 & 0.344 \\
$60+$ & 397.251 & 0.349 & 0.093 & 0.101 & 331.773 & 1.314 & 0.328 & 0.367 \\
\hline
\end{tabular}

The data were sorted by a $10 \mathrm{~km} / \mathrm{hr}$ interval of speed as inputs of the calculation for the emissions inventory. Raw emission rates $(\mathrm{g} / \mathrm{s})$ were processed by the algorithm provided by Equations 4-17 through 4-19. Using the probability density function of acceleration as the weight coefficient, the raw data were converted into weighted data.

The weighted emission factors $(\mathrm{g} / \mathrm{veh} / \mathrm{km})$, which are part of the results of this study, are compared with the arithmetic mean values of the emission factors (see Appendix B). Appendix B shows the differences between the results calculated by the three different approaches. In general, the weighted values are higher than the average. This result is consistent with the hypothesis (Armstrong et al., 2004; Chan et al., 2005; Kauhaniemi et al., 2008; Parrish, 2006) that the limitation of average-based methods to effectively reflect the real-time, site-specific emissions due to the variations of road conditions, traffic fleet and volume, driving patterns, and fuel composition, etc.

In general, when speed increases, the emission factor $(\mathrm{g} / \mathrm{km})$ decreases, reaching the lowest points at speeds of $50-70 \mathrm{~km} / \mathrm{hr}$, which presents a consistent pattern with earlier studies (see Chapters $1 \&$ 2). The weighted emissions inventory includes more of the effects of speed and acceleration on emissions (see comparison with average emission in Tables 4-1 through 4-6), and can be used to predict emissions from time-patterned on- 
road traffic.

\subsection{Data}

The data used for the emissions inventory development were collected in Nanjing, China, with the cooperation of the Southeast University, as part of a Chinese National Science Foundation sponsored study ${ }^{7}$ for urban traffic pollution control. The measurement device used to collect the data is the SEMTECH-DS, a portable emissions measuring system manufactured by the Sensors, Inc. ${ }^{8}$ The system was installed on board the testing vehicles, and had instantaneous speed and emission readings recorded as the vehicle was operating during various hours and in varied traffic conditions. The most common types of motor vehicles were selected for the emission rate measurement. The testing routes and intervals were combined to cover most of the speed ranges of featured traffic hours and road types. Records of speed readings range from $0 \mathrm{~km} / \mathrm{hr}$ (idling) through up to $70 \mathrm{~km} / \mathrm{hr}$ (free-flow), and operating times from 8:00 am - 6:00 pm local time.

\subsubsection{Vehicles}

Three groups of vehicles were selected to represent the major types of automobiles within the testing area. They are categorized as: 1) light-duty gasoline car, 2) diesel van and medium truck, and 3) heavy-duty diesel bus. Heavy trucks are prohibited in most of the metro area in Nanjing and were not included in this measurement. See Table 4-7 for vehicle details.

\footnotetext{
${ }^{7}$ Key Issues of Controlling Air Pollution of Urban Transportation (No.50778041), sponsored by National Science Foundation of China

${ }^{8}$ Sensors, Inc., 6812 State Road, Saline, MI 48176, USA
} 
Table 4-7: Vehicles used for three categories

\begin{tabular}{l|ccccc}
\hline \multicolumn{1}{c}{ Category } & Model & Engine (L) & Mass $(\mathrm{kg})$ & Odometer $(\mathrm{km})$ & Fuel \\
\hline & Kia & 1.6 & 1255 & 75778 & Gasoline \\
(I)- & Buick & 1.6 & 1250 & 40771 & Gasoline \\
Gasoline & Jetta & 2.0 & 1350 & 53467 & Gasoline \\
light duty & Suzuki & 2.0 & 1350 & 62335 & Gasoline \\
\hline (II)- & Iveco & 2.8 & 2350 & 45800 & Diesel \\
$\begin{array}{l}\text { Diesel me- } \\
\text { dium duty }\end{array}$ & Ford & 2.8 & 2020 & 79880 & Diesel \\
\hline (III) - & Bus \#1 & - & - & - & Diesel \\
Diesel & Bus \#2 & - & - & - & Diesel \\
\hline
\end{tabular}

- Category (I) vehicles are installed with a three-way catalyst, gasoline engine, with a weight of less than 1500 kilograms $(3307 \mathrm{lbs})$, high in power/weight ratio.

- Category (II) and (III) vehicles are installed with a three-way catalyst, diesel engine, with a weight of over 2000 kilograms (4410 lbs), high in power/weight ratio.

According to 2008 statistics for Nanjing city (Wu, 2009), the Category (I) vehicles make up the majority $(80 \%)$ of the total traffic fleet of the city. Most of them (95\%) are gasoline powered and the rest, $5 \%$, which are taxi fleets, are fueled with liquefied natural gas. An overview of the $\mathrm{VKT}^{9}$ of each vehicle type is summarized in Table 4-8.

The vehicles involved in this measurement are composed of light-duty cars, vans, and light-duty trucks. Trials were also operated for buses. The following subsection will discuss the routes and the time periods during which these measurements were taken, and the calculation with the data for the emissions inventory.

\footnotetext{
${ }^{9}$ VKT/VMT (Vehicle Kilometers/Miles Traveled) is an indicator of the on-road transportation activities taking place during a given time interval within an area. It is calculated as the total mileage traveled by the vehicles involved in the concerned network or area.
} 
Table 4-8: Vehicle types and VKT (Vehicle Kilometers Traveled)

\begin{tabular}{ccccc}
\hline Vehicle Type & Unit (Veh) & $\begin{array}{c}\text { Daily Average } \\
\text { VKT }(\mathrm{km})\end{array}$ & $\begin{array}{c}\text { Daily Total VKT } \\
(10,000 \mathrm{veh} \cdot \mathrm{km})\end{array}$ & VKT (\%) \\
\hline Ligh Duty & 259990 & 60 & 1559.9 & $57.00 \%$ \\
Bus & 5074 & 200 & 101.5 & $3.70 \%$ \\
Taxi & 9055 & 300 & 271.7 & $9.90 \%$ \\
Medium Truck & 43637 & 60 & 261.8 & $9.60 \%$ \\
Electric Cycle & 330318 & 15 & 495.5 & $18.10 \%$ \\
Motorcycle & 40199 & 12 & 48.2 & $1.80 \%$ \\
Total & 688273 & - & 2738.6 & $100.00 \%$ \\
\hline
\end{tabular}

Table 4-9: Routes of the testing drives

\begin{tabular}{cccccc}
\hline Route ID & Type & Length $(\mathrm{km})$ & Route ID & Type & Length $(\mathrm{km})$ \\
\hline A1 & Highway & 2.1 & B7 & Arterial & 2.5 \\
A2 & Highway & 4.8 & B8 & Arterial & 2.2 \\
A3 & Highway & 2.8 & B9 & Arterial & 2.6 \\
A4 & Highway & 3.8 & B10 & Arterial & 1.7 \\
A5 & Highway & 3.0 & B11 & Arterial & 0.9 \\
B1 & Arterial & 2.3 & C1 & Collector & 2.1 \\
B2 & Arterial & 2.7 & C2 & Collector & 1.2 \\
B3 & Arterial & 1.9 & C3 & Collector & 0.9 \\
B4 & Arterial & 1.9 & C4 & Collector & 1.3 \\
B5 & Arterial & 4.8 & D1 & Collector & 0.5 \\
B6 & Arterial & 2.3 & D2 & Collector & 0.5 \\
\hline
\end{tabular}

\subsubsection{The Measurements}

The measurements were made during specific hours on weekdays. Rush hours ( 7 am -9 am \& $5 \mathrm{pm}-7 \mathrm{pm})$, and non-rush hours (11 am $-3 \mathrm{pm})$ were covered for each of the three categories. Routes were mostly composed of urban arterial roads; typical streets and alleys in the downtown area were chosen, in order to include as many characteristics in the area where congestion most likely occurs. A summary of the testing routes are shown in Table 4-9.

The emission data were recorded second-by-second with the device SEMTECH-DS on board while the testing vehicle was being driven in real traffic flows in the concerned 
area. The readings were taken from the tailpipe, however the engine source emission is not included in this study. Each route has been tested twice with each vehicle of each category. More testing data are presented in Appendix A.

\subsection{The calculation of the ETC}

To calculate the time-dependent Environmental Traffic Capacity (ETC), the daytime of a normal weekday is divided into ten consecutive hours $(8 \mathrm{am}-6 \mathrm{pm})$. To determine the varying pattern of the ETC, the method introduced in previous sections is used to estimate the ETC for each of the ten hours separately. This process will be repeated for each of the two criteria pollutants $\left(\mathrm{CO}, \mathrm{NO}_{\mathrm{x}}\right)$ to determine by which pollutant the ETC will be kept at the lower level. See Equation 4-16 and Figure 4-8.

The inputs needed for the calculation are:

1. Physical configuration of the street: width, average height of side buildings.

2. Meteorological data: dominant wind direction, street level wind speed.

3. Traffic data: hourly volume per vehicle category.

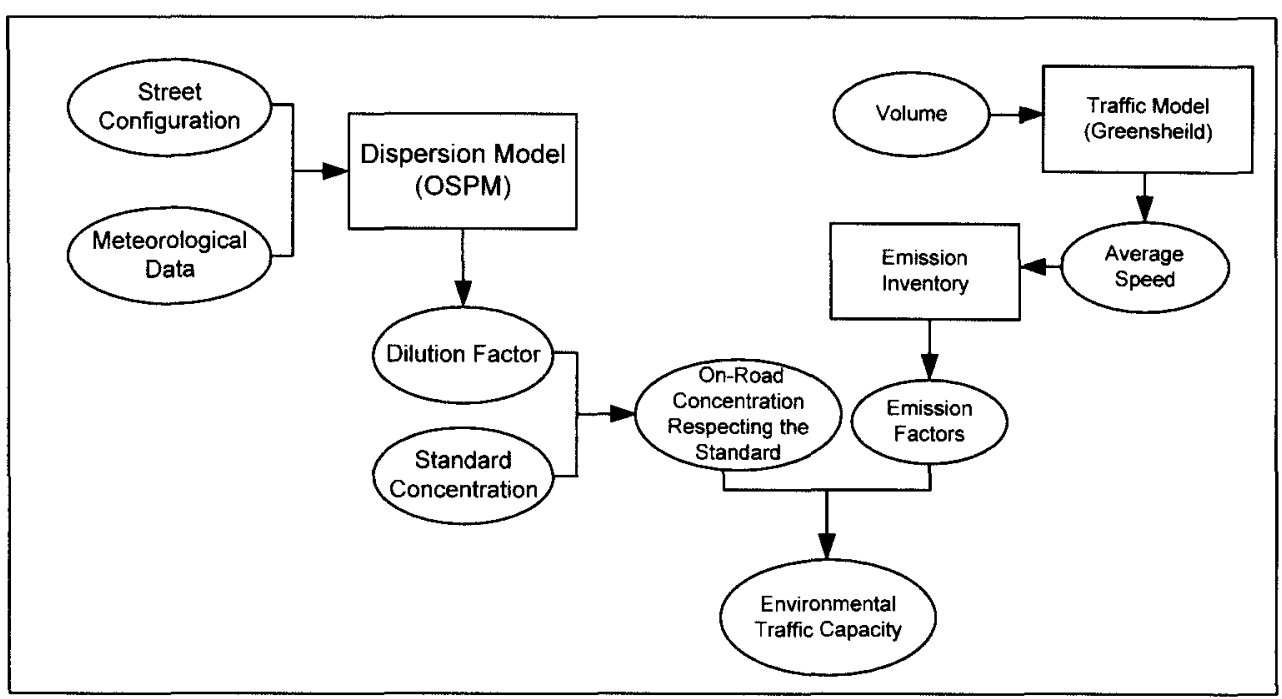

Figure 4-8: Flow chart of the methodology 
Figure 4-8 illustrates the procedure of the method to calculate the ETC:

The first step is to input the street configuration and wind direction/speed into the dispersion model, which utilizes the OSPM in this study, to calculate the dilution factor. The dilution factor is used to multiply the total amount of pollution produced by the traffic on road. The concentration of pollution will be diluted as the pollutants reach the adjacent impacted area after the process of dilution is completed by the direct wind and/or turbulence.

The second step is to combine the standard concentration of a certain pollutant with the dilution factor attained in step one. This will determine the amount of pollution on the road, from which the concentration on the adjacent area is diluted. This actually is an inverse process of the OSPM model. The result will be the permitted amount of pollution from traffic on the road.

The third step is to input the traffic data into a traffic model, using Greenshield's model in this study, to obtain the average speed of traffic under different volumes. The speed then is combined with the emissions inventory developed in Section 4.2 , to obtain the emission factors.

The last step is to calculate the ETC by using Equation 4-15.

After repeating the procedure of these steps for all concerned pollutants, the minimum ETC will be the capacity to meet the pollution standards. This is demonstrated in the following chapter for the city of Nanjing, China. 


\section{CHAPTER 5 APPLICATION: A CASE STUDY OF A ROAD SECTION IN NANJING, CHINA}

In this chapter, an application of the methodology described in Chapter 4 to determine the environmental traffic capacity on a road section in downtown Nanjing is presented. The objective of this chapter is to test the ability of the approach developed in predicting the variation of environmental traffic capacity by time series (hours). Alternatives of traffic control are suggested after the ETC is determined, including road surface reconfiguration and temporary increase of speed limit.

The chapter is organized as follows. Section 5.1 describes the site selected for this case study. Section 5.2 describes the data. Section 5.3 presents the results and analysis.

\subsection{Site for the Case Study}

The city of Nanjing is located in southeast China with metro area of $200 \mathrm{~km}^{2}$, and population of $6,400,000$. In 2005 , the number of motor vehicles in Nanjing was 688,000 , including 311,519 passenger cars (NEPB, 2005).

The North Taiping Road is a main arterial connection located in the northeast part of the downtown area in Nanjing. It is north/south bound, connecting traffic to the northeast part of the city through the center of the downtown area. The road configuration is three lanes in each direction, with a width of 3.0 meters for each lane. The total width of the road surface is 24.6 meters. The east side of the street is characterized as high-density 
residential, with buildings of 18 meters average height; the area on west side is characterized by commercial and business buildings with average heights of 16 meters. The street axis forms an angle of 20 degrees with North.

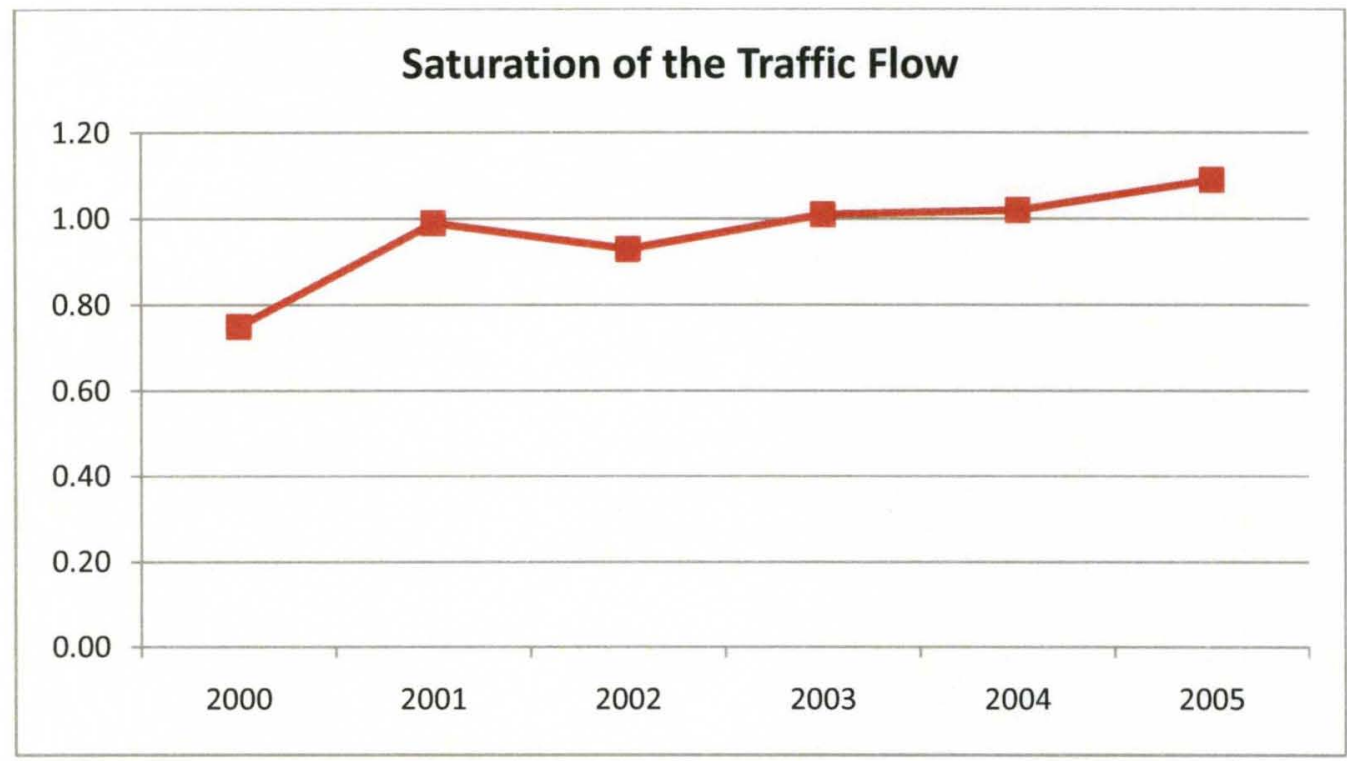

Figure 5-1: Increasing annual average saturation of the flow in downtown area, Nanjing

The increasing traffic volumes in Nanjing city have been causing heavy traffic congestion, especially within the downtown area, since the late 1990s. The congestion creates increasingly high mobile-sourced air pollution aggregated over the areas adjacent to traffic. According to measurements by Nanjing Environment Protection Bureau in 2005, the daily concentration of $\mathrm{PM}_{10}$ along motor ways is averagely $0.492 \mathrm{mg} / \mathrm{m}^{3}$, which is 2.7 times higher than the average value of $0.183 \mathrm{mg} / \mathrm{m}^{3}$ in other areas; the daily average concentration of mono-nitrogen oxides $\left(\mathrm{NO}_{\mathrm{x}}\right)$ along the arterial roadside is 0.075 $\mathrm{mg} / \mathrm{m}^{3}$, compared with an average $0.049 \mathrm{mg} / \mathrm{m}^{3}$ within distant communities away from the traffic (NEPB, 2008).

In order to determine the environmental traffic capacity on a typical road within 
downtown Nanjing, a 778-meter section of the $N$. Taiping $R d$ was selected as a site for this case study. The section connects another two east/west arterial roads running across the north and south ends of this section, respectively. As mentioned, the section is configured as 24.6 meters in width, with buildings of 16-meter and 18-meter average height on west and east side respectively. In the next sections, the environmental traffic capacity of this section is calculated for each of the 10 consecutive hours during a weekday. The designated traffic capacity for this section is $4350 \mathrm{pcu} / \mathrm{hr}$ (2-directional), congestion density is $120 \mathrm{pcu} / \mathrm{lane} / \mathrm{km}$, and the speed limit in the downtown area of Nanjing is $40 \mathrm{~km} / \mathrm{hr}$. Figure 5-2 illustrates the basic physical configuration of this road.
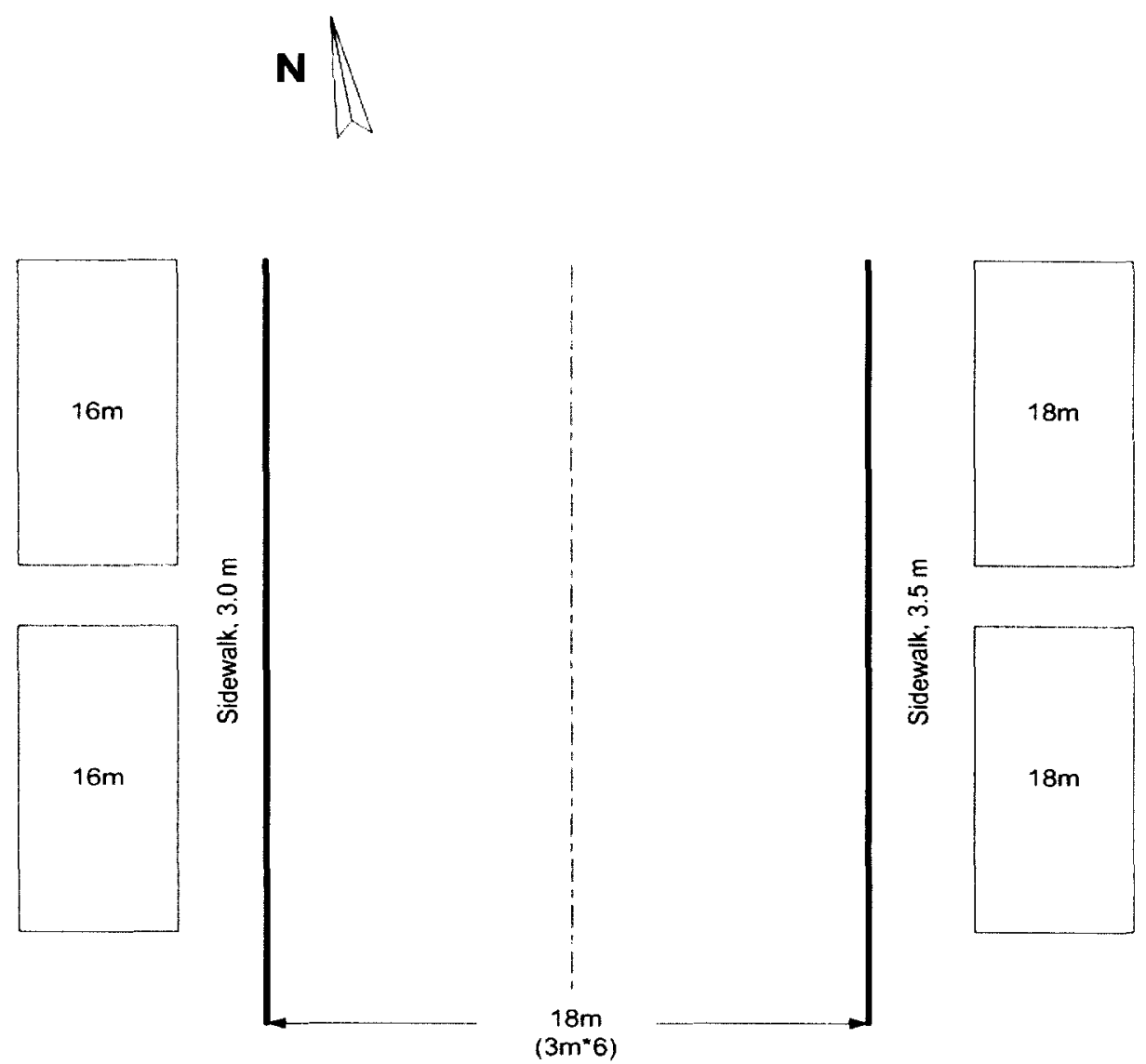

Figure 5-2: Configuration of the case study site 


\subsection{Traffic and Meteorological Data}

\section{Traffic Data}

In addition to the emissions data obtained by the approach in Chapter 4, traffic and meteorological data are needed as inputs for the calculation.

The hourly volumes for both directions of the test section were measured for 10 consecutive hours in 3 weekdays (Dec $15-17,2009$ ). Since the trucks are prohibited in downtown area, Nanjing, the traffic mix during the daytime is composed of cars, vans, light duty trucks and buses. Motorcycles are not included in this study, since their contribution to the emission in Nanjing is low compared to cars and buses (NEPB, 2005).

The traffic data were collected separately, by vehicle category, with the average of the three days value taken as the daily traffic data. The average volume and standard deviation are listed in Tables 5-1 and 5-2. The hourly volumes are also converted to Passenger-Car Unit (PCU). See in Table 5-3 the convertors for each group.

Table 5-1: Hourly volumes on the testing section (north bound)

\begin{tabular}{|c|c|c|c|c|c|c|}
\hline \multicolumn{7}{|c|}{ Percent of Volume $(\%)$} \\
\hline Time & $\begin{array}{c}\text { Category } \\
\text { (I) }\end{array}$ & $\begin{array}{l}\text { Category } \\
\text { (II) }\end{array}$ & $\begin{array}{c}\text { Category } \\
\text { (III) }\end{array}$ & Volume & $\begin{array}{l}\text { Standard } \\
\text { Deviation }\end{array}$ & $\begin{array}{l}\text { volume } \\
\text { (PCU) }\end{array}$ \\
\hline 08:00-09:00 & 87 & 3 & 10 & 1191 & 16.80 & 1310 \\
\hline 09:00-10:00 & 88 & 4 & 8 & 1187 & 12.50 & 1282 \\
\hline 10:00-11:00 & 90 & 4 & 6 & 1153 & 25.42 & 1222 \\
\hline $11: 00-12: 00$ & 90 & 3 & 7 & 966 & 12.49 & 1034 \\
\hline $12: 00-13: 00$ & 86 & 4 & 10 & 810 & 10.26 & 891 \\
\hline $13: 00-14: 00$ & 88 & 4 & 8 & 765 & 7.64 & 826 \\
\hline $14: 00-15: 00$ & 90 & 4 & 6 & 937 & 18.25 & 993 \\
\hline $15: 00-16: 00$ & 88 & 4 & 8 & 1105 & 19.66 & 1193 \\
\hline $16: 00-17: 00$ & 86 & 4 & 10 & 1293 & 17.56 & 1422 \\
\hline 17:00-18:00 & 86 & 4 & 10 & 1346 & 18.68 & 1481 \\
\hline
\end{tabular}


Table 5-2: Hourly volumes on the testing section (south bound)

\begin{tabular}{|c|c|c|c|c|c|c|}
\hline \multicolumn{7}{|c|}{ Percent of Volume (\%) } \\
\hline Time & $\begin{array}{c}\text { Category } \\
\text { (I) }\end{array}$ & $\begin{array}{l}\text { Category } \\
\text { (II) }\end{array}$ & $\begin{array}{l}\text { Category } \\
\text { (III) }\end{array}$ & Volume & $\begin{array}{l}\text { Standard } \\
\text { Deviation }\end{array}$ & $\begin{array}{l}\text { Volume } \\
\text { (PCU) }\end{array}$ \\
\hline 08:00-09:00 & 82 & 4 & 14 & 1294 & 18.04 & 1475 \\
\hline 09:00-10:00 & 83 & 5 & 12 & 1273 & 13.53 & 1426 \\
\hline 10:00-11:00 & 82 & 7 & 11 & 1263 & 14.15 & 1402 \\
\hline $11: 00-12: 00$ & 83 & 6 & 11 & 1050 & 13.75 & 1166 \\
\hline $12: 00-13: 00$ & 83 & 8 & 9 & 942 & 11.50 & 1027 \\
\hline $13: 00-14: 00$ & 84 & 7 & 9 & 926 & 12.22 & 1009 \\
\hline $14: 00-15: 00$ & 87 & 6 & 7 & 1019 & 10.97 & 1090 \\
\hline $15: 00-16: 00$ & 82 & 7 & 11 & 1036 & 13.50 & 1150 \\
\hline $16: 00-17: 00$ & 82 & 4 & 14 & 1110 & 20.50 & 1265 \\
\hline $17: 00-18: 00$ & 77 & 7 & 16 & 1230 & 11.02 & 1427 \\
\hline
\end{tabular}

Table 5-3: Convertors to PCU for each vehicle group ${ }^{10}$

\begin{tabular}{cccccccc}
\hline Vehicle & Bicycle & Motorcycle & (a) & (b) & RV & (c) & (d) \\
\hline Convertor & 0.2 & 0.4 & 0.6 & 1.0 & 1.2 & 2.0 & 3.0 \\
\hline
\end{tabular}

(a) - compact cars.

(b) - passenger cars, vans, or trucks under $3000 \mathrm{~kg}$.

(c) - buses or trucks under $9000 \mathrm{~kg}$.

(d) - trucks over $9000 \mathrm{~kg}$.

\section{Meteorological Data}

The data for wind direction and wind speed were obtained from the database of the Nanjing Environmental Protection Bureau. As defined in Chapter 4, the wind direction (with the street axis) and the street level wind speed are represented, respectively, by $\theta$ (degree) and $u_{b}(\mathrm{~m} / \mathrm{s})$. The data indicate that the hourly average wind speed in a winter day in Nanjing is $0.30(\mathrm{~m} / \mathrm{s})$. The street level wind speed and dominant direction are listed in Table 5-4. The wind direction and its standard deviation are denoted by $\varphi$ (degree)

\footnotetext{
${ }^{10}$ The convertors are defined by the Chinese Urban Transportation Design Manual, 2000.
} 
and $\sigma(\varphi)$ in the table, respectively. The dilution factors are calculated by OSPM (see in Chapter 4). For more details about dilution factor and inverse modeling by OSPM, see Le Bihan (2002).

Table 5-4: Hourly wind speeds and directions

\begin{tabular}{cccccc}
\hline $\begin{array}{c}\text { Measure } \\
\text { Time }\end{array}$ & $u_{b}$ & $\varphi$ & $\sigma(\varphi)$ & $\theta$ & $\begin{array}{c}\text { Dilution } \\
\text { Factor }\end{array}$ \\
\hline $8: 30$ & 0.28 & 34.5 & 26.9 & 14.5 & 0.634 \\
$9: 30$ & 0.32 & 22.5 & 26.6 & 2.5 & 0.549 \\
$10: 30$ & 0.32 & 78.5 & 37.6 & 58.5 & 0.591 \\
$11: 30$ & 0.18 & 348 & 11.4 & 328 & 0.791 \\
$12: 30$ & 0.23 & 61.5 & 8.8 & 41.5 & 0.660 \\
$13: 30$ & 0.31 & 15.6 & 21.3 & -4.4 & 0.601 \\
$14: 30$ & 0.39 & 128.5 & 20.3 & 108.5 & 0.529 \\
$15: 30$ & 0.26 & 7.1 & 25.2 & -12.9 & 0.428 \\
$16: 30$ & 0.42 & 272 & 69.2 & 252 & 0.454 \\
$17: 30$ & 0.25 & 192.3 & 81.8 & 172.3 & 0.517 \\
Average & 0.30 & - & 32.9 & - & 0.576 \\
\hline
\end{tabular}

Figure 5-3 illustrates the fluctuation of the dilution factors during the ten hour period. The value of the dilution factor indicates the effect of the wind and/or turbulence that transports the emission to the analysis position at the roadside. Generically, the higher the value, the stronger the effect is for wind/turbulence carrying the pollutants to the roadside. The data show that the highest dilution factor occurs at 11:00am - 12:00pm. It indicates the meteorological conditions during this hour over the test area are least able to disperse the on-road emissions.

\section{Pollution Standard}

In the Nanjing area, the winter season encompasses the months of November through February. The concentration of $\mathrm{CO}$ usually increases to high levels in the winter (NEPB, 2008). Since the computation procedure is the same for each emission criteria, only CO 
and $\mathrm{NO}_{\mathrm{x}}$, the dominant pollutants in the winter in Nanjing, were used to calculate the ETC for the two standards. See Table 5-5 for the Chinese national standard concentration (1-hour aggregated) of each pollutant.

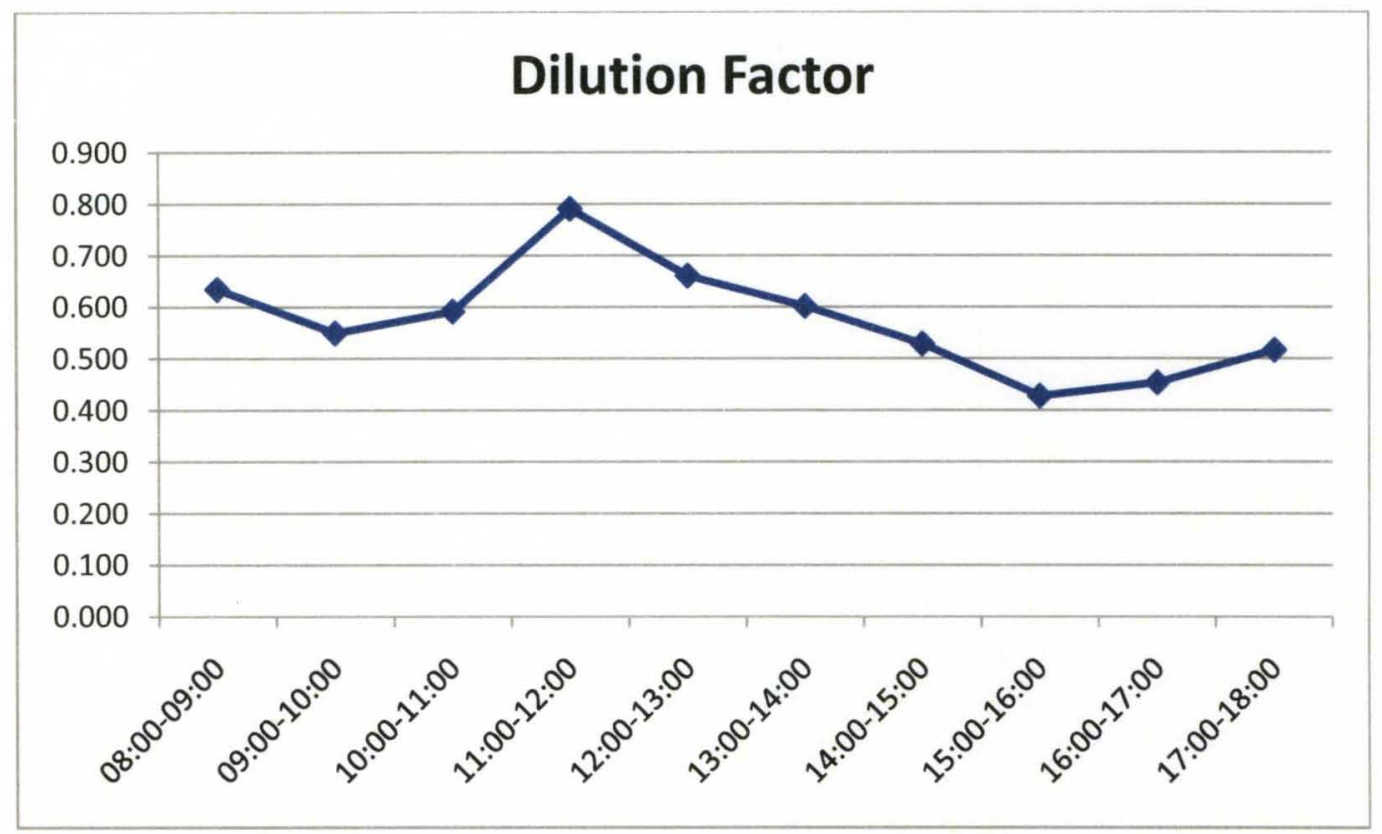

Figure 5-3: Hourly average dilution factor by time

Table 5-5: 1-Hour average concentration at various locations in Nanjing (NEPB 2008)

\begin{tabular}{c|ccccc|cccccc}
\hline \multirow{2}{*}{$\begin{array}{c}\text { Collecting } \\
\text { Location }\end{array}$} & \multicolumn{6}{|c}{ Sourly Average Concentration $\left(\mathrm{mg} / \mathrm{m}^{3}\right)$} \\
\cline { 2 - 11 } & $\mathrm{NO}_{\mathrm{x}}$ & $\mathrm{NO}_{2}$ & $\mathrm{CO}$ & $\mathrm{PM}_{10}$ & $\mathrm{HC}$ & $\mathrm{NO}_{\mathrm{x}}$ & $\mathrm{NO}_{2}$ & $\mathrm{CO}$ & $\mathrm{PM}_{10}$ & $\mathrm{HC}$ \\
\hline Commercial & 0.064 & 0.018 & 1.9 & 0.164 & 0.44 & 0.167 & 0.063 & 2.26 & 0.21 & 0.62 \\
Arterial Road & 0.138 & 0.018 & 2.53 & 0.234 & 0.96 & 0.226 & 0.075 & 2.95 & 0.296 & 0.61 \\
Industrial & 0.046 & 0.014 & 1.18 & 0.202 & 0.64 & 0.14 & 0.054 & 2.55 & 0.271 & 0.51 \\
$\begin{array}{c}\text { Recreation } \\
\text { Transportation } \\
\text { Facility }\end{array}$ & 0.035 & 0.015 & 1.48 & 0.141 & 0.51 & 0.09 & 0.049 & 2.08 & 0.193 & 0.59 \\
$\begin{array}{c}\text { National } \\
\text { Standard }\end{array}$ & 0.071 & 0.016 & 1.77 & 0.185 & 0.64 & 0.156 & 0.060 & 2.46 & 0.243 & 0.58 \\
\hline
\end{tabular}

According to the statistics provided by the Nanjing Environmental Protection Bureau 
(2008), $80 \%$ of the air pollution is caused by on-road mobile sources in Nanjing. Therefore, only emissions from the transportation sector were considered in the case study.

By implementing the procedure developed in Chapter 4, the ETC for each of the ten hours of a typical weekday is determined. As mentioned earlier, the calculations utilized Microsoft Office Excel $2007^{\circ}$ and Matlab 7.0 $0^{\circ}$. Results and analysis are presented in Section 5.3.

\subsection{Results}

\section{Average Speed}

The traffic data are input to the traffic model, which uses Greensheild's speed-flow model, to estimate the hourly average speed. The designated traffic capacity for the test section is $4350 \mathrm{pcu} / \mathrm{hr}$ (2-directional), congestion density is $120 \mathrm{pcu} / \mathrm{lane} / \mathrm{km}$, and the speed limit in the downtown area of Nanjing has been set as $40 \mathrm{~km} / \mathrm{hr}$. To evaluate the traffic conditions, the volume/capacity ratio is also presented for each of the 10 hours.

Table 5-6: Hourly volume and average speed $(\mathrm{km} / \mathrm{hr})$ estimated by the traffic model

\begin{tabular}{ccccccc}
\hline \multirow{2}{*}{$\begin{array}{c}\text { Time } \\
\text { Interval }\end{array}$} & \multicolumn{2}{c}{ North Bound } & \multicolumn{2}{c}{ South Bound } & Total Volume & V/C \\
\cline { 2 - 6 } & $\begin{array}{c}\text { Volume } \\
(\mathrm{PCU})\end{array}$ & $\begin{array}{c}\text { Speed } \\
(\mathrm{km} / \mathrm{hr})\end{array}$ & $\begin{array}{c}\text { Volume } \\
(\mathrm{PCU})\end{array}$ & $\begin{array}{c}\text { Speed } \\
(\mathrm{km} / \mathrm{hr})\end{array}$ & $(\mathrm{PCU})$ & \\
\hline 08:00-09:00 & 1310 & 21.47 & 1475 & 20.92 & 2785 & 0.64 \\
09:00-10:00 & 1282 & 25.87 & 1426 & 21.93 & 2708 & 0.62 \\
10:00-11:00 & 1222 & 26.10 & 1402 & 25.40 & 2624 & 0.60 \\
$11: 00-12: 00$ & 1034 & 33.93 & 1166 & 28.06 & 2199 & 0.51 \\
12:00-13:00 & 891 & 36.37 & 1027 & 34.85 & 1918 & 0.44 \\
13:00-14:00 & 826 & 36.66 & 1009 & 29.56 & 1836 & 0.42 \\
14:00-15:00 & 993 & 31.41 & 1090 & 27.47 & 2084 & 0.48 \\
15:00-16:00 & 1193 & 27.95 & 1150 & 28.12 & 2343 & 0.54 \\
16:00-17:00 & 1422 & 21.10 & 1265 & 25.93 & 2688 & 0.62 \\
17:00-18:00 & 1481 & 19.23 & 1427 & 21.93 & 2907 & 0.67 \\
\hline Average & 1165 & 28.01 & 1244 & 26.42 & 2409 & 0.55 \\
\hline
\end{tabular}




\section{Time-Dependent Emission Factor}

By using the average speed data, the emissions inventory developed in Chapter 4 was used to obtain the emission factor per vehicle category for each hour. The results are presented as:

Table 5-7: Speed and corresponding emission factor, north bound.

\begin{tabular}{c|c|ccc|ccc}
\hline \multirow{2}{*}{$\begin{array}{c}\text { Time } \\
\text { Interval }\end{array}$} & \multirow{2}{*}{$\begin{array}{c}\text { Speed } \\
(\mathrm{km} / \mathrm{hr})\end{array}$} & $\begin{array}{c}\text { Category } \\
\text { I }\end{array}$ & Category & Category & \multicolumn{3}{c}{ NOx (g/veh/km) } \\
& & Category & Category & Category \\
\hline $08: 00-09: 00$ & 21.47 & 9.796 & 11.515 & 14.865 & 0.326 & 0.652 & 1.677 \\
$09: 00-10: 00$ & 25.87 & 9.796 & 11.515 & 14.865 & 0.326 & 0.652 & 1.677 \\
$10: 00-11: 00$ & 26.10 & 9.796 & 11.515 & 14.865 & 0.326 & 0.652 & 1.677 \\
$11: 00-12: 00$ & 33.93 & 6.184 & 9.466 & 7.271 & 0.217 & 0.277 & 0.937 \\
$12: 00-13: 00$ & 36.37 & 6.184 & 9.466 & 7.271 & 0.217 & 0.277 & 0.937 \\
$13: 00-14: 00$ & 36.66 & 6.184 & 9.466 & 7.271 & 0.217 & 0.277 & 0.937 \\
$14: 00-15: 00$ & 31.41 & 6.184 & 9.466 & 7.271 & 0.217 & 0.277 & 0.937 \\
$15: 00-16: 00$ & 27.95 & 9.796 & 11.515 & 14.865 & 0.326 & 0.652 & 1.677 \\
$16: 00-17: 00$ & 21.10 & 9.796 & 11.515 & 14.865 & 0.326 & 0.652 & 1.677 \\
$17: 00-18: 00$ & 19.23 & 12.466 & 17.93 & 16.066 & 0.379 & 0.830 & 2.986 \\
\hline
\end{tabular}

Table 5-8: Speed and corresponding emission factor, south bound.

\begin{tabular}{c|c|ccc|ccc}
\hline \multirow{2}{*}{$\begin{array}{c}\text { Time } \\
\text { Interval }\end{array}$} & \multirow{2}{*}{$\begin{array}{c}\text { Speed } \\
(\mathrm{km} / \mathrm{hr})\end{array}$} & $\begin{array}{c}\text { Category } \\
\text { I }\end{array}$ & Category & Category & \multicolumn{3}{c}{ NOx $(\mathrm{g} / \mathrm{veh} / \mathrm{km})$} \\
\hline Category & Category & Category \\
III & & II & II & III \\
09:00:00 & 20.92 & 9.796 & 11.515 & 14.865 & 0.326 & 0.652 & 1.677 \\
$10: 00-11: 00$ & 21.93 & 9.796 & 11.515 & 14.865 & 0.326 & 0.652 & 1.677 \\
$11: 00-12: 00$ & 25.40 & 9.796 & 11.515 & 14.865 & 0.326 & 0.652 & 1.677 \\
$12: 00-13: 00$ & 28.06 & 9.796 & 11.515 & 14.865 & 0.326 & 0.652 & 1.677 \\
$13: 00-14: 00$ & 29.85 & 6.184 & 9.466 & 7.271 & 0.217 & 0.277 & 0.937 \\
$14: 00-15: 00$ & 27.47 & 9.184 & 9.466 & 7.271 & 0.217 & 0.277 & 0.937 \\
$15: 00-16: 00$ & 28.12 & 9.796 & 11.515 & 14.865 & 0.326 & 0.652 & 1.677 \\
$16: 00-17: 00$ & 25.93 & 9.796 & 11.515 & 14.865 & 0.326 & 0.652 & 1.677 \\
$17: 00-18: 00$ & 21.93 & 9.796 & 11.515 & 14.865 & 0.326 & 0.652 & 1.677 \\
\hline
\end{tabular}




\section{Time-Dependent ETC by $\mathrm{CO}$ as the Criterion}

After the time-dependent emission factors are determined, the ETC can be calculated and compared to the $\mathrm{CO}$ and $\mathrm{NO}_{\mathrm{x}}$ standards respectively. The method based on Equations 4-15 and 4-16 is used to obtain the ETC value for each hour, using the CO emission standard for its criterion. Results are shown in Table 5-9.

As observed, the $\mathrm{V} / \mathrm{C}$ ratio reaches the lowest value (0.42), when the ETC reaches its highest value, which is $1278 \mathrm{pcu} / \mathrm{h}$ with respect to the $\mathrm{CO}$ standard. However, the lowest ETC occurs in the hour 11:00 - 12:00, when the $\mathrm{V} / \mathrm{C}$ ratio is not at its highest value. The reason is that the dilution factor at this moment reaches its highest level, which means the meteorological condition is at its worst for diluting the emissions aggregated above the nearby area. See Figures 5-4 and 5-7.

One of the objectives of this dissertation is to find the difference between the capacity with respect to traffic and the capacity with respect to air quality. Therefore, the ratio of ETC-to-volume as an indicator was used for this purpose (see Figure 5-6).

Using the hour of 13:00-14:00 as an example, the actual volume is $1836 \mathrm{pcu}$; the ratio of $\mathrm{ETC} /$ volume is 0.70 , the highest in the series, which means the ETC at this point is closest to the actual volume on road, or the vehicle speed during this hour is closest to the "cross point speed", $u_{x}$, illustrated in Figure 4-5. In other words, policy makers need to limit the volume to that of the ETC, in order to keep the emissions under control. To adjust the traffic volume to the ETC, one option is to reduce one lane in each direction, for a total of $1450 \mathrm{pcu} / \mathrm{hr}$ reduction in volume. This measure is based on the assumption that the congestion density remains the same ${ }^{11}$ as $120 \mathrm{pcu} / \mathrm{lane} / \mathrm{km}$.

\footnotetext{
${ }^{11}$ A constant congestion density indicates that the speed remains the same as it was before the number of lanes was changed to reduce the volume.
} 
Table 5-9: ETC by CO, daytime in winter, Nanjing

\begin{tabular}{|c|c|c|c|c|c|c|c|c|}
\hline \multirow{2}{*}{$\begin{array}{c}\text { Time } \\
\text { Interval }\end{array}$} & \multicolumn{3}{|c|}{ North Bound } & \multicolumn{3}{|c|}{ South Bound } & \multirow{2}{*}{$\begin{array}{l}\text { Volume } \\
\text { (PCU) }\end{array}$} & \multirow{2}{*}{$\begin{array}{l}\text { ETC } \\
\text { (PCU) }\end{array}$} \\
\hline & $\begin{array}{c}\text { Category } \\
\text { I }\end{array}$ & Category II & $\begin{array}{c}\text { Category } \\
\text { III }\end{array}$ & $\begin{array}{c}\text { Category } \\
\text { I }\end{array}$ & $\begin{array}{c}\text { Category } \\
\text { II }\end{array}$ & $\begin{array}{c}\text { Category } \\
\text { III }\end{array}$ & & \\
\hline 08:00-09:00 & 287 & 10 & 33 & 294 & 14 & 50 & 2785 & 772 \\
\hline 09:00-10:00 & 340 & 15 & 31 & 344 & 21 & 50 & 2708 & 882 \\
\hline 10:00-11:00 & 322 & 14 & 21 & 321 & 27 & 43 & 2624 & 814 \\
\hline $11: 00-12: 00$ & 294 & 10 & 23 & 294 & 21 & 39 & 2199 & 743 \\
\hline $12: 00-13: 00$ & 424 & 20 & 49 & 476 & 46 & 52 & 1918 & 1168 \\
\hline $13: 00-14: 00$ & 469 & 21 & 43 & 541 & 45 & 58 & 1836 & 1278 \\
\hline $14: 00-15: 00$ & 444 & 20 & 30 & 467 & 32 & 38 & 2084 & 1097 \\
\hline $15: 00-16: 00$ & 468 & 21 & 43 & 409 & 35 & 55 & 2343 & 1128 \\
\hline $16: 00-17: 00$ & 445 & 21 & 52 & 365 & 18 & 62 & 2688 & 1077 \\
\hline $17: 00-18: 00$ & 333 & 15 & 39 & 273 & 25 & 57 & 2907 & 837 \\
\hline Average & 383 & 17 & 36 & 378 & 28 & 50 & 2409 & 980 \\
\hline
\end{tabular}

Another example is when the largest difference between the ETC and current volume occurs, in the hour 17:00 - 18:00 (see Table 5-9). To meet the CO standard, a reduction of 2070 pcu per hour must be obtained for this section in both directions. In reality, it is difficult to find a solution to obtain this amount of traffic volume reduction by physically redefining the road section. Therefore, other options need to be considered.

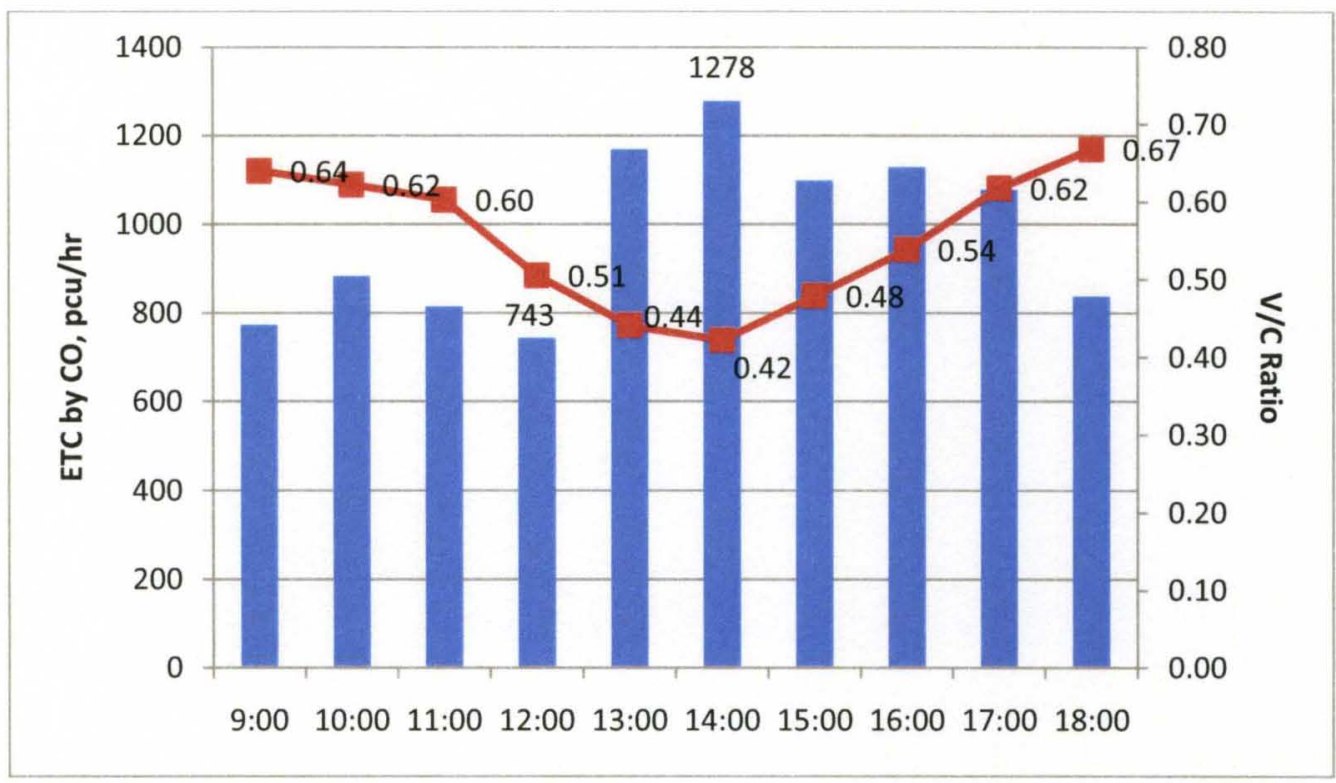

Figure 5-4: ETC by $\mathrm{CO}$ and $\mathrm{V} / \mathrm{C}$ ratio, daytime in winter, Nanjing 


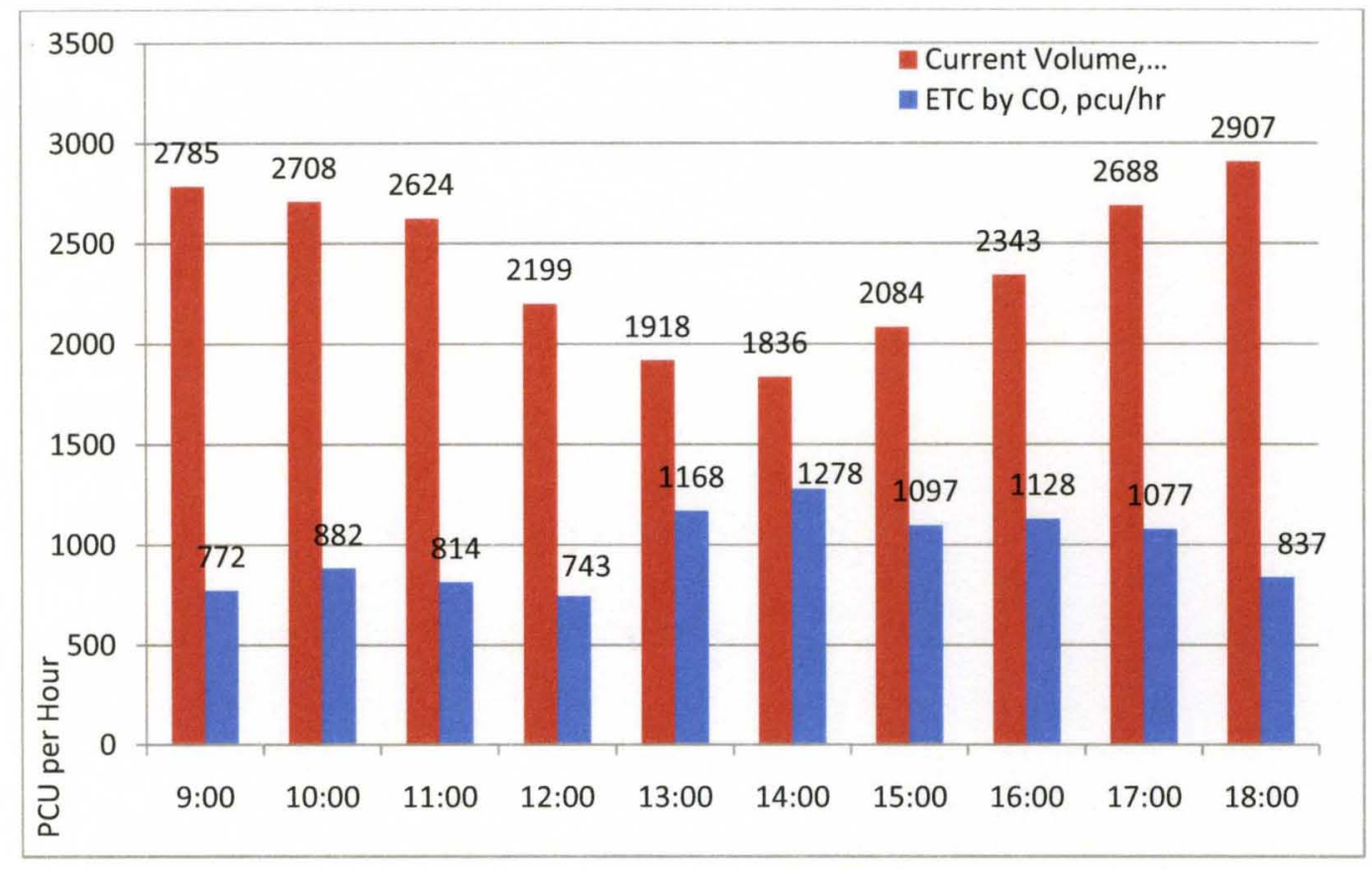

Figure 5-5: ETC by $\mathrm{CO}$ and current volume, daytime in winter, Nanjing

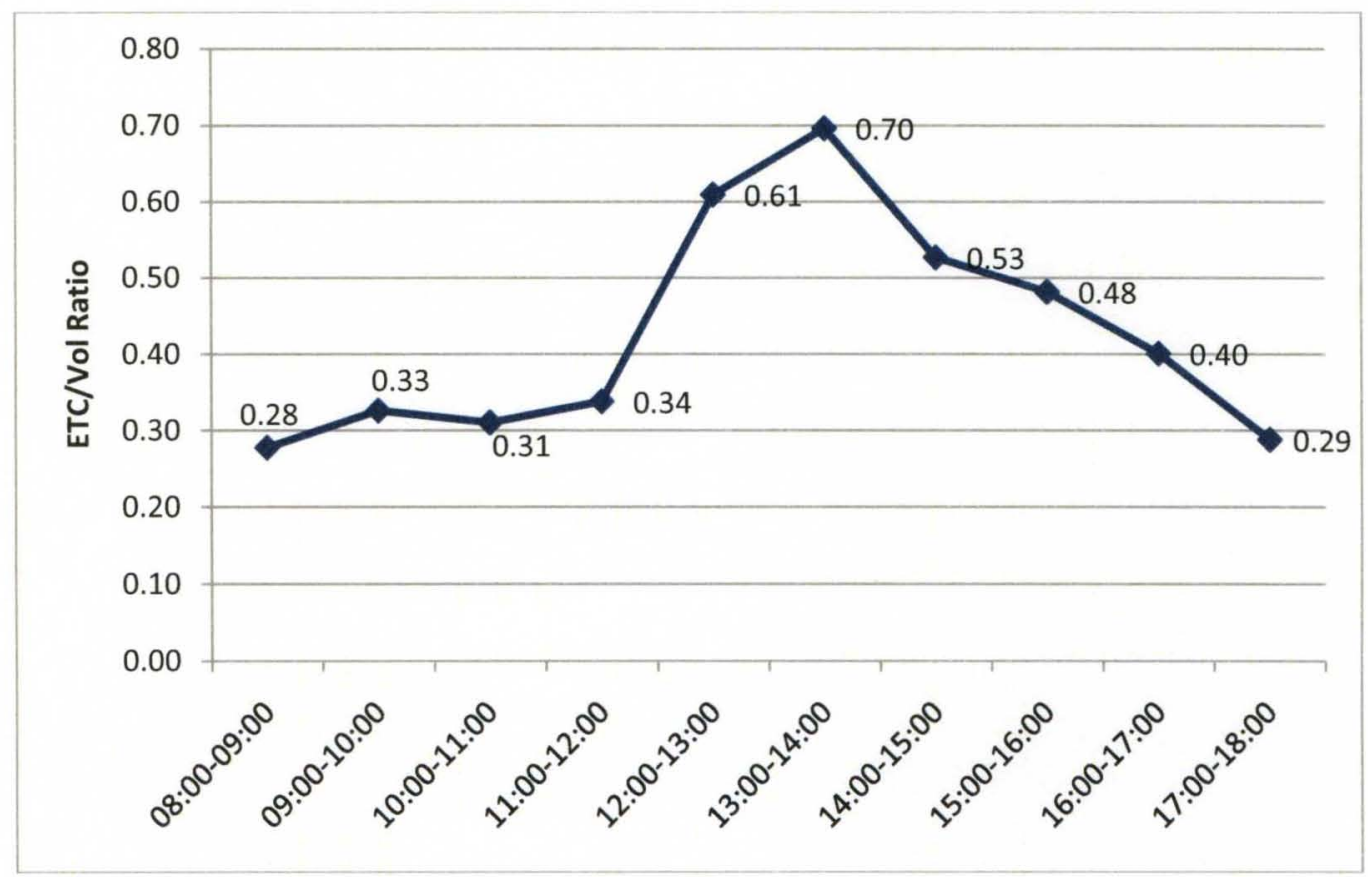

Figure 5-6: ETC-to-volume ratio for each hour (CO) 


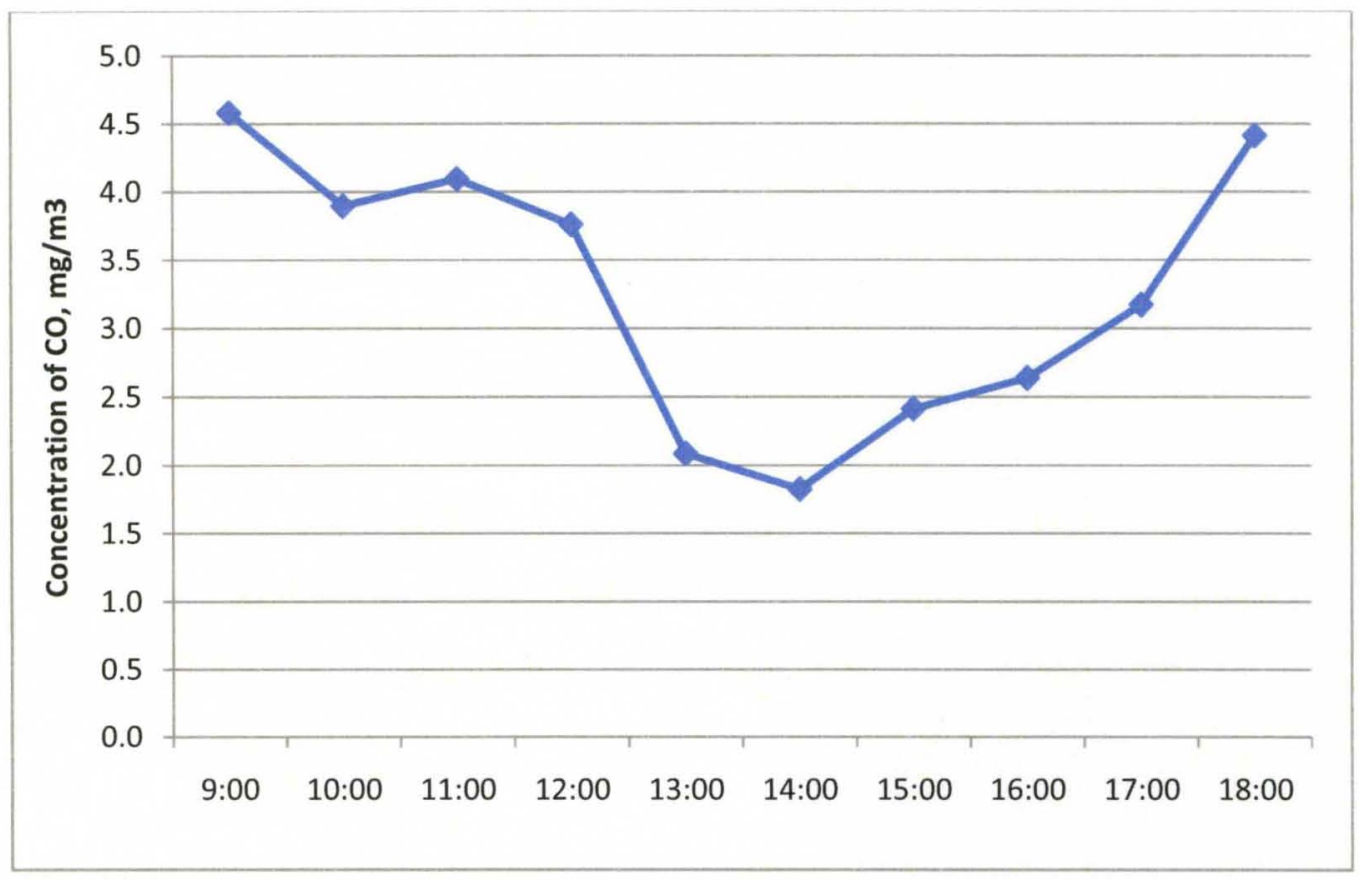

Figure 5-7: Aggregated CO concentration, daytime in winter, Nanjing

\section{$\underline{\text { Time-Dependent ETC by NO }} \times$ as the Criterion}

The same procedure is repeated for $\mathrm{NO}_{\mathrm{x}}$ as the criterion. The results are shown in Table 5-10 and Figure 5-8.

As shown in Table 5-10, the average ETC for the ten hours is $1558 \mathrm{pcu}$, which is higher than 980 pcu using CO as the criterion (see Table 5-9). This indicates that the emissions of $\mathrm{CO}$ are more severe than $\mathrm{NO}_{\mathrm{x}}$ in the area affected by this road section.

The results illustrate that the highest ETC occurs in the hour 13:00 - 14:00, when $\mathrm{V} / \mathrm{C}$ ratio reaches 0.42 . The ETC at this point is $2121 \mathrm{pcu}$, exceeding the actual volume of 1836 pcu. This implies that driving conditions on this road section during this period allow for more vehicles. However, considering the hour 8:00 - 9:00 (see Figure 5-8), the section actually could only allow for 1169 pcu compared to the 2785 pcu actual volume (see Table 5-6). This indicates that one lane should be eliminated in each direction of the 
road section.

Table 5-10: ETC by $\mathrm{NO}_{x}$, daytime in winter, Nanjing

\begin{tabular}{|c|c|c|c|c|c|c|c|c|}
\hline \multirow{2}{*}{$\begin{array}{l}\text { Time } \\
\text { Interval }\end{array}$} & \multicolumn{3}{|c|}{ North Bound } & \multicolumn{3}{|c|}{ South Bound } & \multirow{2}{*}{$\begin{array}{l}\text { Volume } \\
\text { (PCU) }\end{array}$} & \multirow{2}{*}{$\begin{array}{c}\text { ETC } \\
\text { (PCU) }\end{array}$} \\
\hline & $\begin{array}{c}\text { Category } \\
\text { I }\end{array}$ & $\begin{array}{c}\text { Category } \\
\text { II }\end{array}$ & Category III & Category I & $\begin{array}{c}\text { Category } \\
\text { II }\end{array}$ & $\begin{array}{c}\text { Category } \\
\text { III }\end{array}$ & & \\
\hline 08:00-09:00 & 435 & 15 & 50 & 446 & 22 & 76 & 2785 & 1169 \\
\hline 09:00-10:00 & 537 & 24 & 49 & 543 & 33 & 79 & 2708 & 1392 \\
\hline 10:00-11:00 & 523 & 23 & 35 & 522 & 45 & 70 & 2624 & 1322 \\
\hline $11: 00-12: 00$ & 468 & 16 & 36 & 469 & 34 & 62 & 2199 & 1183 \\
\hline $12: 00-13: 00$ & 690 & 32 & 80 & 775 & 75 & 84 & 1918 & 1901 \\
\hline $13: 00-14: 00$ & 778 & 35 & 71 & 899 & 75 & 96 & 1836 & 2121 \\
\hline $14: 00-15: 00$ & 761 & 34 & 51 & 800 & 55 & 64 & 2084 & 1880 \\
\hline $15: 00-16: 00$ & 746 & 34 & 68 & 652 & 56 & 87 & 2343 & 1798 \\
\hline $16: 00-17: 00$ & 677 & 31 & 79 & 554 & 27 & 95 & 2688 & 1636 \\
\hline $17: 00-18: 00$ & 470 & 22 & 55 & 384 & 35 & 80 & 2907 & 1180 \\
\hline Average & 608 & 27 & 57 & 604 & 46 & 79 & 2409 & 1558 \\
\hline
\end{tabular}

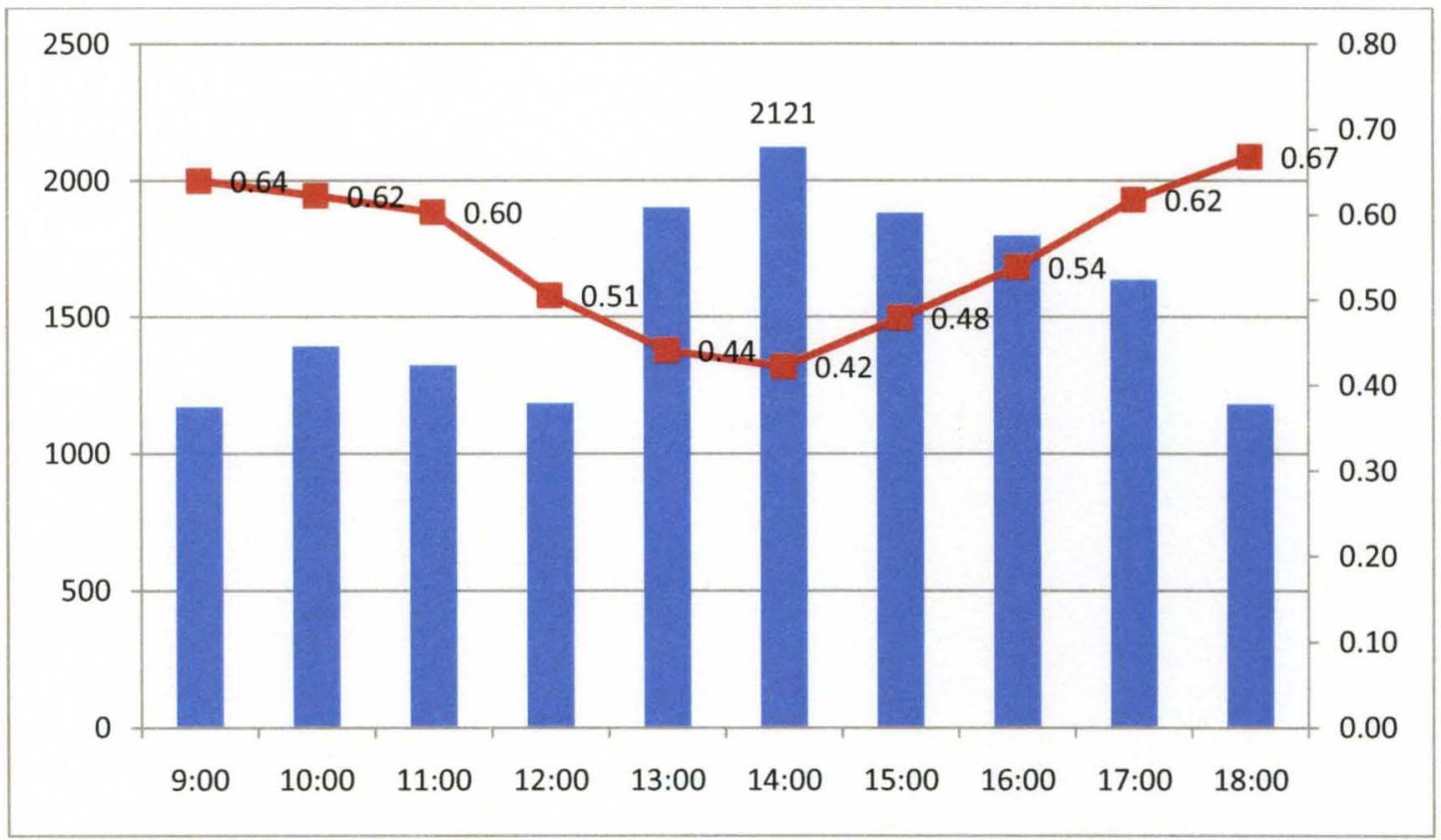

Figure 5-8: ETC by $\mathrm{NO}_{\mathrm{x}}$ and $\mathrm{V} / \mathrm{C}$ ratio, daytime in winter, Nanjing 


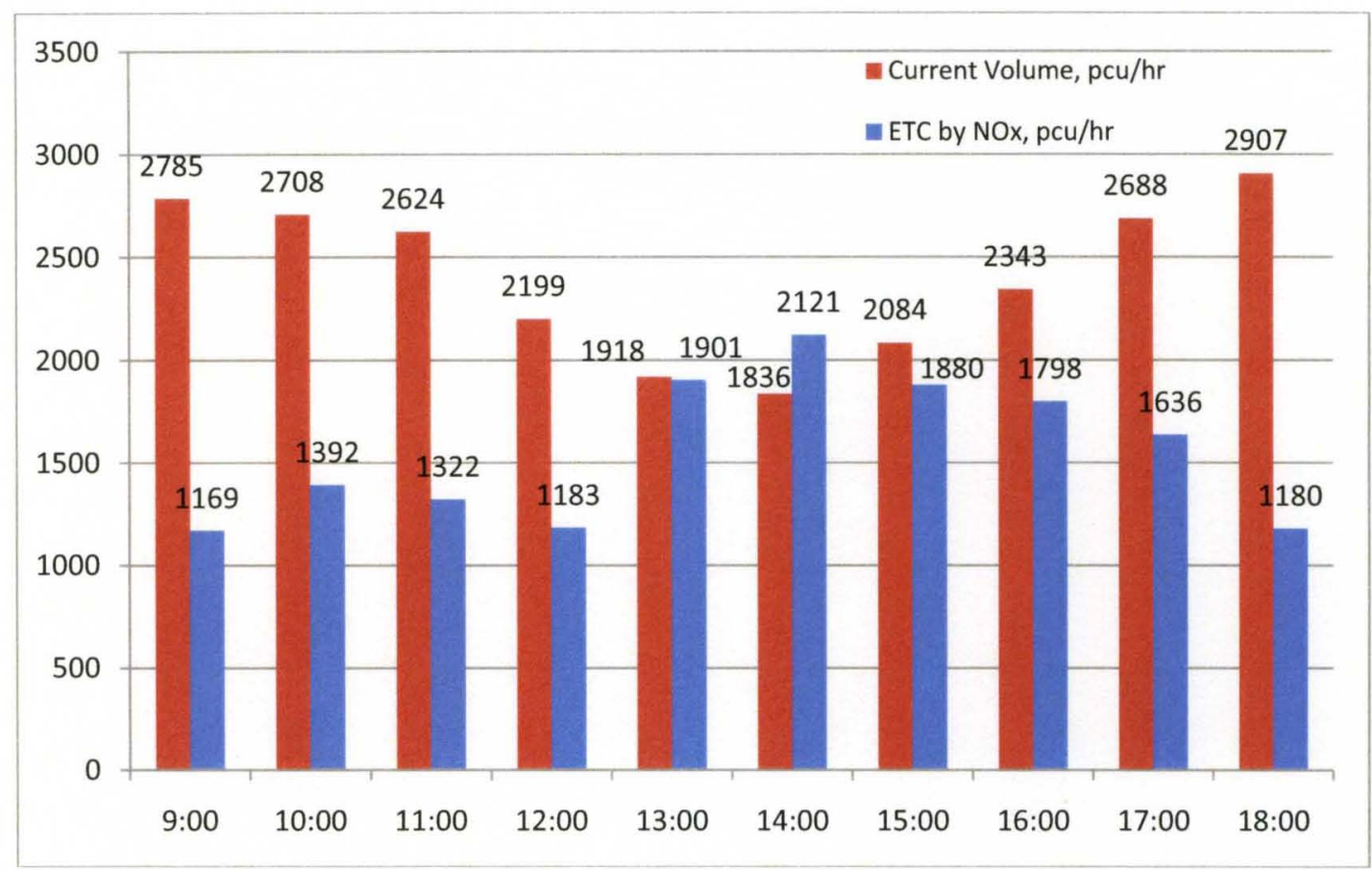

Figure 5-9: ETC by $\mathrm{NO}_{\mathrm{x}}$ and current volume, daytime in winter, Nanjing

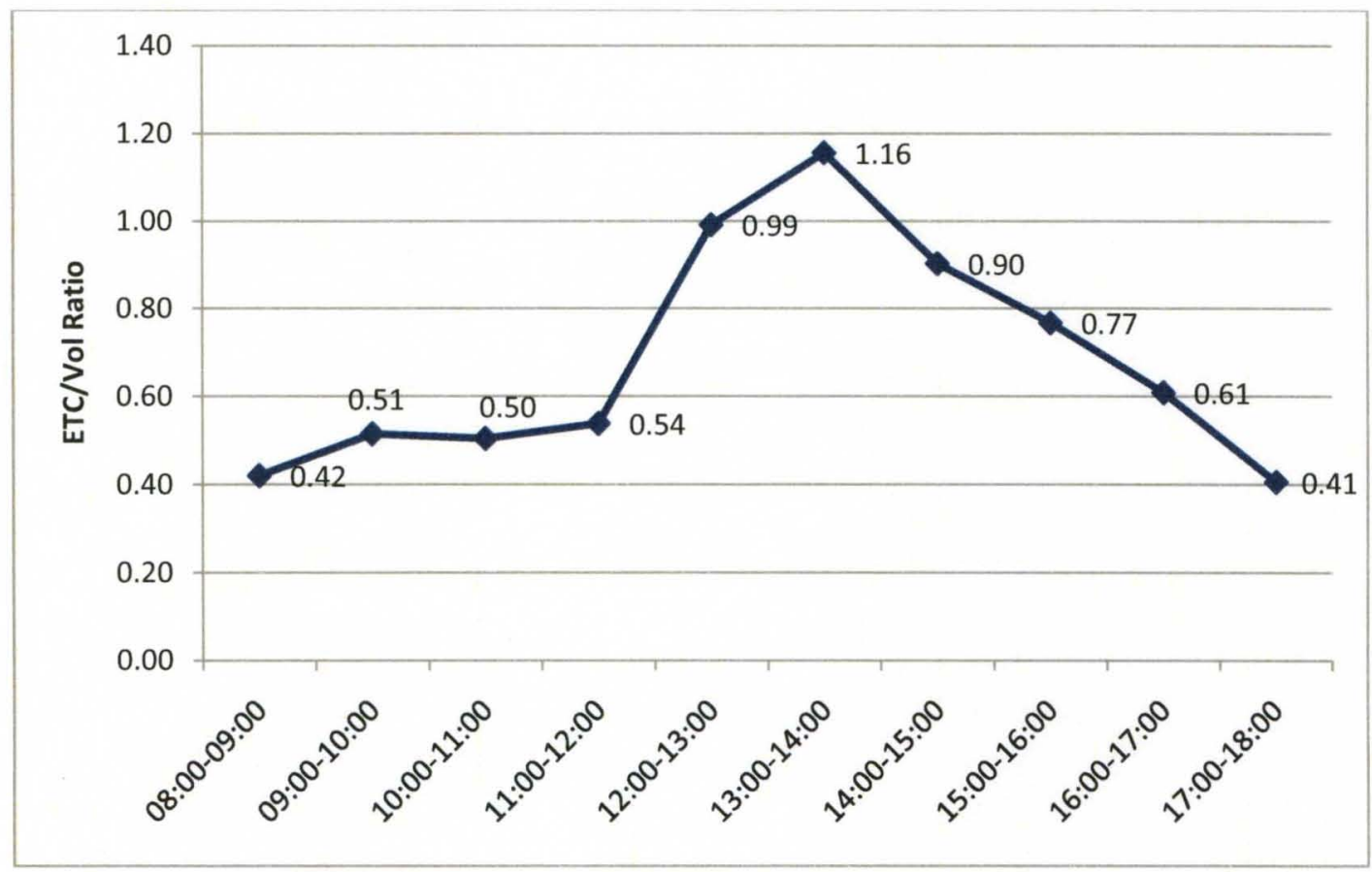

Figure 5-10: ETC-to-volume ratio for each hour $\left(\mathrm{NO}_{\mathrm{x}}\right)$ 


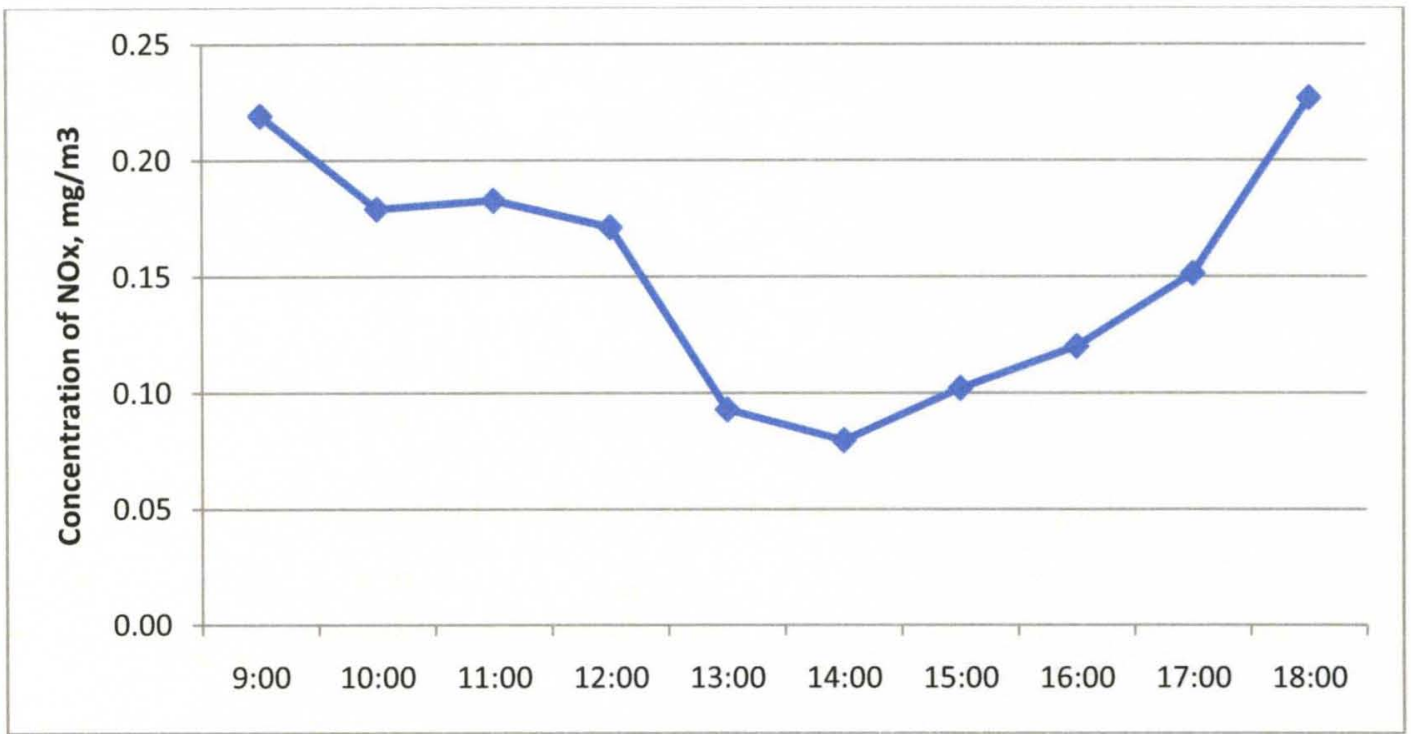

Figure 5-11: Aggregated $\mathrm{NO}_{\mathrm{x}}$ concentration, daytime in winter, Nanjing

Compared to the average ETC for CO as the criterion ( $980 \mathrm{pcu} / \mathrm{hr})$, the average ETC by $\mathrm{NO}_{\mathrm{x}}$ per the criterion is increased by $59.0 \%(1558 \mathrm{pcu} / \mathrm{hr})$. The highest ETC for both pollution criteria $\left(\mathrm{CO}, \mathrm{NO}_{\mathrm{x}}\right)$ occurs in the hour of 13:00-14:00, which are $1278 \mathrm{pcu} / \mathrm{hr}$ and $2121 \mathrm{pcu} / \mathrm{hr}$, respectively. It can be suggested that the $\mathrm{CO}$ has a higher priority for the ETC than $\mathrm{NO}_{\mathrm{x}}$ as the criterion. As a result, $\mathrm{CO}$ should be taken as the primary pollutant for this area.

Another observation is that the average ETC in the afternoon (15:00 - 18:00) is higher than in the morning $(9: 00-12: 00)$, although the $\mathrm{V} / \mathrm{C}$ values are similar (see Figures 5-4 and 5-8). The reason for this is that the average dilution factor in the afternoon (0.482) is lower than in the morning $(0.641)$, which agrees with the fact that the wind speed/direction also has an effect on the ETC (Lin, 2008; Wu, 2009; Zhu, 2008). 


\subsection{Improvements by Using the ETC}

For policy makers, the ETC provides a standard of traffic volume with respect to air quality. As concluded in Section 5.3, CO is the primary criterion for the case study area, two options for controlling the volume/speed to meet the CO standard are presented in this section.

\section{Option 1: Physical Reconfiguration}

One option is the elimination of one lane in each direction of the road section. For a six-lane two-directional roadway, the current volume would be reduced by one third, and the street is narrowed to 18.6 meters in width. The speed limit in the downtown area is still $40 \mathrm{~km} / \mathrm{hr}$, and the congestion density remains the same.

Since the cross-section dimensions of the street has been changed, the dilution factors need to be recalculated. See Figure 5-12.

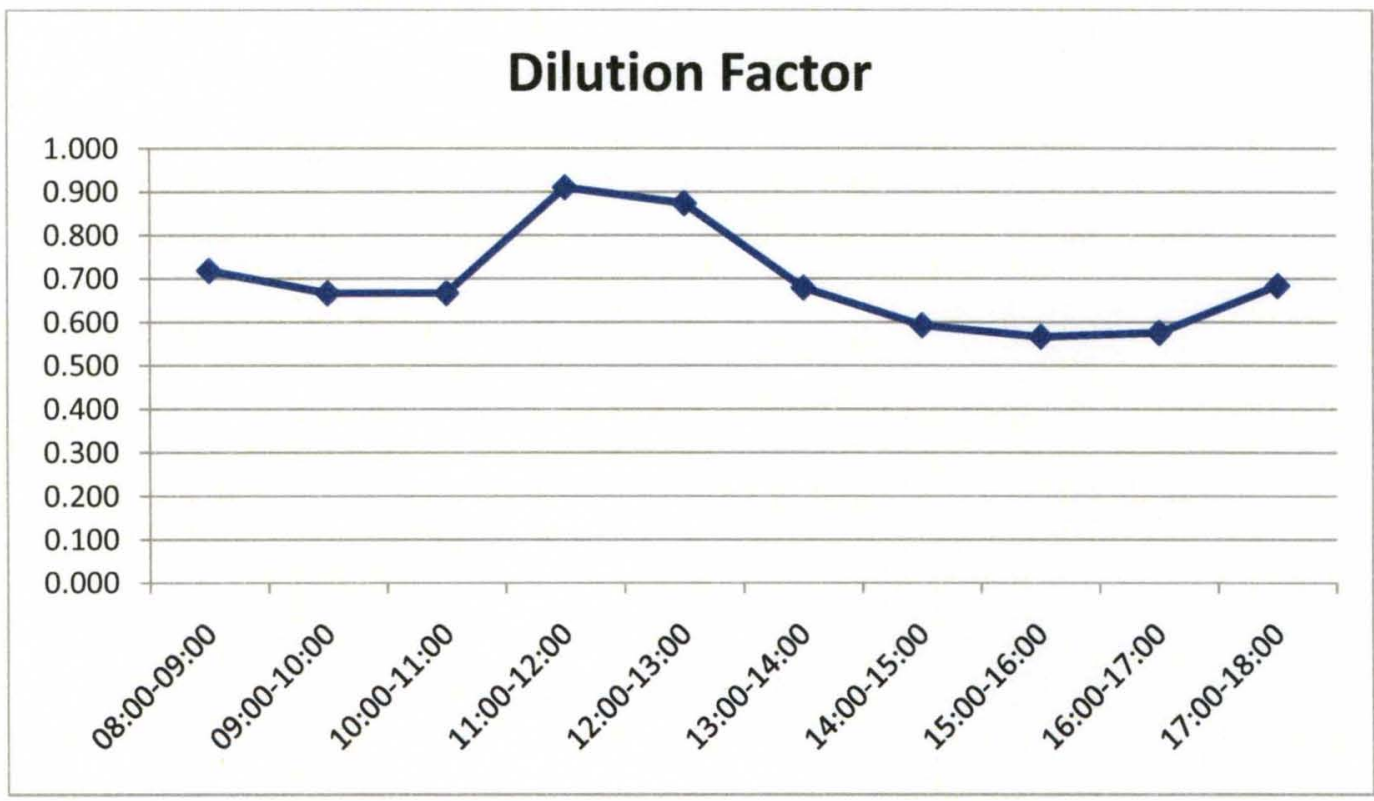

Figure 5-12: Dilution factors recalculated, after one lane is eliminated for each direction 
Table 5-11: ETC by CO, after one lane is eliminated for each direction

\begin{tabular}{|c|c|c|c|c|c|c|c|c|}
\hline \multirow{2}{*}{$\begin{array}{l}\text { Time } \\
\text { Interval }\end{array}$} & \multicolumn{3}{|c|}{ North Bound } & \multicolumn{3}{|c|}{ South Bound } & \multirow{2}{*}{$\begin{array}{l}\text { Volume } \\
\text { (PCU) }\end{array}$} & \multirow{2}{*}{$\begin{array}{c}\text { ETC } \\
\text { (PCU) }\end{array}$} \\
\hline & $\begin{array}{c}\text { Category } \\
\text { I }\end{array}$ & $\begin{array}{c}\text { Category } \\
\text { II }\end{array}$ & $\begin{array}{c}\text { Category } \\
\text { III }\end{array}$ & $\begin{array}{c}\text { Category } \\
\text { I }\end{array}$ & $\begin{array}{c}\text { Category } \\
\text { II }\end{array}$ & $\begin{array}{c}\text { Category } \\
\text { III }\end{array}$ & & \\
\hline 08:00-09:00 & 254 & 9 & 29 & 260 & 13 & 44 & 1857 & 682 \\
\hline 09:00-10:00 & 281 & 13 & 26 & 284 & 17 & 41 & 1805 & 727 \\
\hline 10:00-11:00 & 285 & 13 & 19 & 285 & 24 & 38 & 1749 & 721 \\
\hline 11:00-12:00 & 255 & 9 & 20 & 256 & 18 & 34 & 1466 & 645 \\
\hline $12: 00-13: 00$ & 321 & 15 & 37 & 360 & 35 & 39 & 1279 & 883 \\
\hline $13: 00-14: 00$ & 415 & 19 & 38 & 480 & 40 & 51 & 1224 & 1132 \\
\hline $14: 00-15: 00$ & 396 & 18 & 26 & 416 & 29 & 34 & 1389 & 979 \\
\hline $15: 00-16: 00$ & 354 & 16 & 32 & 309 & 26 & 41 & 1562 & 853 \\
\hline $16: 00-17: 00$ & 352 & 16 & 41 & 288 & 14 & 49 & 1792 & 850 \\
\hline 17:00-18:00 & 252 & 12 & 29 & 206 & 19 & 43 & 1938 & 633 \\
\hline Average & 316 & 14 & 30 & 314 & 24 & 41 & 1606 & 810 \\
\hline
\end{tabular}

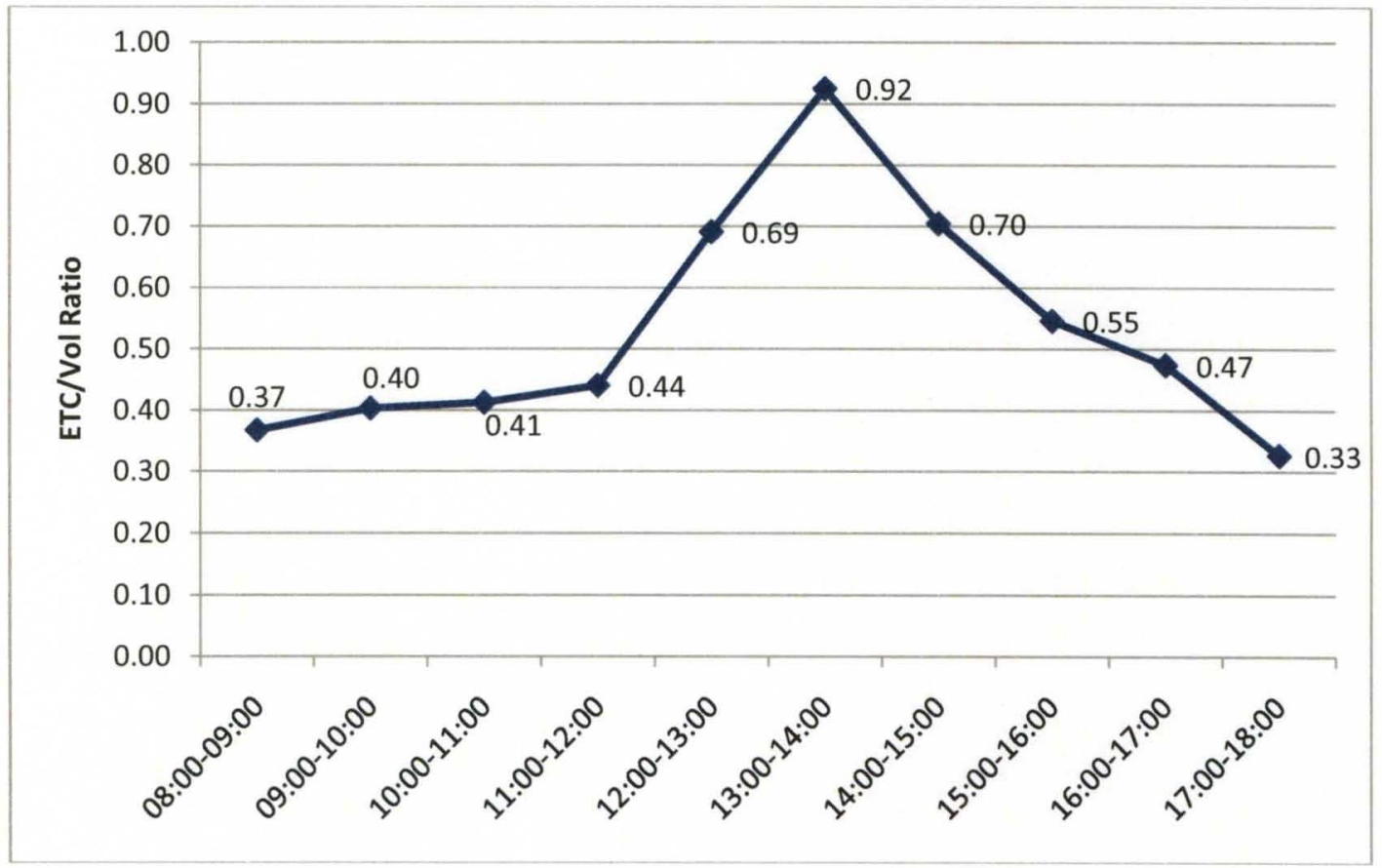

Figure 5-13: Ratio of ETC-to-volume, after one lane is eliminated for each direction 


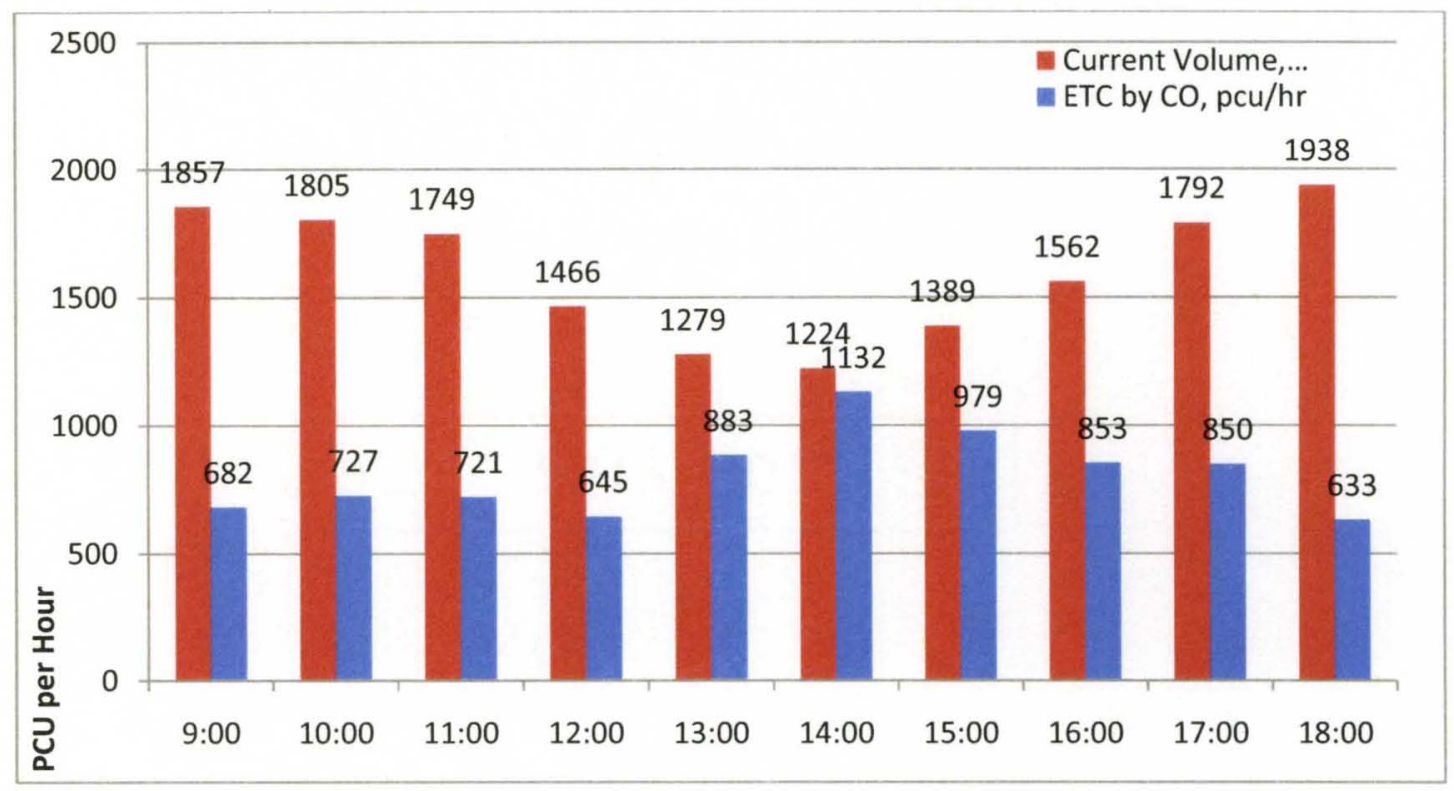

Figure 5-14: The ETC vs. volume, after one lane is eliminated for each direction

The ETC is recalculated as shown in Table 5-11. The daily percentage of ETC to volume is now $50.5 \%$, an increase of $9.8 \%$ compared to $40.7 \%$ before the reconfiguration of the road section. Figures 5-13 and 5-14 illustrate the decrease of the difference between the ETC and the volume.

The results show that by reconfiguring the physical dimensions of the road, the volume becomes closer to the ETC. It is also indicated that a relative $\mathrm{CO}$ reduction can be reached by this improvement.

\section{Option 2: Increasing the Speed Limit}

Another option is to increase the speed limit in order to bring the average speed of the volume closer to the "cross point speed", $u_{x}$ (see in Chapter 4).

As mentioned, the current speed limit in downtown Nanjing is $40 \mathrm{~km} / \mathrm{hr}$. This option is an increased limit as $60 \mathrm{~km} / \mathrm{hr}$ for the area. As the speed increases for the entire area, the vehicles' emission factors would decrease, as discussed in previous chapters. The per- 
centage of ETC to the volume by increasing the speed limit to $60 \mathrm{~km} / \mathrm{hr}$ becomes $61.1 \%$, which is higher than the $50.5 \%$ by remodeling the road (eliminating a lane in each direction), or $40.7 \%$ before either improvement. In other words, option two has better effect than option one on $\mathrm{CO}$ emission control for the case study area.

Table 5-12: ETC by CO, after speed limit increased to $60 \mathrm{~km} / \mathrm{hr}$

\begin{tabular}{|c|c|c|c|c|c|c|c|c|}
\hline \multirow{2}{*}{$\begin{array}{l}\text { Time } \\
\text { Interval }\end{array}$} & \multicolumn{3}{|c|}{ North Bound } & \multicolumn{3}{|c|}{ South Bound } & \multirow{2}{*}{$\begin{array}{l}\text { Volume } \\
\text { (PCU) }\end{array}$} & \multirow{2}{*}{$\begin{array}{c}\text { ETC } \\
\text { (PCU) }\end{array}$} \\
\hline & $\begin{array}{c}\text { Category } \\
\text { I }\end{array}$ & $\begin{array}{c}\text { Category } \\
\text { II }\end{array}$ & $\begin{array}{c}\text { Category } \\
\text { III }\end{array}$ & $\begin{array}{c}\text { Category } \\
\text { I }\end{array}$ & $\begin{array}{c}\text { Category } \\
\text { II }\end{array}$ & $\begin{array}{c}\text { Category } \\
\text { III }\end{array}$ & & \\
\hline 08:00-09:00 & 468 & 16 & 54 & 479 & 23 & 82 & 2785 & 1257 \\
\hline 09:00-10:00 & 549 & 25 & 50 & 555 & 33 & 80 & 2708 & 1422 \\
\hline 10:00-11:00 & 514 & 23 & 34 & 513 & 44 & 69 & 2624 & 1301 \\
\hline $11: 00-12: 00$ & 435 & 14 & 34 & 436 & 32 & 58 & 2199 & 1100 \\
\hline $12: 00-13: 00$ & 575 & 27 & 67 & 646 & 62 & 70 & 1918 & 1584 \\
\hline $13: 00-14: 00$ & 629 & 29 & 57 & 726 & 61 & 78 & 1836 & 1714 \\
\hline $14: 00-15: 00$ & 653 & 29 & 44 & 686 & 47 & 55 & 2084 & 1612 \\
\hline $15: 00-16: 00$ & 751 & 34 & 68 & 656 & 56 & 88 & 2343 & 1810 \\
\hline $16: 00-17: 00$ & 723 & 34 & 84 & 592 & 29 & 101 & 2688 & 1749 \\
\hline $17: 00-18: 00$ & 464 & 22 & 54 & 380 & 35 & 79 & 2907 & 1166 \\
\hline Average & 576 & 25 & 55 & 567 & 42 & 76 & 2409 & 1471 \\
\hline
\end{tabular}

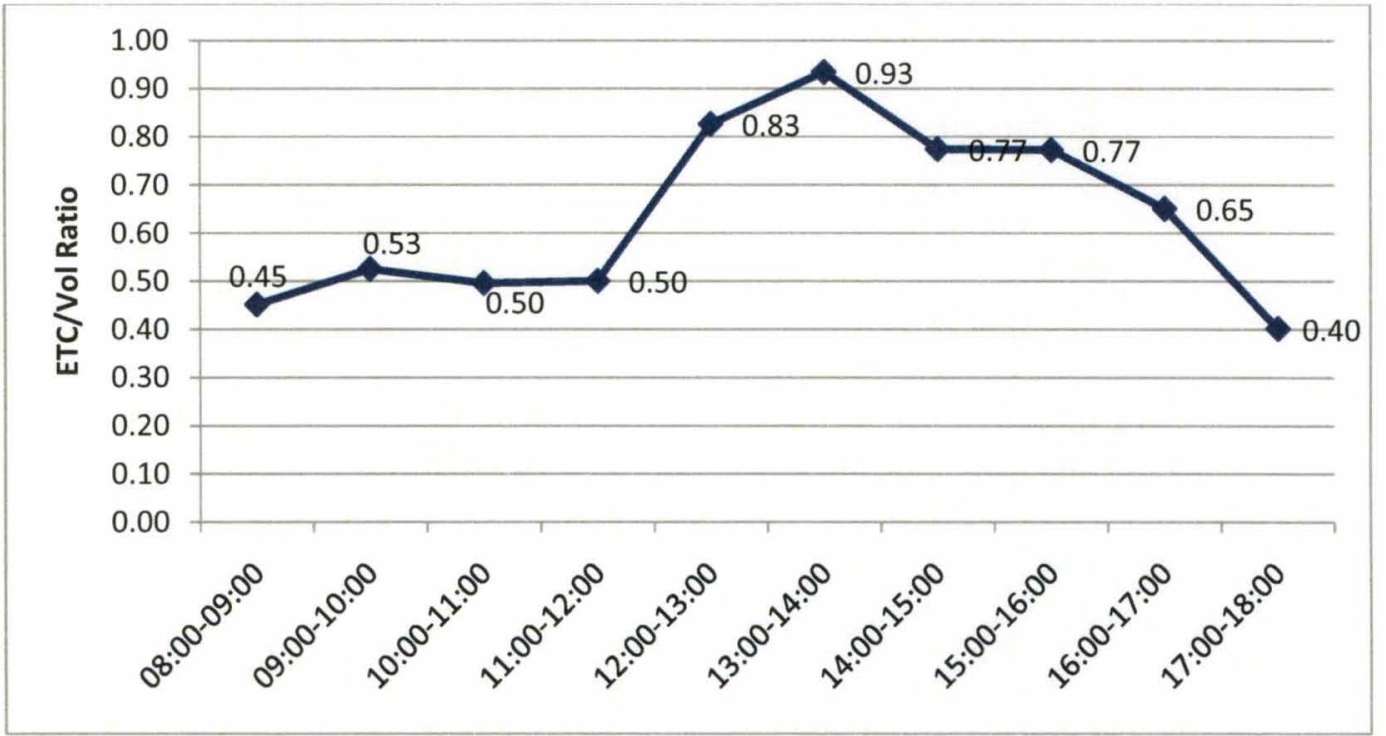

Figure 5-15: Ratio of ETC-to-volume, after speed limit increased to $60 \mathrm{~km} / \mathrm{hr}$ 


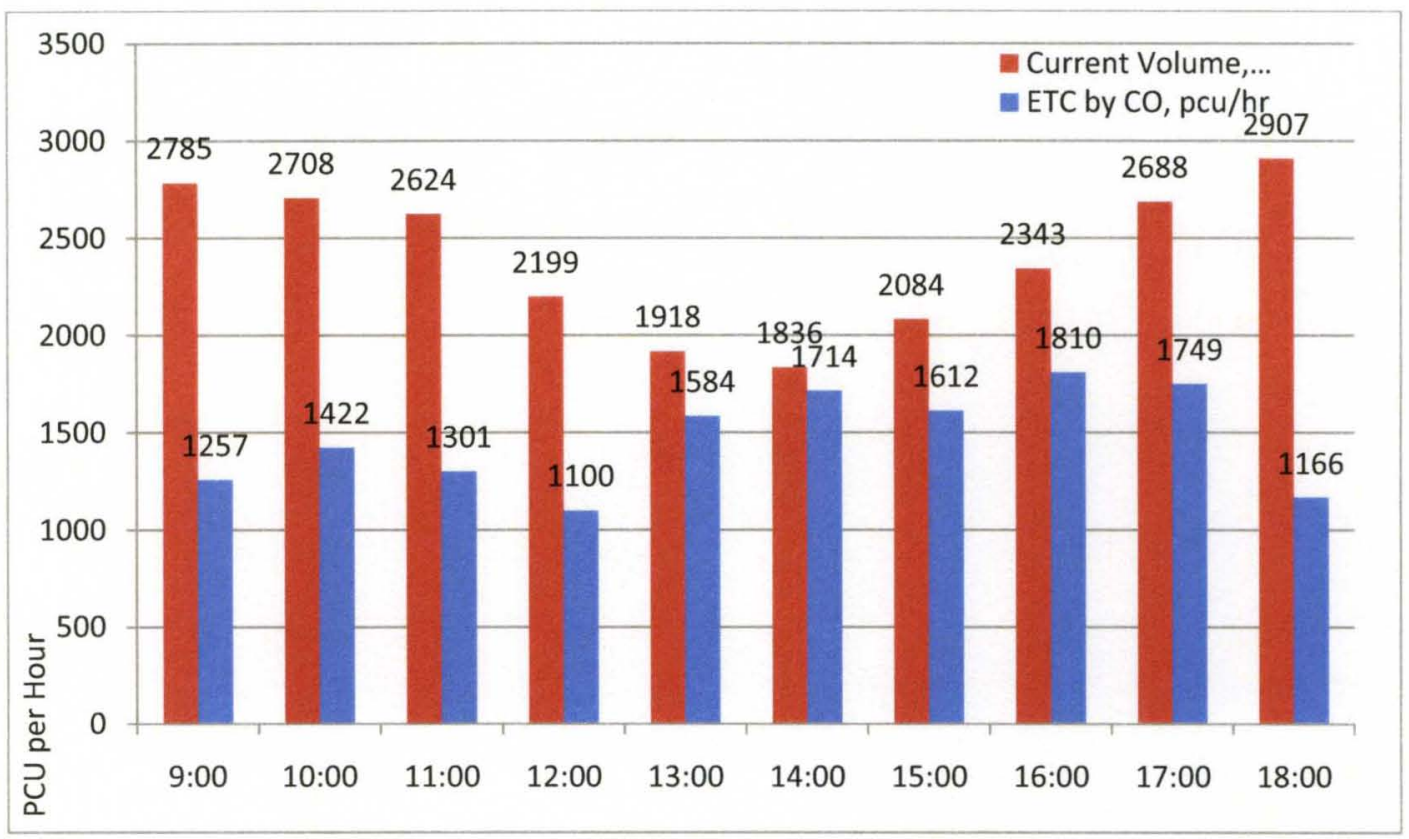

Figure 5-16: The ETC vs. volume, after speed limit increased to $60 \mathrm{~km} / \mathrm{hr}$

Table 5-12 shows the recalculated ETC with the speed limit being increased from 40 $\mathrm{km} / \mathrm{hr}$ to $60 \mathrm{~km} / \mathrm{hr}$. Figures 5-15 and 5-16 illustrate the difference between ETC and the volume after the speed limit is increased.

\subsection{Summary}

This chapter presents an application of the methodology developed in Chapter 4 to estimate the ETC for ten consecutive hours on a road section in downtown Nanjing, China. The two dominant pollutants in downtown Nanjing (NEPB 2008), $\mathrm{CO}$ and $\mathrm{NO}_{\mathrm{x}}$, were chosen as the calculation criteria. The ETC reaches its highest value in the hour 13:00 14:00 when $\mathrm{V} / \mathrm{C}$ is at 0.42 for both criteria. The wind/turbulence has an effect on emissions dilution, while the traffic volume determines the driving conditions on the road. These two effects combine to determine the patterns of the ETC.

As shown in the results, the ETC under the restriction of $\mathrm{CO}$ is lower than the ETC 
under the $\mathrm{NO}_{\mathrm{x}}$ as the criterion. This suggests that the ETC for $\mathrm{CO}$ as the criterion be used for the environmental traffic capacity of this road section.

Comparing two options of improvements using ETC for $\mathrm{CO}$ as the criterion, a conclusion may be drawn for this case study that increasing the speed limit in the entire area has more significant effect on reducing the pollution from traffic.

Naturally, safety and other engineering issues such as roadway geometrics must be considered when making decisions regarding increases in speed limits or reductions in the number of lanes. However, using the information gained from an ETC analysis can be of significant value to those who make such decisions. 


\section{CHAPTER 6 CONCLUSIONS}

In this chapter, the main contributions and results of this dissertation are summarized. In addition, the limitations that can be addressed in future research and recommend other research aspects that have not been explored in this dissertation are identified.

In Chapter 4, a methodology for estimating the environmental traffic capacity was developed. The method is composed of two components. The first component includes a procedure to determine the relationship between the time-dependent volumes and the ETC. The average speed is the key factor that connects the ETC and the actual traffic volume. The basic theory of this factor is that, as the volume determines the driving conditions of the vehicles, such as speed range and acceleration frequency, these driving conditions in turn affect the capacity of the road itself with respect to the air quality.

The second component of the method includes an integration of an acceleration probability model with the emission data measured by a series of test drives over a road network in Nanjing. The frequency density function is applied as a weighting factor for developing a speed/acceleration-based emissions inventory. As the result, the weighted rates and factors of pollutant $\mathrm{CO}_{2}, \mathrm{CO}, \mathrm{HC}$ and $\mathrm{NO}_{\mathrm{x}}$, for three vehicle categories are obtained. The weighted factors of $\mathrm{CO}, \mathrm{HC}$ and $\mathrm{NO}_{\mathrm{x}}$ are also compared with the arithmetic mean value of the emissions. The weighted data developed in this research have shown 
higher values than the average data. This can be explained by the limited ability of average-based methods to reflect the variations in speed and acceleration (see Chapter 2). By applying the acceleration probability function as the weight to the emission factors that have been grouped into seven speed ranges $(10 \mathrm{~km} / \mathrm{hr}$ interval $)$, the weighted emissions inventory was developed for each of the three vehicle categories.

In Chapter 5, the approach developed in this research is implemented for a case study in Nanjing, which is a medium-sized city located in southeast China. CO and NOx, the two dominant pollutants in downtown Nanjing (NEPB, 2008), were chosen as the calculation criteria. The ETC reaches its highest value in the hour 13:00-14:00 when V/C is at 0.42 for both criteria. The pattern of dilution factors shows that the variation of ETC is determined by both wind/turbulence and the traffic volumes. The results of the case study show that the ETC under $\mathrm{CO}$ restriction is lower than $\mathrm{NO}_{\mathrm{x}}$. As a result, the ETC generated by using $\mathrm{CO}$ as the criterion for the environmental traffic capacity of the road section was chosen. By testing two options of improvements using ETC, a conclusion was drawn that, for the case study presented in this dissertation, increasing speed limit for the whole area can lead to a better result of alleviating traffic pollution than reconfiguring the road section itself.

The complete procedure of estimating ETC for the case study presents a sample of projecting the future environmental capacity for the transportation sector in urban area. By simply adding up all the ETC values for each section of a road network, it is feasible to estimate the total number of vehicles that the area is able to accommodate with respect to air quality. 
Issues for future related research on ETC include:

1. The emissions inventory has been developed based on the speed derived by a traffic model. In this dissertation, the Greenshield's speed-flow model to derive the speed of the traffic flow was used. Future research should address how to overcome the limitations of the traffic speed model in order to provide better generality of the method. More specifically, the challenge will be how to integrate the method with several traffic models or with one single model to adopt different road types and traffic conditions. Also, Greenshield's model has generally been replaced in the United States by the method recommended in the Transportation Research Board's Highway Capacity Manual (HCM). The $2010 \mathrm{HCM}$ is due to be released in the fall of 2010. Figure 9-8 from the $2000 \mathrm{HCM}$ shows the method currently used.

2. The aggregation of pollutants has been estimated based on dilution factors determined by the OSPM dispersion model. Other dispersion models, such as CALINE4 (CALTRAN, 1989), are worthy of exploring with an ETC study. Scenarios with intersection modeled are also of interest.

3. Three categories of vehicles were tested to develop the emissions inventory. Heavy trucks and motorcycles are not included in the measurements. In order to represent more complete emission sources on roadways, other measurements or databases, including those of heavy trucks, motorcycles, or other vehicle types in a specific study area should be acquired and used for a more comprehensive emissions inventory.

4. Considering the availability of data or measurement equipment, the method 
can be extended to other types of emissions, such as hydrocarbons and particulate matter.

5. The ETC has been estimated for a single weekday in the winter season. For long-term projection of planning procedures, days in seasons other than winter should be analyzed for the ETC distribution over time.

The following aspects of the research on ETC are not examined by this dissertation. However, it is recommended that future studies:

1. Develop the compatibility of the methodology with traffic models other than the Greenshield's model, to reflect more specific characteristics of the speed and acceleration on different road types. Specifically, the method recommended in the $2010 \mathrm{HCM}$ should be incorporated into the ETC procedure.

2. Include more information of the vehicles for the emissions inventory. More specific grouping of vehicle categories needs to be developed by future researchers. This is also important for policy makers to address solutions to relieve the stress of pollution by redefining the fleet.

3. Based on the algorithm provided in Chapter 4 , it is feasible and worthwhile to compile a set of software tools, in which combinations of different road types, meteorological conditions, and fleet components are included. The system can be applied to a variety of dimensions for different road networks. 


\section{REFERENCES}

Abou Zeid, M., Chabini, I., Nam, E. K., \& Cappiello, A. (2002). Probabilistic modeling of acceleration in traffic networks as a function of speed and road type. The IEEE 5 th International Conference on Intelligent Transportation Systems, Sep 2002, 472- 478.

An, F., Barth, M., Scora, G., \& Ross, M. (1998). Modeling enleanment emissions for lightduty vehicles. Transportation Research Record, 1641.

Armstrong, J. M., \& Khan, A. M. (2004). Modeling urban transportation emissions. Computers, Environment and Urban Systems, 28 (2004), 421-433.

Asian Development Bank. (2003). Reducing vehicle emissions in Asia, Policy guidelines for reducing vehicle emissions in Asia. Manila: Asian Development Bank.

Bai, Eisinger, \& Niemeier, (2009). MOVES vs. EMFAC: A comparison of greenhouse gas emissions using Los Angeles County. U.C. Davis-Caltrans Air Quality Project, University of California, 5-10.

Barth, M., An, F., Younglove, T., Scora, G., Levine, C., Ross, M., \& Wenzel, T. (2000). Development of a comprehensive modal emissions model (Final report). National Cooperative Highway Research Program Project.

Berkowicz, R., Hertel, O., Sørensen, N. N., \& Michelsen, J.A. (1995a). Modeling air pollution from traffic in urban areas. Proceedings, IMA Conference on Flow and Dispersion through Groups of Obstacles, University of Cambridge, 28-30. 
Berkowicz, R., Palgrem, F., Hertel, O., \& Vignati, E. (1996). Using measurements of air pollution in streets for evaluation of urban air quality-meteorological analysis and model calculations. Science of the Total Environment, 189/190, 259-265.

Berkowicz, R., \& Hertel, O. (1997). Modeling traffic pollution in streets. Ministry of Environmental and Energy, National Environmental Research Institute.

Boeft, den J., Eerens, H.C., Tonkelaar, den W.A.M., \& Zandveld, P.Y.J. (1995). CAR International: A simple model to determine city street quality. Science of the Total Environment, 189/190, 321-326.

Buchanan, C. (1973). Traffic in Towns. London: UK Department of Transport.

CALTRAN. (1989). CALINE4- A dispersion model for predicting air pollution concentrations near roadways. Sacramento: Department of Transportation, CA.

Cappiello, A. (2002). Modeling traffic flow emissions. (Master Thesis), Massachusetts Institute of Technology.

CARB (2007). Calculating emission inventories for vehicles in California, California Air Resources Board. (http://www.arb.ca.gov/msei/onroad/latest_version.htm)

Chan, T. L., Ning, Z., Leung, C. W., Cheung, C. S., Hung, W. T., \& Dong, G. (2004). On-road remote sensing of petrol vehcile emissions measurement and emission factors estimation in Hong Kong. Atmosphere Environment (38), 2066-2066.

Cheng, J. (2004). Modeling Urban Environmental Traffic. Journal of Chang'an University (Natural Science Edition), Vol. 24, No.5, 94-98.

Colornie, A., Laniado E. and Muratori, S. (1999). Decision support systems for environmental impact assessment of transport infrastructures, Transportation Research D. 
DePaul, F.T., \& Sheih, C.M. (1986). Measurements of wind velocities in a street canyon, Atmospheric Environment, 20, 455-459.

Eerens, H.C., Sliggers, C.J. and van den Hout, K.D. (1993). The Dutch method to determine city air quality, Atmospheric Environment, 27B, 389-399.

Environmental Protection Agency (1986). Environmental capacity: an approach to marine pollution prevention. Report of Study, GESAMP, (30), 49.

Environmental Protection Agency. (1993). Automobiles and carbon monoxide (EPA 400F-92-006). Ann Arbor, MI: EPA National Vehicle and Fuel Emissions Laboratory. Retrieved from http://www.epa.gov/otaq/consumer/03-co.pdf

Environmental Protection Agency. (2001a). National air quality and emission trends report, 1999. EPA454-R-01-004. United States Environmental Protection Agency.

Environmental Protection Agency. (2001b). EPA's New Generation Mobile Source Emissions Model: Initial Proposal and Issues. Publication EPA 420-R-01-007, Office of Air and Radiation, Office of Research and Development, Region 4. United States Environmental Protection Agency.

Environmental Protection Agency. (2003) User's Guide to MOBILE6.1 and MOBILE6.2, EPA420-R-03-010, United States Environmental Protection Agency.

Environmental Protection Agency. (2009). National Emissions Inventory (NEI) Air Pollutant Emissions Trends Data and Estimation Procedures. United States Environmental Protection Agency. 
Environmental Protection Agency. (2010). Technical Guidance on the Use of MOVES2010 for Emission Inventory Preparation in State Implementation Plans and Transportation Conformity, United States Environmental Protection Agency.

Esteves-Booth, A., Muneer, T., Kubie, J., \& Kirby, H. (2002). A review of vehicular emission models and driving cycles. Proceedings of the Institution of Mechanical Engineers, Part C: Journal of Mechanical Engineering Science, (216), 777-797.

Fu, Lixin (1998). Simulation of Air Pollutants Dispersion in Urban Blocks, Tsinghua University, 35-41.

Garber, N. J., \& Hoel, L. A. (2001). Traffic and Highway Engineering, 3rd Edition. Brooks/Cole, The Wadsworth Group, California, 179.

Goodwin R. (1996). A model of automobiles exhaust emissions during high-power driving episodes and related issues. University of Michigan, Ann Arbor, Michigan.

Hall, F. L. (1992). Traffic Stream Characteristics. Traffic Flow Theory, Transportation Research Board, Chapter 2, 16-20.

Hertel, O., \& Berkowicz, R., (1989). Modeling pollution from traffic in a street canyon. Evaluation of data and model development, DMU Luft A-129, 77.

Hertel, O., \& Berkowicz, R. (1994). Modeling NO2 concentrations in a street canyon. DMU Luft A-131, 31.

Hoek, G., Brunekreef, B., \& Goldbohm, S., (2002). Association between mortality and indicators of traffic-related air pollution in the Netherlands: a cohort study, Lancet 360 (9341) (2002), 1203-1209. 
Hoffmann, B., Moebus, S., \& Mohlenkamp, S. (2007). Residential exposure to traffic is associated with coronary atherosclerosis, Circulation 116 (5) (2007), 489-496.

Holdsworth, J., \& Singleton, D. J. (1979). Environmental Capacity of Roads, Papers of the Fifth Australian Transport Research Forum, 219-238.

Holdsworth, J., \& Singleton, D. J. (1980). Environmental Capacity as a Basis for Traffic Management at Local Government Level, 10th ARRB Conference Proceedings, Vol. 10, Part V, 165-173.

Hotchkiss, R.S., \& Harlow, F.H. (1973). Air pollution transport in street canyons, EPAR4-73-029.

IGES. (2007). Air pollution control in the transportation sector: third phase research report of the Urban Environmental Management Project, Kanagawa, Japan: Institute for Global Environmental Strategies.

Johnson, G.T., \& Hunter, L.J. (1995). A numerical study of dispersion of passive scalars in city canyons, Boundary-Layer Meteorology, 75, 235-262.

Johnson, W.B., Ludwig, F.L., Dabbert, W.F., \& Allen, R.J. (1973). An urban diffusion simulation model for carbon monoxide. JAPCA, 23, 490-498.

Kauhaniemi, M., \& Karppinen, A. (2008). Evaluation of a Modeling System for Predicting the Concentrations of PM2.5 in an Urban Area. Atmospheric Environment, 42, 4517-4529.

Klaassen, C.D., \& Plaa, G.L. (1965). Relative effects of various chlorinated hydrocarbons on liver and kidney, Toxicology and Applied Pharmacology, (9), 139-151. 
Le Bihan, O., Wahlin, P., Ketzel, M., Palmgren, F., \& Berkowicz, F. (2002). Application of dispersion modeling for analysis of particle pollution sources in a street canyon. Water, Air, and Soil Pollution (2), 395-404.

Lee, I.Y., \& Park, H.M. (1994). Parameterization of the pollutant transport and dispersion in urban street canyons, Atmospheric Environment, 28, 2343-2349.

Li, T. (2001). Evaluation and Prediction of the Impact of Traffic Emissions on Urban Air Quality. (Doctoral Dissertation), Southeast University, China.

Lin, J. (2008). Urban Environmental Traffic Capacity Analysis. (Master Thesis), Southeast University, China.

Li, T., Lin, J., Wu, M., \& Wang, X. (2009). Concept and spatial Analysis method of urban environmental traffic capacity. Journal of Transportation Engineering, Vol. 135, (11), 873-879.

Litman, T. (2001). Generated traffic and induced travel: implications for transport planning. ITE Journal, (4), 38-47.

Margiotta, R. A. (1996). Improved Vehicle Speed Estimation Procedures for Air Quality and Planning Application. University of Tennessee, Knoxville.

Moriguchi, Y., \& Uehara, K. (1993). Numerical and experimental simulation of vehicle exhaust gas dispersion for complex urban roadways and their surroundings, Journal of Wind Engineering and Industrial Aerodynamics, 46-47, 689-695.

NEPB. (2005). Motor Vehicles and Emissions in Nanjing. Nanjing Environment Protection Bureau, Nanjing, China. 
NEPB. (2008). The current traffic pollution in Nanjing, 2008. Nanjing Environment Protection Bureau, Nanjing, China.

Ntziachristos, L. \& Samaras, Z. (2000). COPERT III Version 2.1: methodology and emission factors. European Topic Centre on Air Emissions, European Environmental Agency.

Omaye, S. (2002). Metabolic modulation of carbon monoxide toxicity. Toxicology 180 (2): 139-150. doi:10.1016/S0300-483X(02)00387-6.

Palmgren, F., Berkowicz, R., Ziv, A. and Hertel, O., (1999). Actual car fleet estimated urban air quality measurements and street pollution models, The Science of the Total Environment 235, 101-109.

Parrish, D. (2006). Critical evaluation of US on-road vehicle emission inventories. Atmospheric Environment, 40 (2006), 2288-2300.

Ritchie, S. G., \& Harris, R. A., (1987). Expert system in transportation engineering. Expert Systems for Civil Engineering, ASCE, 29, 112-125.

Saldiva, P., \& Lichtenfels, A. (1994). Association between air pollution and mortality due to respiratory diseases in children in Sao Paulo, Brazil: A preliminary report. Environmental Research, (65), 218-225.

Shiran, G. (1997). Area-wide environmental capacity based on air pollution criteria. (Doctoral Dissertation), University of New South Wales, Australia.

Schultz D., Younglove, T., \& Barth, M. (2001). Statistical analysis and model validation of automobile emissions. Journal of transportation and statistics, 3, 120-131 
Sharpe, C. P., \& Maxman, R. J. (1973). The environmental capacity of roadway networks. Proc., ASCE Urban Transportation Div. Environmental Impact Specialty Conf., ASCE, New York, 237-253.

Sievers, U., \& Zdunkowski, W.G. (1986). A microscale urban climate model, Beitr. Phys. Atmosph., 59, 1.

Singleton, D. J. (1980). Environmental capacity as a basis for traffic management at local government level. Proc., 10th. ARRB Conf. Proc., 10, 165-173

Singleton, D. J., \& Twiney, P. J. (1983). Envrionmental sensitivity of arterial roads. The 10th Australian Transportation Research Forum, Vol. 2, 165-182.

Sini, J. F., Anquetin, S., \& Mestayer, P. G. (1996). Pollutant dispersion and thermal effects in urban street canyons. Atmospheric Environment 30, 2659-2677.

Song, L., Dunne, M. C., \& Black, J. A. (1993). Models of delay and accident risk to pedestrians in C. F. Daganzo. Proceedings of 12th International Symposium on Transportation and Traffic Theory, 899-910.

TRB. (2000). Highway Capacity Manual. Transportation Research Board. National Research Council, Washington D.C.

van den Hout, K.D., \& Baars, H.P. (1988). Development of two models for the dispersion of air pollution by traffic: the TNO-traffic model and the CAR-model (in Dutch), MTTNO,report R88/192, Delft, the Netherlands.

van den Hout, K.D., \& Duijm, N.J. (1988). The dispersion of traffic emissions: the effect of recirculation near buildings and the influence of trees (in Dutch), MT-TNO, report R88/447, Delft, the Netherlands. 
van den Hout, K.D., Baars, H.P., \& Duijm, N.J. (1989). Effects of buildings and trees on air pollution by road traffic, 8th World Clean Air Congress (Editors, L.J. Brasser and W.C. Mulder), Vol. 4, Elsevier, Amsterdam.

WBCSD (2001). Mobility 2001 - World mobility at the end of the twentieth century and its sustainability. Massachusetts Institute of Technology Laboratory for Energy and the Environment and Charles River Associates Inc.

Wu, M. (2009). Study on the Driving Cycle and Emission Characteristics of Nanjing Gasoline Car. Southeast University, China.

Yamartino, R.J., \& Wiegand, G., (1986). Development and evaluation of simple models for flow, turbulence and pollutant concentration fields within an urban street canyon. Atmospheric Environment, 20, 2137-2156

Zhu, Zhigao (2008). Traffic Assignment Modeling: Under the Consideration of Urban Environmental Traffic Capacity. (Master Thesis), Southeast University, China. 


\section{APPENDIX A}

Operating Data of One Testing Vehicle (Partial) 
Table A-1: Definition of Operating Status

\begin{tabular}{ccl}
\hline NO. & Status & Definition \\
\hline 1 & Idl (Idle) & Vehicle Idling \\
2 & Acc (Accelerate) & Vehicle accelerating at $0.1 \mathrm{~m} / \mathrm{s}^{2}$ or harder \\
3 & Dec (Decelerate) & Vehicle decelerating at $-0.1 \mathrm{~m} / \mathrm{s}^{2}$ or harder \\
4 & Crs (Cruise) & Vehicle operating with acceleration of $(-0.1,0.1) \mathrm{m} / \mathrm{s}^{2}$ \\
5 & Average Speed & Equals route length divided by total operating time \\
6 & Average running Speed & Equals route length divided by the time when vehicle is moving \\
\hline
\end{tabular}

Table A-2: Parameters of Testing Vehicle Category (I)

\begin{tabular}{ccc}
\hline Parameter & Unit & Value \\
\hline Weight & $\mathrm{kg}$ & 1250 \\
Length & $\mathrm{mm}$ & 4515 \\
Width & $\mathrm{mm}$ & 1725 \\
Height & $\mathrm{mm}$ & 1445 \\
Transmission & & 5-Speed Manual \\
Engine & & I-4, 1.6 Liter \\
Air-to-fuel & & 9.5 \\
Fuel & & 93 Gasoline \\
Max Power & $\mathrm{kw}$ & 78 \\
Rpm_Max pow- & $\mathrm{rpm}$ & 6000 \\
er & $\mathrm{N} * \mathrm{~m}$ & 146 \\
Max torque & $\mathrm{rpm}$ & 3600 \\
Rpm_Max tor- & $\mathrm{km} / \mathrm{h}$ & 180 \\
que & $\mathrm{L} / 100 \mathrm{~km}$ & 8 \\
Max speed & & Euro IV \\
Emission & & $195 / 55 \mathrm{R} 15$ \\
Front tire & & $195 / 55 \mathrm{R} 15$ \\
Rear tire & $\mathrm{km}$ & 40771 \\
Mileage & &
\end{tabular}


Table A-3: Operating Status of Routes, Vehicle Category (I)

\begin{tabular}{cccc|ccccc|cccc}
\hline \multirow{2}{*}{ Route ID } & \multirow{2}{*}{$\begin{array}{c}\text { Length } \\
(\mathrm{m})\end{array}$} & $\begin{array}{c}\text { Time in } \\
\text { operation }\end{array}$ & \multirow{2}{*}{$\begin{array}{c}\text { Time in } \\
\text { motion }\end{array}$} & \multicolumn{4}{|c|}{ Time (s) } & \multicolumn{4}{|c}{ Percentage (\%) } \\
\cline { 6 - 12 } & & $(\mathrm{s})$ & & Idl & Acc & Dec & Crs & Idl & Acc & Dec & Crs \\
\hline B1 & 700 & 415 & 328 & 87 & 123 & 152 & 53 & 21.0 & 29.0 & 37.0 & 13.0 \\
B2 & 1500 & 1038 & 721 & 317 & 296 & 286 & 139 & 31.0 & 29.0 & 27.0 & 13.0 \\
B5 & 630 & 86 & 86 & 0 & 48 & 35 & 3 & 0.0 & 56.0 & 41.0 & 3.0 \\
C2 & 570 & 400 & 400 & 0 & 100 & 102 & 198 & 0.0 & 25.0 & 26.0 & 49.0 \\
C3 & 950 & 336 & 280 & 56 & 64 & 90 & 126 & 17.0 & 19.0 & 27.0 & 37.0 \\
B6 & 550 & 799 & 467 & 332 & 209 & 183 & 75 & 42.0 & 26.0 & 23.0 & 9.0 \\
B7 & 550 & 107 & 69 & 38 & 25 & 18 & 26 & 36.0 & 23.0 & 17.0 & 24.0 \\
C4 & 585 & 801 & 634 & 167 & 233 & 239 & 162 & 21.0 & 29.0 & 30.0 & 20.0 \\
B9 & 920 & 869 & 802 & 67 & 314 & 300 & 188 & 8.0 & 36.0 & 34.0 & 22.0 \\
B10 & 620 & 766 & 580 & 186 & 241 & 228 & 111 & 24.0 & 31.0 & 30.0 & 15.0 \\
\hline
\end{tabular}

Table A-4: Time and percentage of speed ranges $(10 \mathrm{~km} / \mathrm{hr}$ interval $)$

\begin{tabular}{c|cc|cc|cc|cc|cc|cc|cc}
\hline \multirow{2}{*}{ Route } & \multicolumn{2}{|c|}{ ldling } & \multicolumn{2}{|c|}{$(0,10]$} & \multicolumn{2}{c|}{$(10,20]$} & \multicolumn{2}{c|}{$(20,30]$} & \multicolumn{2}{c|}{$(30,40]$} & \multicolumn{2}{|c|}{$(40,50]$} & \multicolumn{2}{|c}{$>50$} \\
& $(\mathrm{~S})$ & $(\%)$ & $(\mathrm{S})$ & $(\%)$ & $(\mathrm{S})$ & $(\%)$ & $(\mathrm{S})$ & $(\%)$ & $(\mathrm{S})$ & $(\%)$ & $(\mathrm{S})$ & $(\%)$ & $(\mathrm{S})$ & $(\%)$ \\
\hline B1 & 87 & 0.21 & 82 & 0.2 & 89 & 0.21 & 86 & 0.21 & 45 & 0.11 & 26 & 0.06 & 0 & 0 \\
B2 & 317 & 0.31 & 117 & 0.13 & 123 & 0.12 & 256 & 0.26 & 118 & 0.13 & 47 & 0.05 & 0 & 0 \\
B5 & 0 & 0 & 19 & 0.22 & 31 & 0.36 & 31 & 0.36 & 5 & 0.06 & 0 & 0 & 0 & 0 \\
C2 & 0 & 0 & 249 & 0.62 & 151 & 0.38 & 0 & 0 & 0 & 0 & 0 & 0 & 0 & 0 \\
C3 & 56 & 0.17 & 32 & 0.1 & 74 & 0.22 & 149 & 0.44 & 19 & 0.05 & 6 & 0.02 & 0 & 0 \\
B6 & 332 & 0.42 & 109 & 0.14 & 106 & 0.13 & 212 & 0.26 & 40 & 0.05 & 0 & 0 & 0 & 0 \\
B7 & 38 & 0.36 & 15 & 0.14 & 36 & 0.33 & 18 & 0.17 & 0 & 0 & 0 & 0 & 0 & 0 \\
C4 & 167 & 0.21 & 203 & 0.25 & 363 & 0.45 & 68 & 0.09 & 0 & 0 & 0 & 0 & 0 & 0 \\
B9 & 67 & 0.08 & 190 & 0.22 & 211 & 0.25 & 304 & 0.35 & 97 & 0.1 & 0 & 0 & 0 & 0 \\
B10 & 186 & 0.24 & 151 & 0.2 & 130 & 0.17 & 154 & 0.2 & 132 & 0.17 & 13 & 0.02 & 0 & 0 \\
\hline
\end{tabular}


Table A-5: Statistical analysis of the speed $(\mathrm{km} / \mathrm{hr})$ on each route

\begin{tabular}{|c|c|c|c|c|c|}
\hline \multirow{2}{*}{ Route } & \multicolumn{3}{|c|}{ Average Speed } & \multirow{2}{*}{$\begin{array}{c}\text { Average } \\
\text { Running } \\
\text { Speed }\end{array}$} & \multirow{2}{*}{$\begin{array}{l}\text { Maximum } \\
\text { Speed }\end{array}$} \\
\hline & $\mathrm{Km} / \mathrm{hr}$ & $\begin{array}{c}95 \% \\
\text { Confidence } \\
\end{array}$ & $\begin{array}{c}\text { Standard } \\
\text { Deviation }\end{array}$ & & \\
\hline $\mathrm{B} 1$ & 15.92 & $14.63,17.21$ & 13.34 & 20.14 & 46.6 \\
\hline $\mathrm{B} 2$ & 14.37 & $13.79,15.49$ & 13.98 & 21.07 & 46.4 \\
\hline B5 & 17.41 & $15.65,19.17$ & 8.21 & 17.41 & 31.9 \\
\hline $\mathrm{C} 2$ & 8.46 & $8.08,8.84$ & 3.84 & 8.46 & 17.5 \\
\hline $\mathrm{C} 3$ & 17.22 & $16.06,18.38$ & 10.8 & 20.67 & 40.2 \\
\hline B6 & 10.89 & $10.07,11.71$ & 11.78 & 18.63 & 35.4 \\
\hline B7 & 9.42 & $7.74,11.1$ & 8.77 & 14.61 & 23.9 \\
\hline $\mathrm{C} 4$ & 10.1 & $9.59,10.61$ & 7.41 & 12.76 & 25.2 \\
\hline B9 & 17.25 & $16.56,17.93$ & 10.28 & 18.69 & 35.4 \\
\hline B 10 & 15.3 & $14.36,16.24$ & 13.3 & 20.2 & 45.1 \\
\hline
\end{tabular}

Table A-6: Percentage of accelerations

\begin{tabular}{|c|c|c|c|c|c|c|c|c|c|c|c|c|c|c|}
\hline \multirow[b]{2}{*}{ Route } & \multicolumn{2}{|c|}{$a<-0.5$} & \multicolumn{2}{|c|}{$[-0.5,-0.3)$} & \multicolumn{2}{|c|}{$[-0.3,-0.1)$} & \multicolumn{2}{|c|}{$[-0.1,0.1]^{12}$} & \multicolumn{2}{|c|}{$(0.1,0.3]$} & \multicolumn{2}{|c|}{$(0.3,0.5]$} & \multicolumn{2}{|c|}{$a>0.5$} \\
\hline & $\begin{array}{c}\mathrm{T} \\
(\mathrm{s})\end{array}$ & $\begin{array}{c}\mathrm{P} \\
(\%)\end{array}$ & $\begin{array}{c}\mathrm{T} \\
\text { (s) }\end{array}$ & $\begin{array}{c}\mathrm{P} \\
(\%)\end{array}$ & $\begin{array}{c}\mathrm{T} \\
\text { (s) }\end{array}$ & $\begin{array}{c}\mathrm{P} \\
(\%)\end{array}$ & $\begin{array}{c}\mathrm{T} \\
\text { (s) }\end{array}$ & $\begin{array}{c}\mathrm{P} \\
(\%)\end{array}$ & $\begin{array}{c}T \\
(\mathrm{~s})\end{array}$ & $\begin{array}{c}\mathrm{P} \\
(\%)\end{array}$ & $\begin{array}{c}\mathrm{T} \\
\text { (s) }\end{array}$ & $\begin{array}{c}\mathrm{P} \\
(\%)\end{array}$ & $\begin{array}{c}\mathrm{T} \\
(\mathbf{s})\end{array}$ & $\begin{array}{c}\mathbf{P} \\
(\%)\end{array}$ \\
\hline B1 & 26 & 7.9 & 34 & 10.4 & 92 & 28.0 & 53 & 16.2 & 48 & 14.6 & 50 & 15.2 & 25 & 7.6 \\
\hline $\mathrm{B} 2$ & 70 & 9.7 & 54 & 7.5 & 162 & 22.5 & 139 & 19.3 & 165 & 11.9 & 62 & 8.6 & 69 & 9.6 \\
\hline B5 & 11 & 12.8 & 9 & 10.5 & 15 & 17.4 & 3 & 3.5 & 29 & 33.7 & 19 & 22.1 & 0 & 0 \\
\hline $\mathrm{C} 2$ & 1 & 0.3 & 8 & 2.0 & 93 & 23.3 & 198 & 49.5 & 80 & 20.0 & 20 & 5.0 & 0 & 0 \\
\hline C3 & 6 & 2.1 & 19 & 6.8 & 65 & 23.2 & 126 & 45.0 & 27 & 9.6 & 15 & 5.4 & 22 & 7.9 \\
\hline B6 & 70 & 15.0 & 49 & 10.5 & 64 & 13.7 & 75 & 16.1 & 86 & 18.4 & 88 & 18.8 & 35 & 7.5 \\
\hline B7 & 6 & 8.7 & 9 & 13.0 & 3 & 4.3 & 26 & 37.7 & 9 & 13.0 & 4 & 5.8 & 12 & 17.4 \\
\hline $\mathrm{C} 4$ & 30 & 4.7 & 59 & 9.3 & 150 & 23.7 & 162 & 25.6 & 123 & 19.4 & 89 & 14.0 & 21 & 3.3 \\
\hline B9 & 78 & 9.7 & 83 & 10.3 & 139 & 17.3 & 188 & 23.4 & 141 & 17.6 & 119 & 14.8 & 54 & 6.7 \\
\hline B10 & 59 & 10.2 & 71 & 12.2 & 98 & 16.9 & 111 & 19.1 & 69 & 11.9 & 104 & 17.9 & 68 & 11.7 \\
\hline
\end{tabular}

- T- Time

- P-Percentage

${ }^{12}$ Events of idling are not included. 


\section{APPENDIX B}

Weighted Emission Rates and Factors 


\section{Vehicle Category (I)}

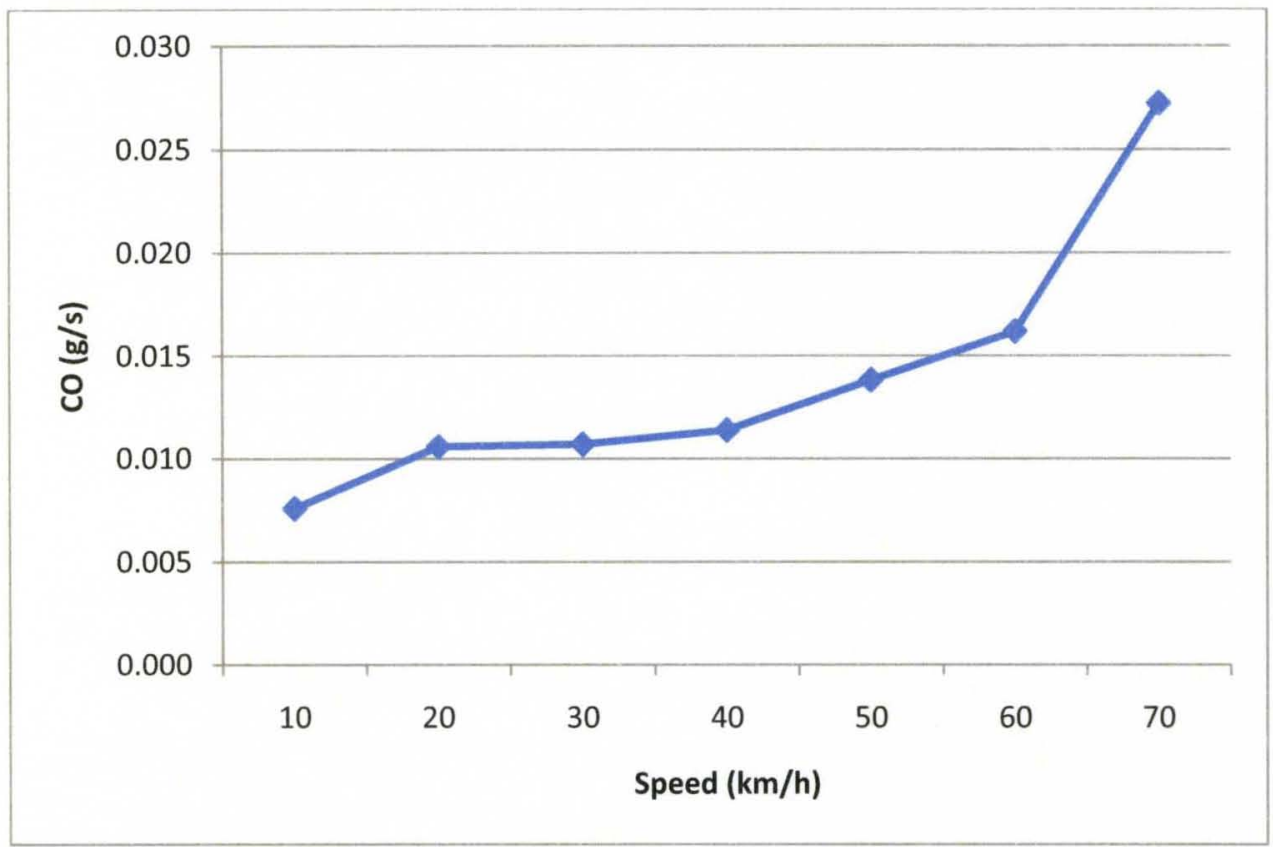

Figure B-1: Emission rate of $\mathrm{CO}$ by speed, vehicle category (I)

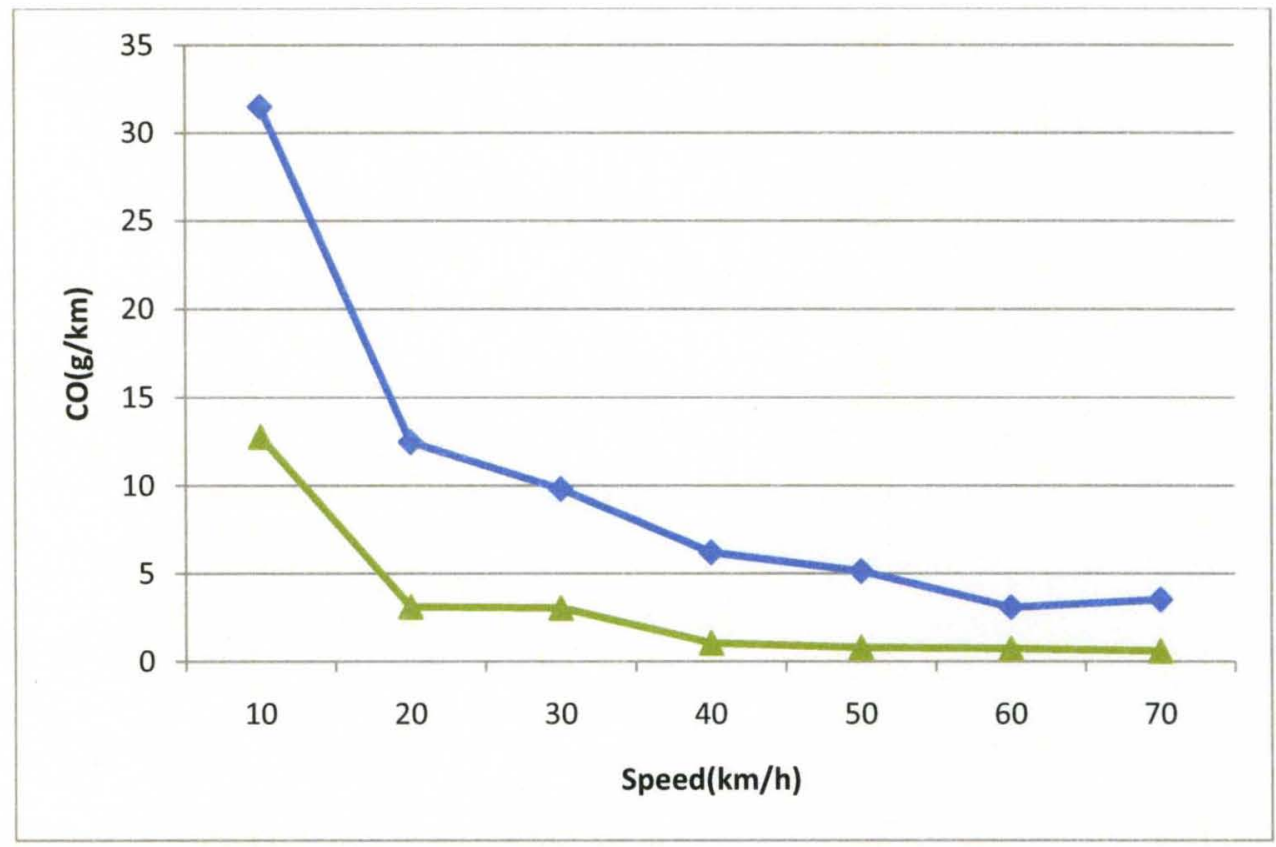

Figure B-2: Emission factor of CO by speed, weighted (square) and average (triangle), vehicle category (I) 


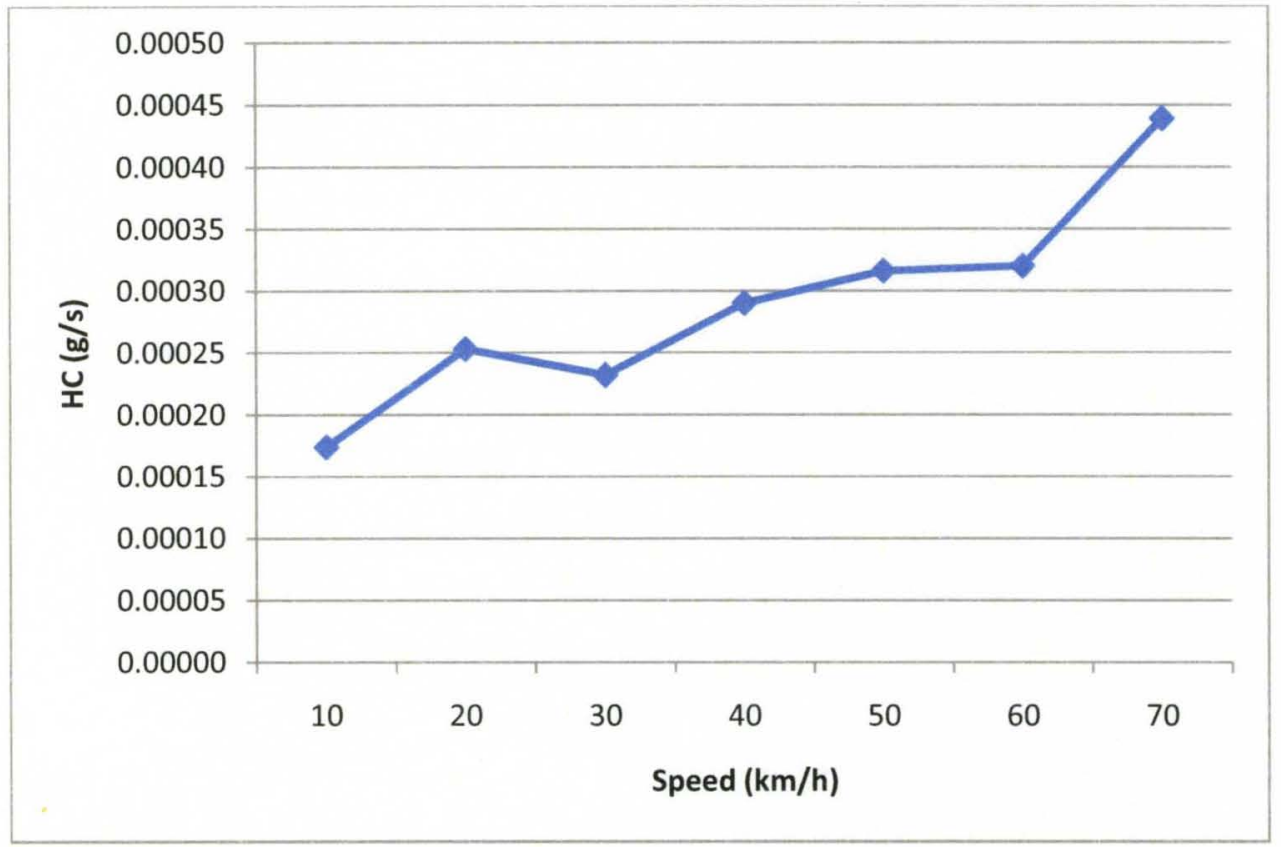

Figure B-3: Emission rate of $\mathrm{HC}$ by speed, vehicle category (I)

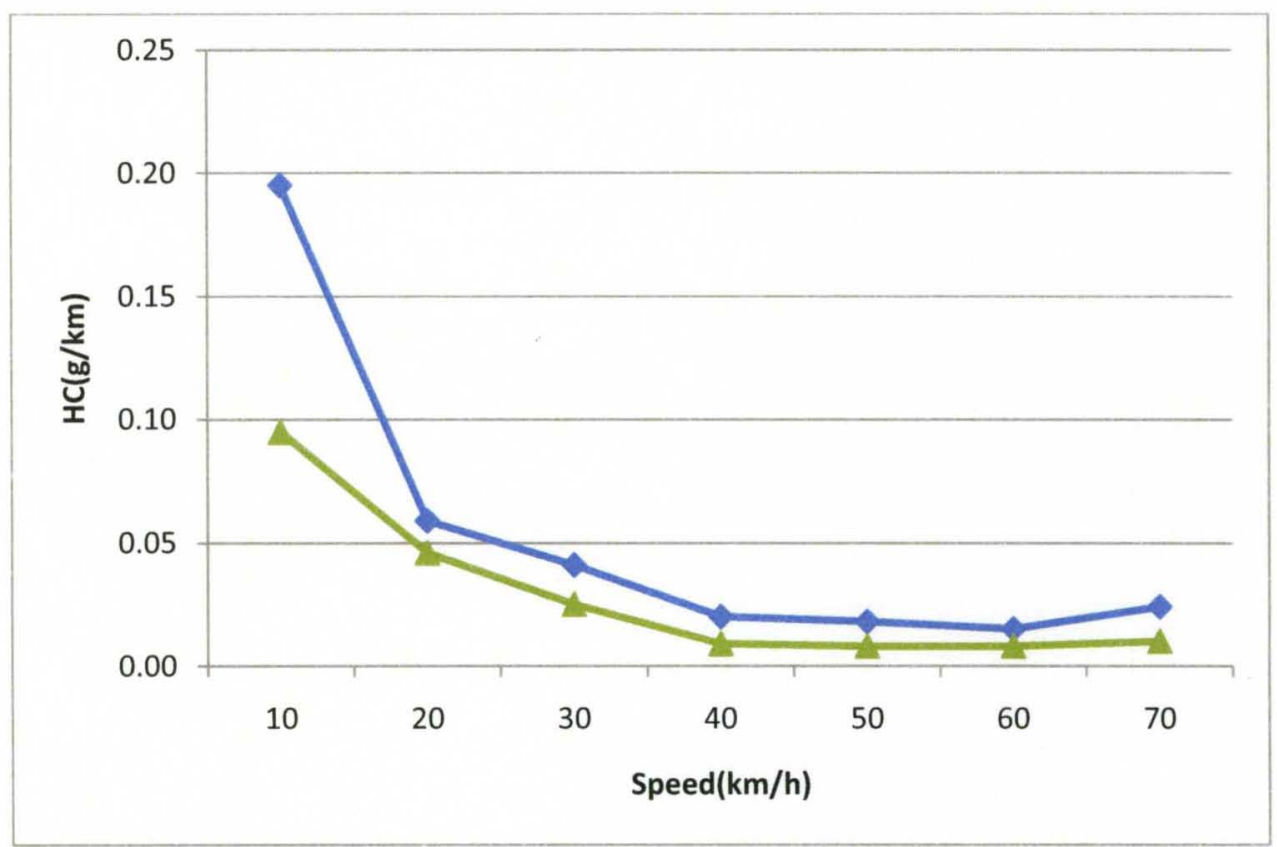

Figure B-4: Emission factor of $\mathrm{HC}$ by speed, weighted (square) and average (triangle), vehicle category (I) 


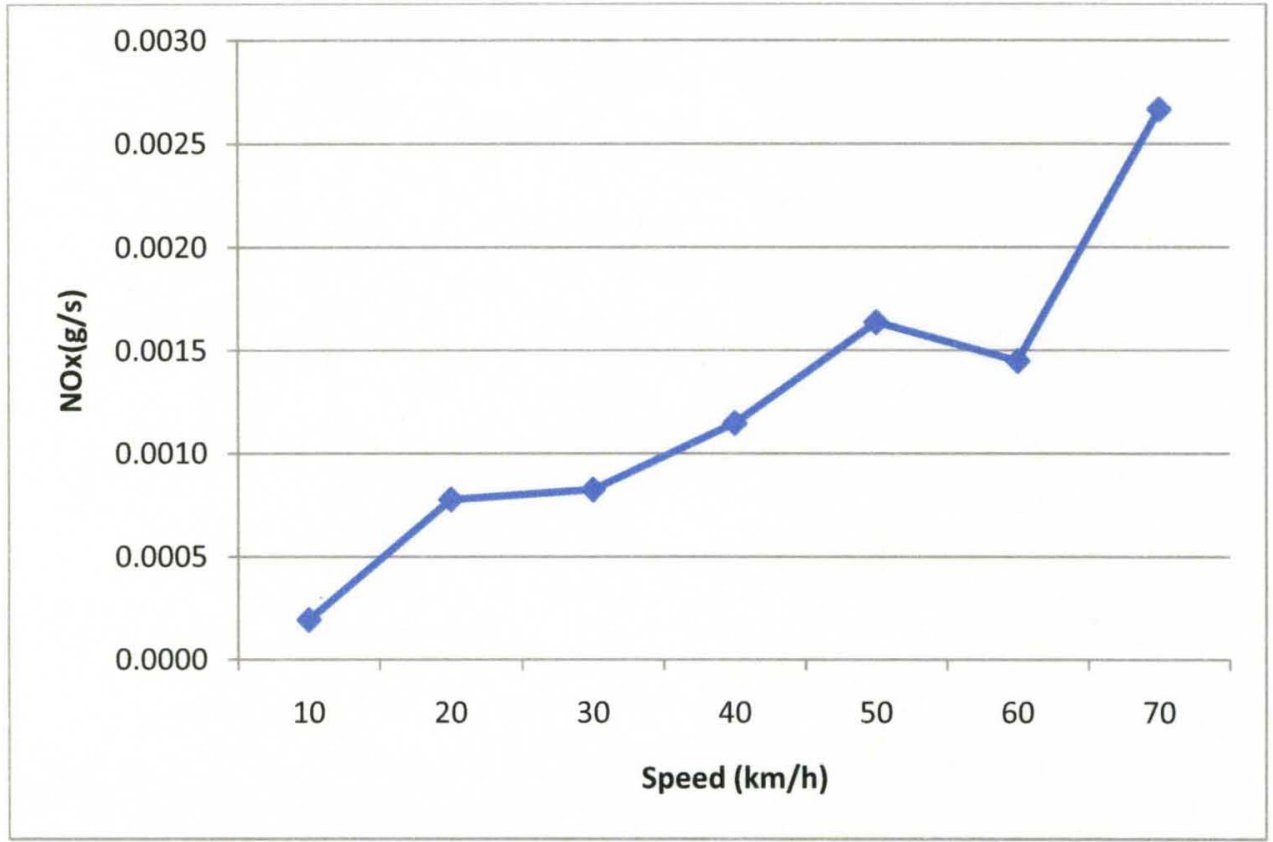

Figure B-5: Emission rate of $\mathrm{NO}_{\mathrm{x}}$ by speed, vehicle category (I)

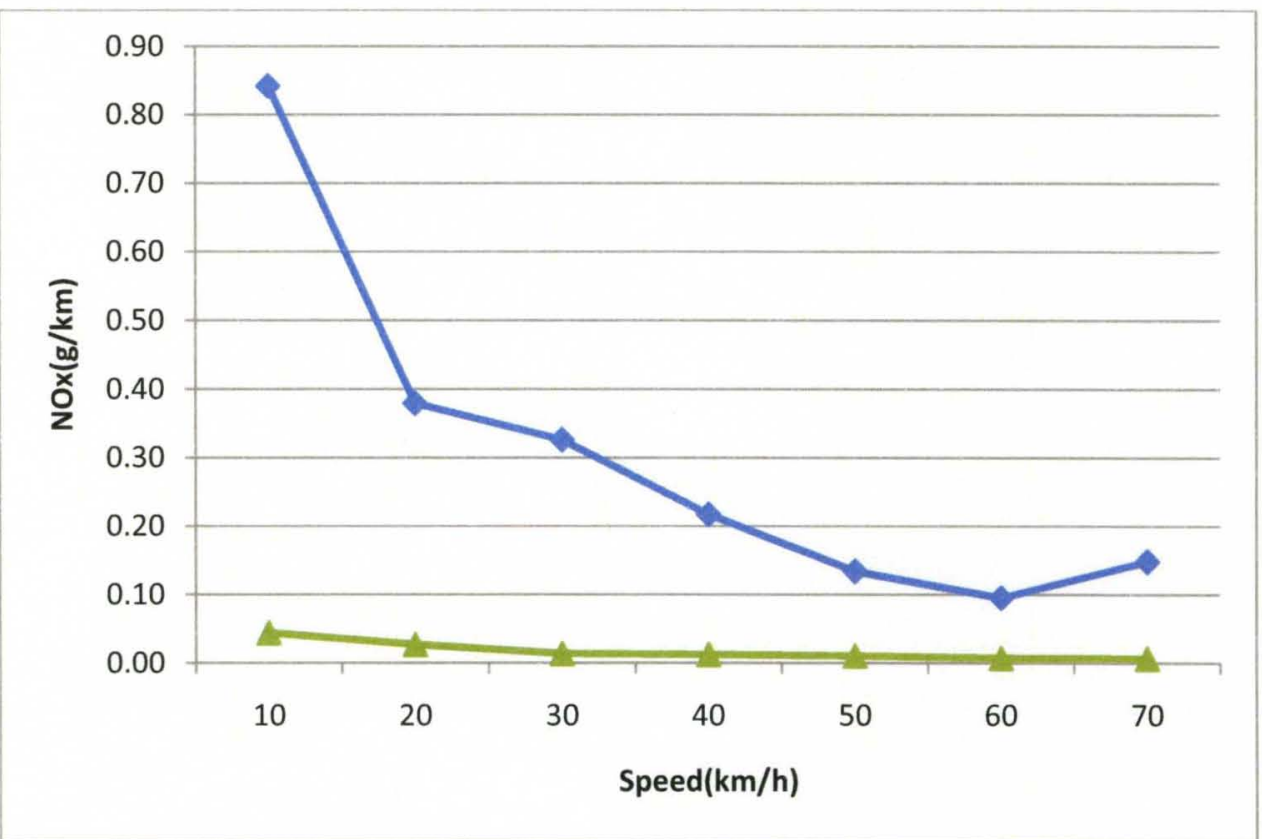

Figure B-6: Emission factor of $\mathrm{NO}_{\mathrm{x}}$ by speed, weighted (square) and average (triangle), vehicle category (I) 


\section{Vehicle Category (II)}

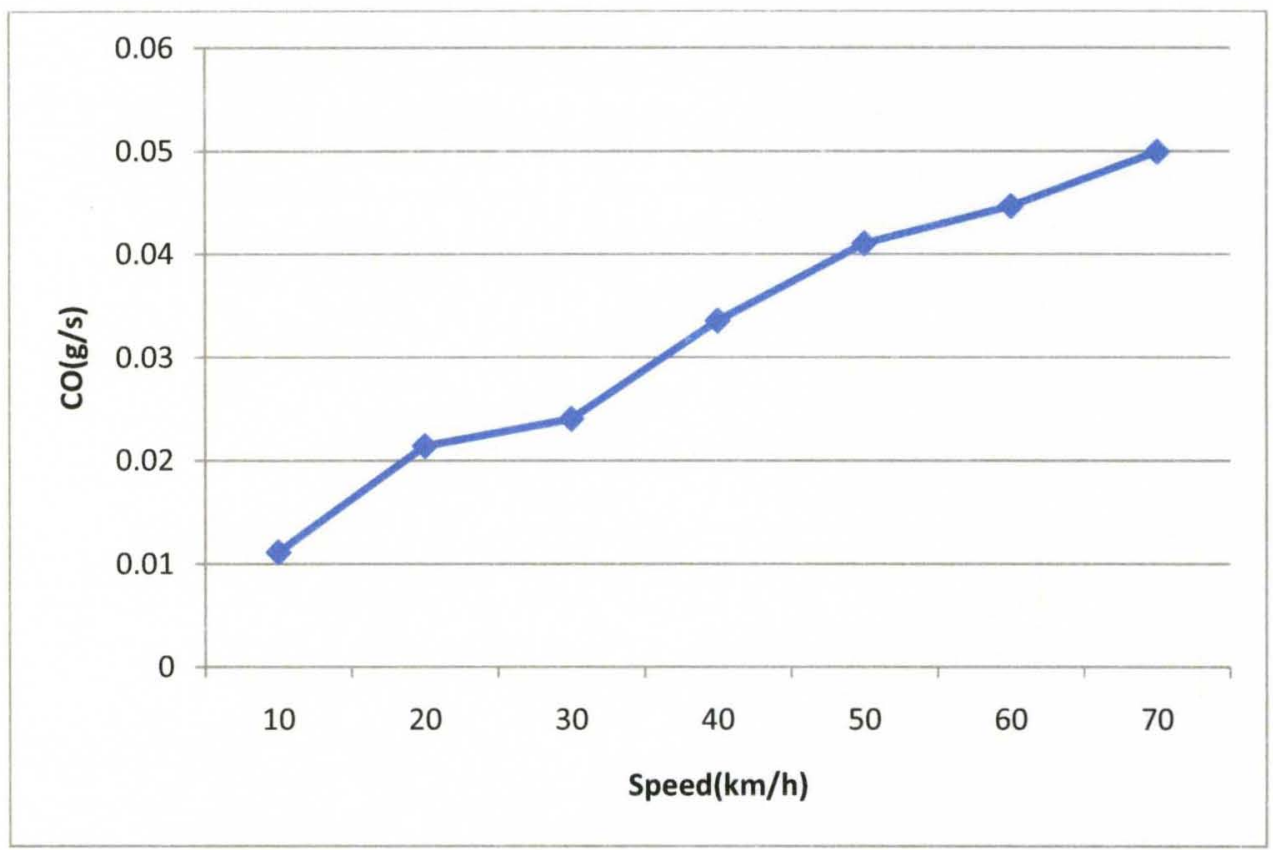

Figure B-7: Emission rate of $\mathrm{CO}$ by speed, vehicle category (II)

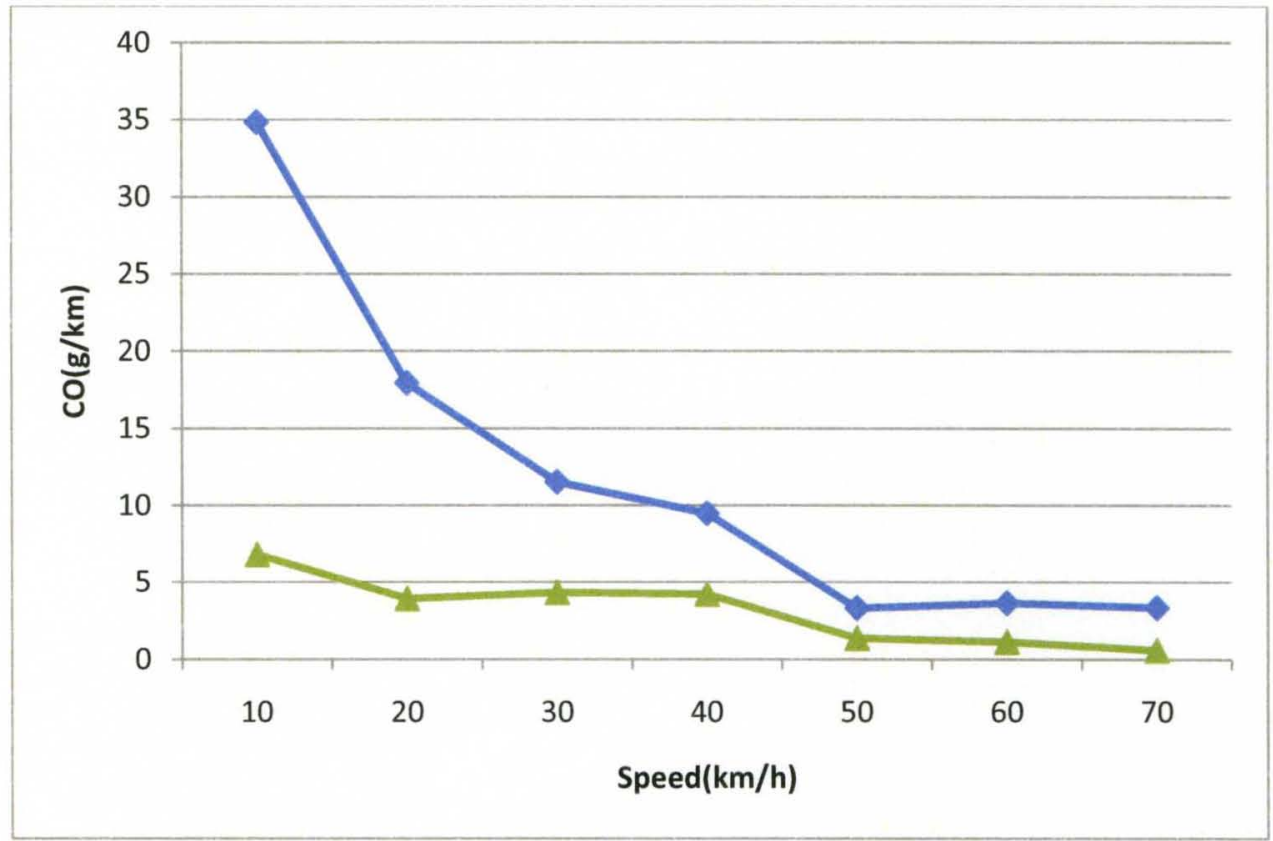

Figure B-8: Emission factor of $\mathrm{CO}$ by speed, weighted (square) and average (triangle), vehicle category (II) 


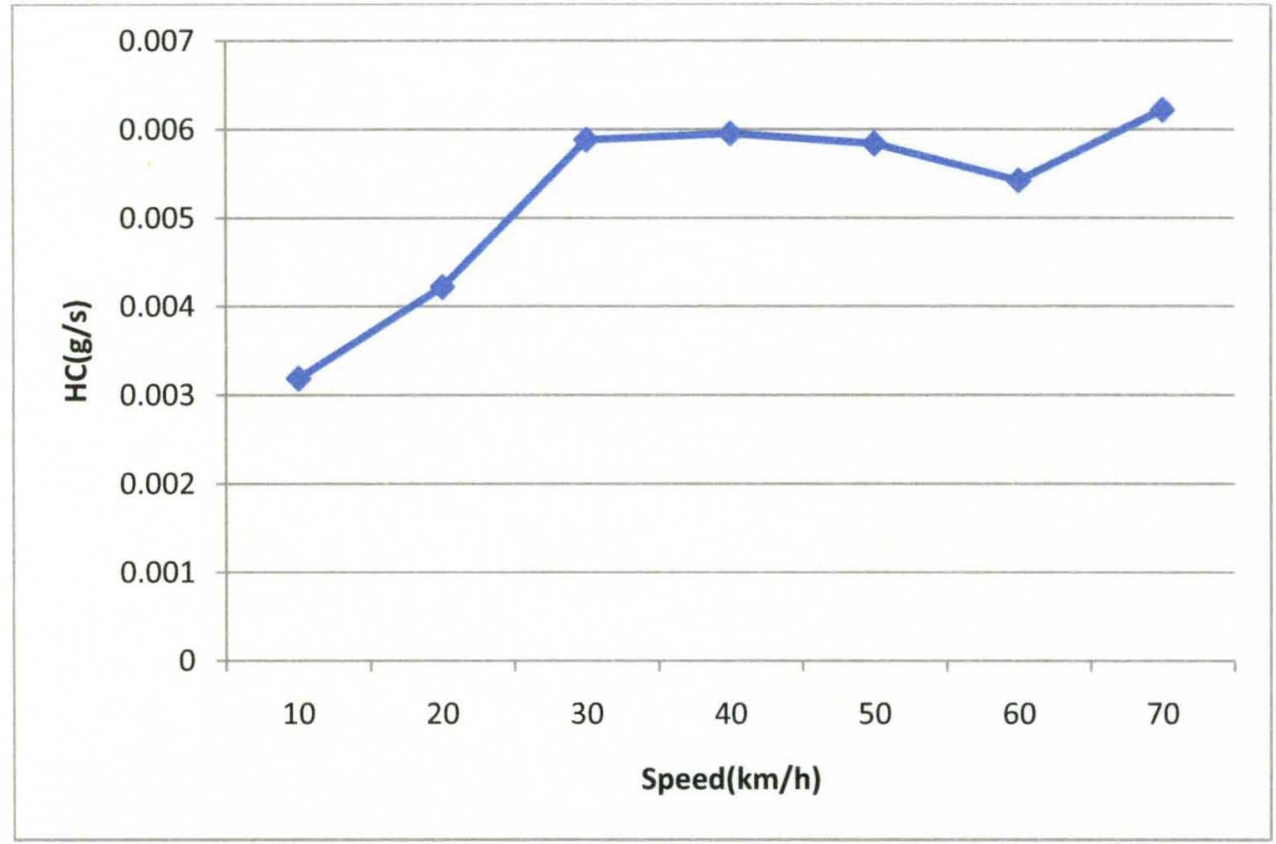

Figure B-9: Emission rate of HC by speed, vehicle category (II)

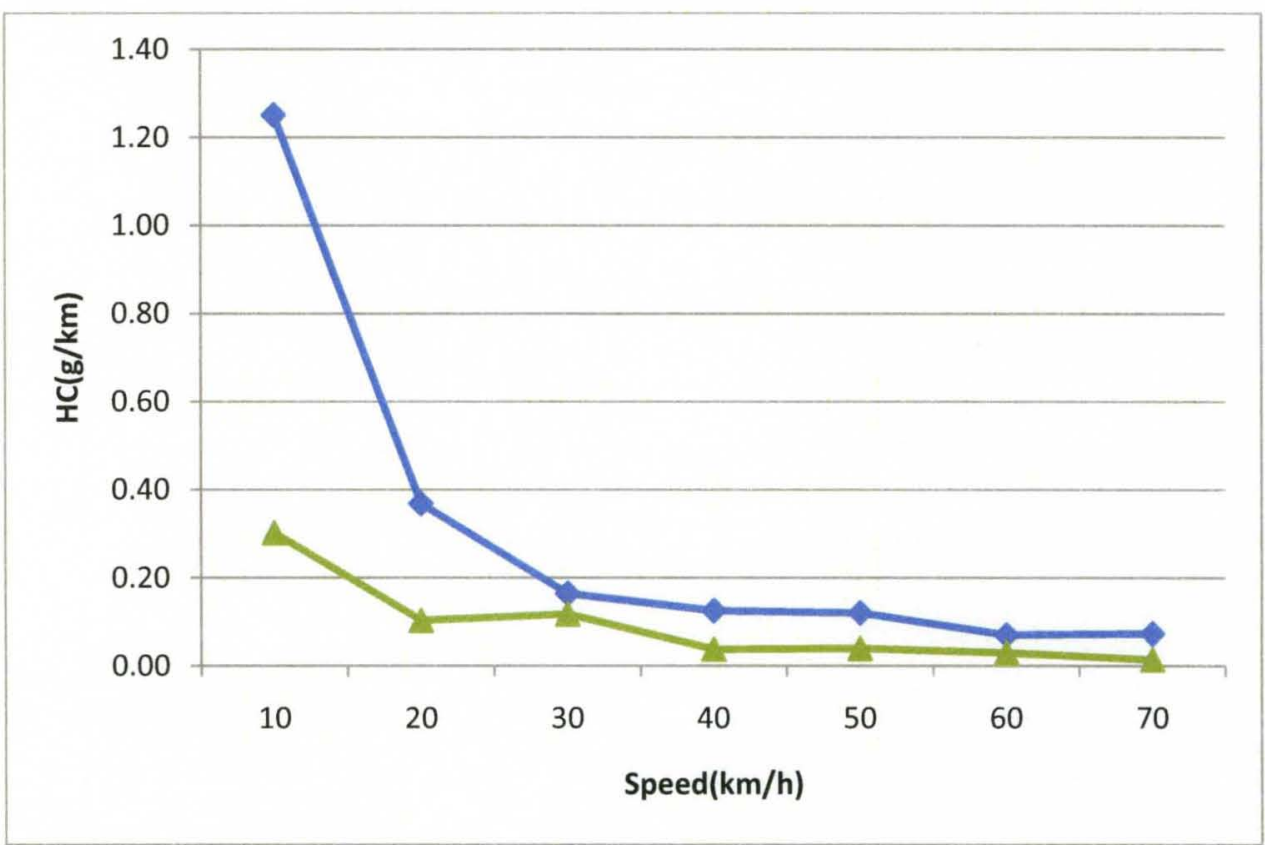

Figure B-10: Emission factor of $\mathrm{HC}$ by speed, weighted (square) and average (triangle), vehicle category (II) 


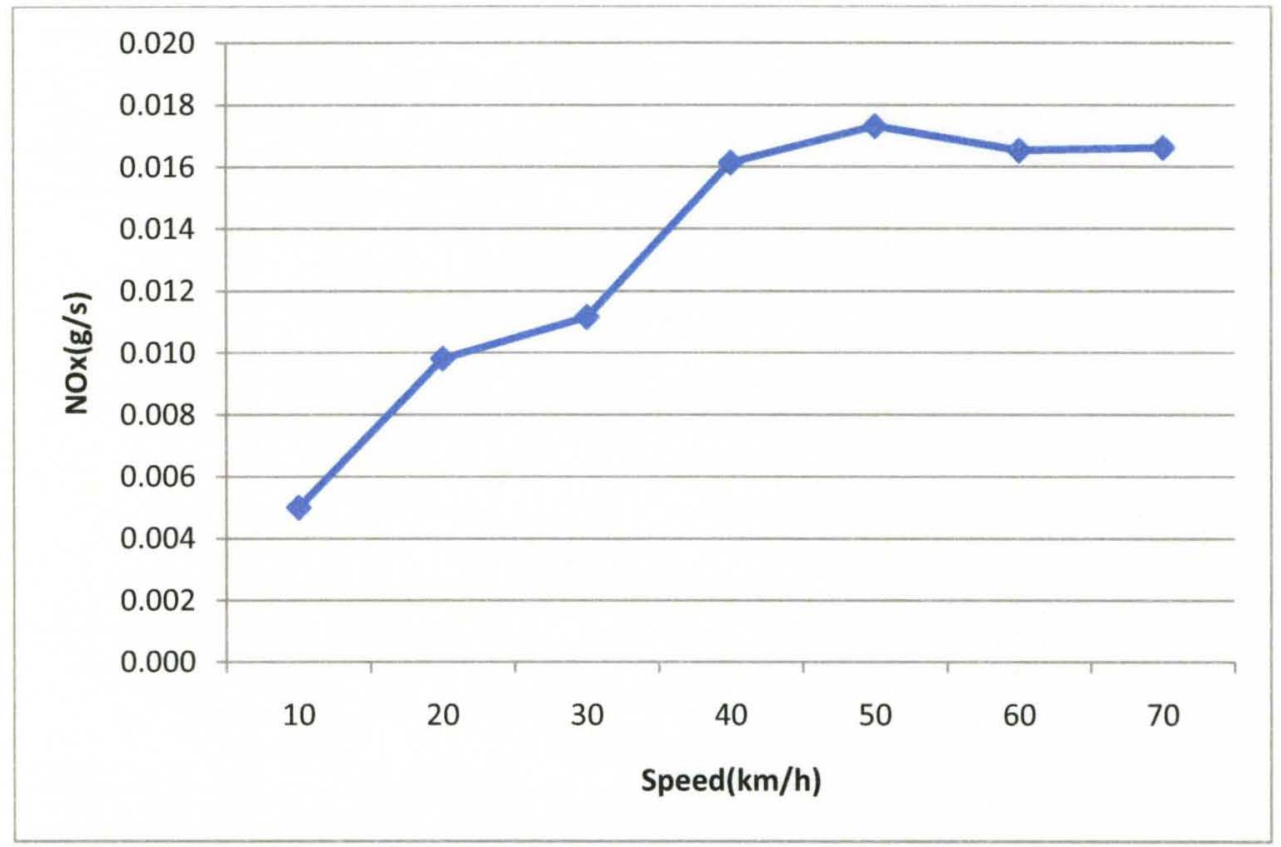

Figure B-11: Emission rate of $\mathrm{NO}_{\mathrm{x}}$ by speed, vehicle category (II)

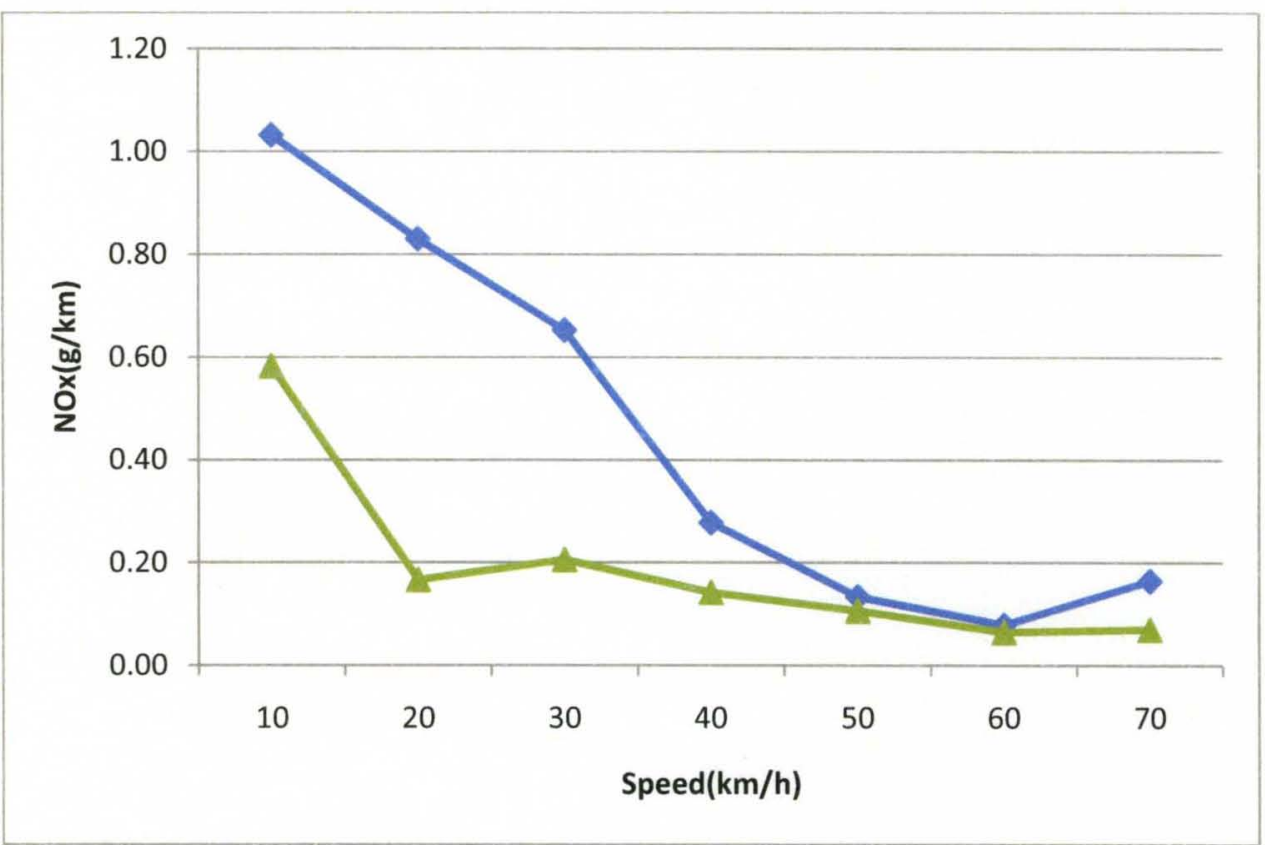

Figure B-12: Emission factor of $\mathrm{NO}_{\mathrm{x}}$ by speed, weighted (square) and average (triangle), vehicle category (II) 


\section{$\underline{\text { Vehicle Category (III) }}$}

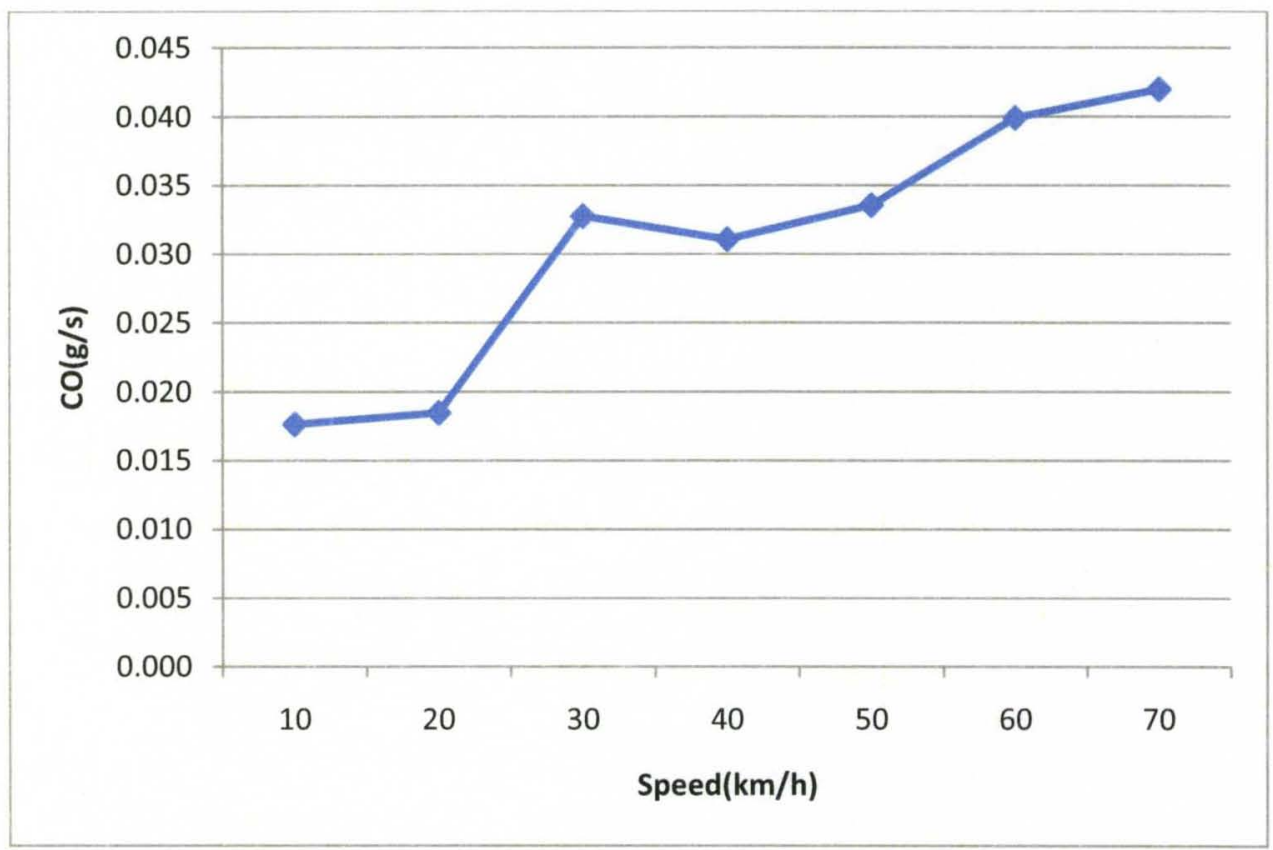

Figure B-13: Emission rate of CO by speed, vehicle category (III)

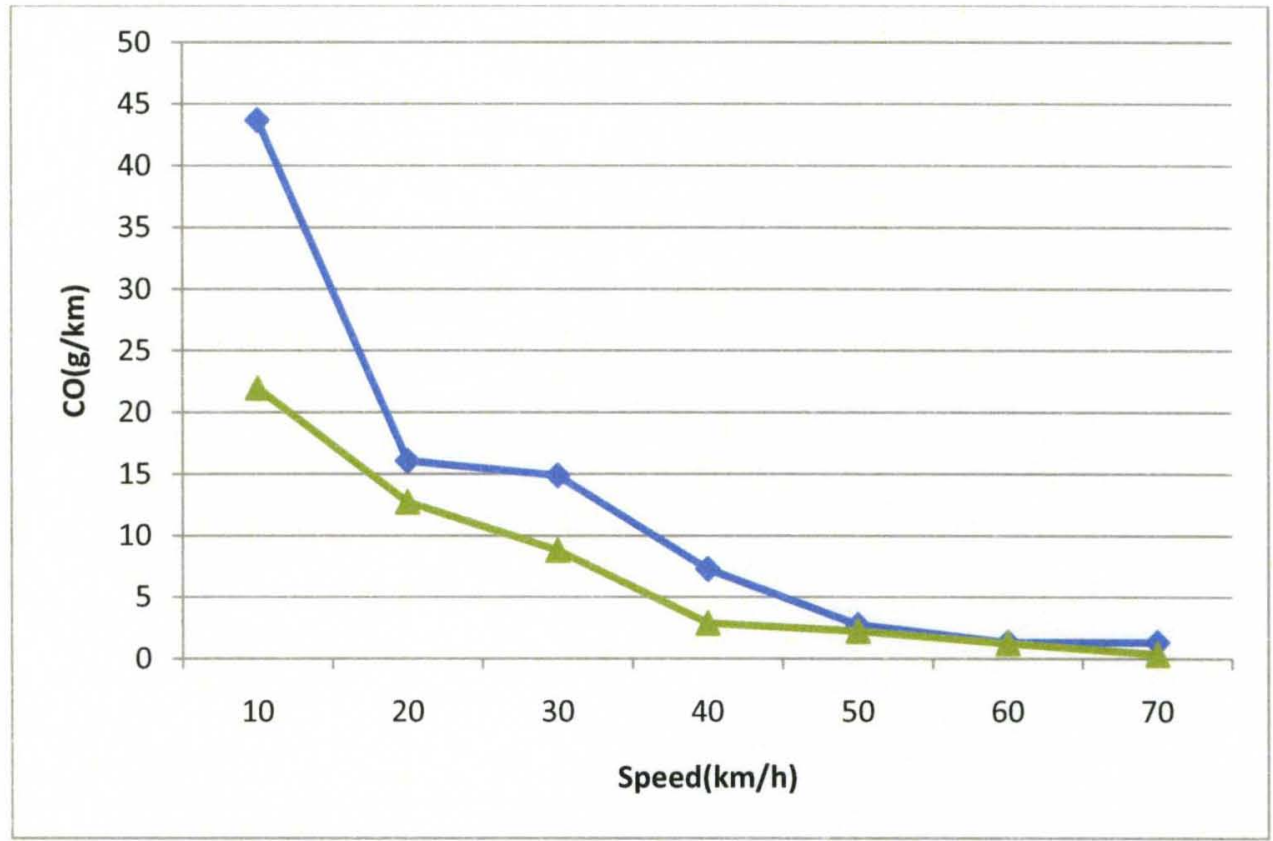

Figure B-14: Emission factor of $\mathrm{CO}$ by speed, weighted (square) and average (triangle), vehicle category (III) 


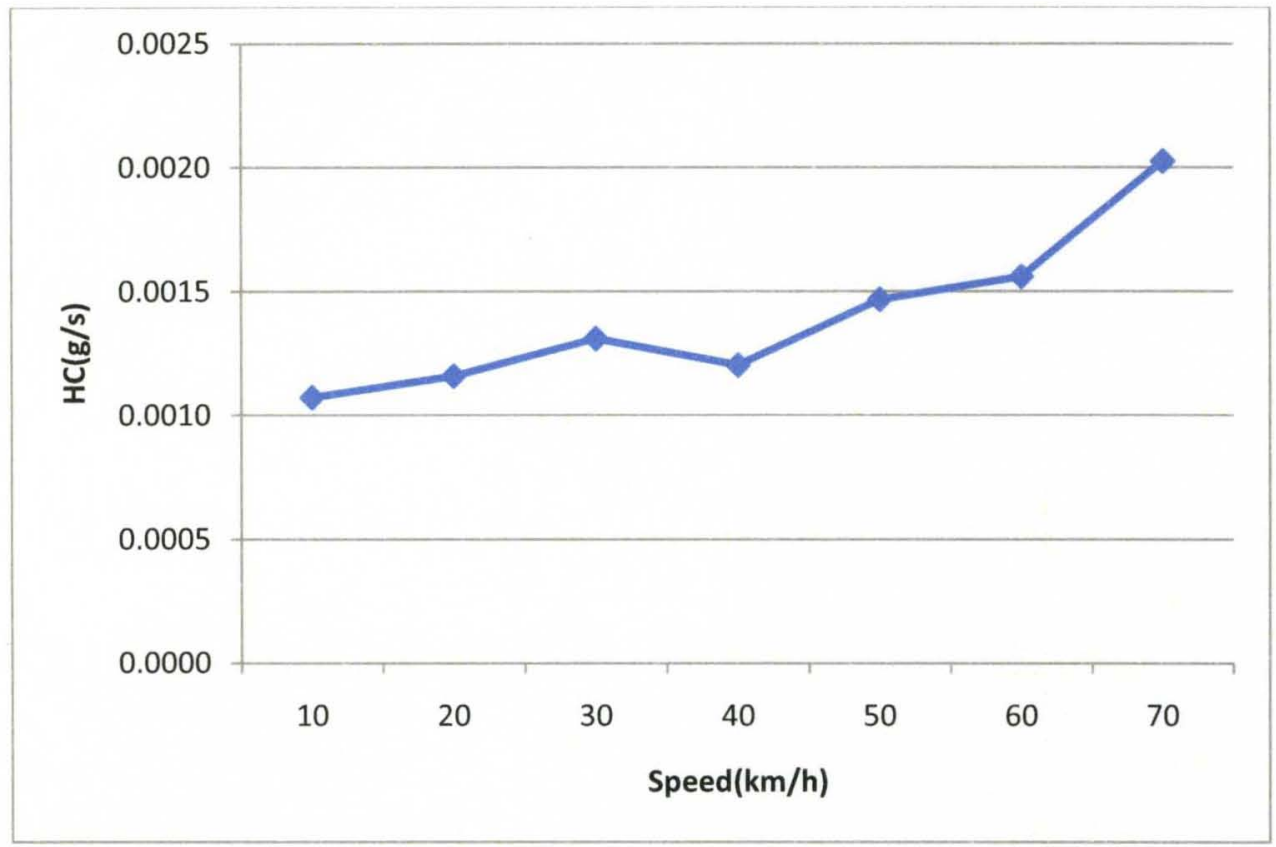

Figure B-15: Emission rate of HC by speed, vehicle category (III)

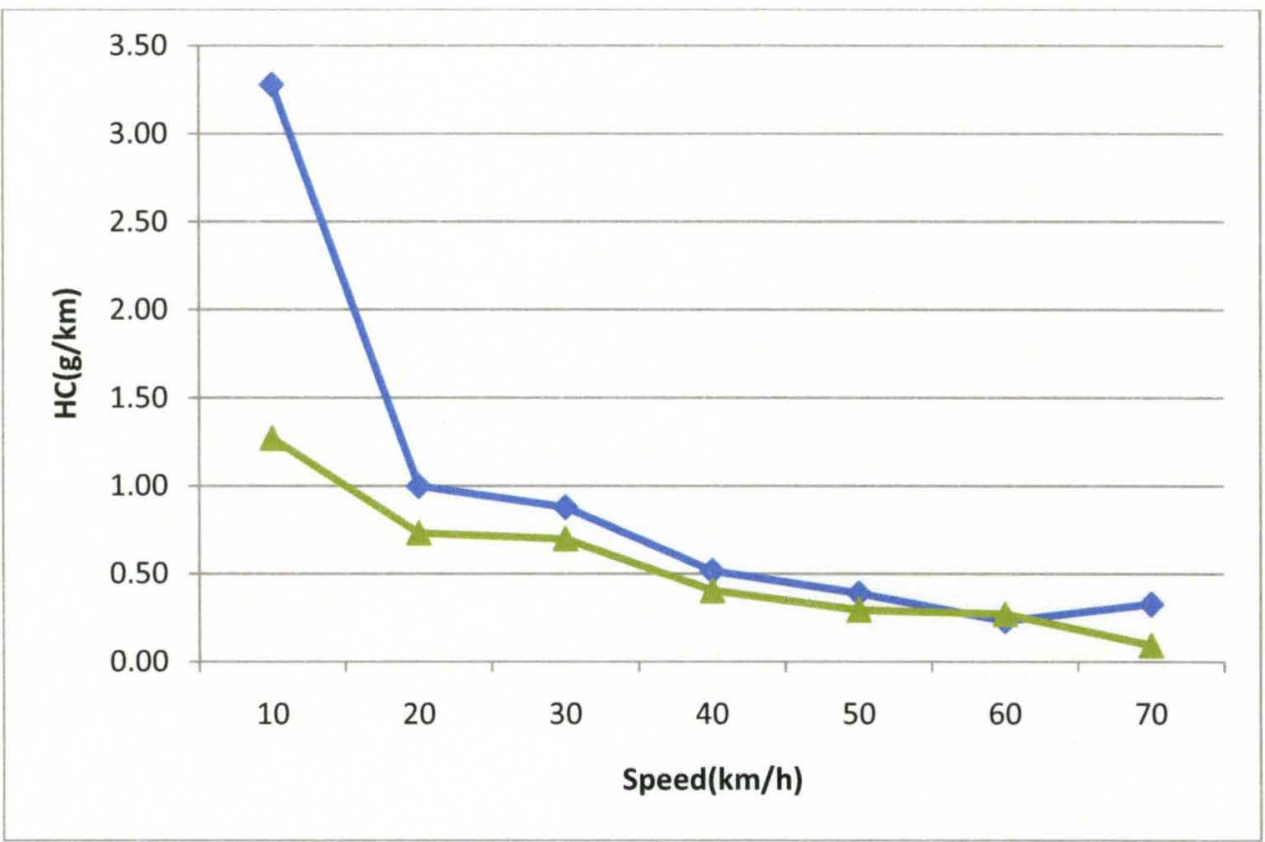

Figure B-16: Emission factor of $\mathrm{HC}$ by speed, weighted (square) and average (triangle), vehicle category (III) 


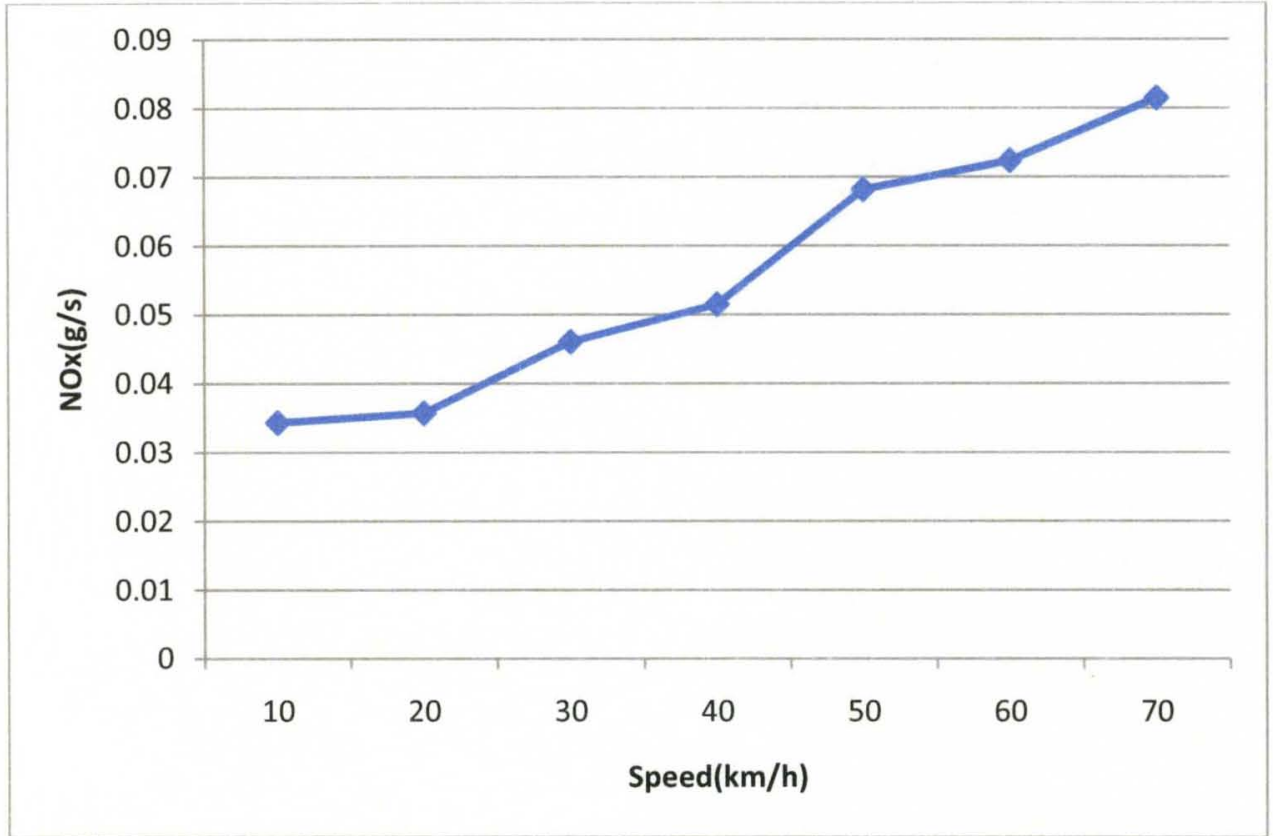

Figure B-17: Emission rate of NOx by speed, vehicle category (III)

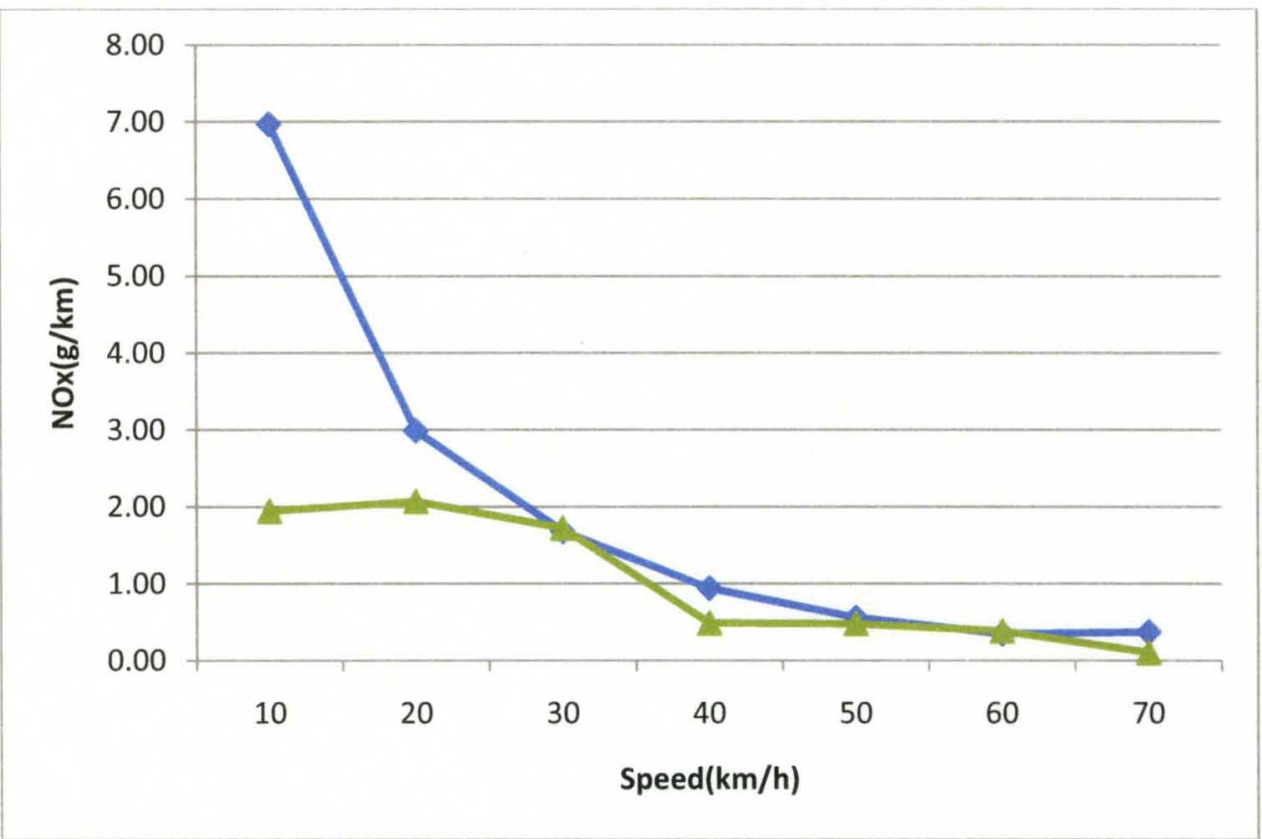

Figure B-18: Emission factor of $\mathrm{NO}_{\mathrm{x}}$ by speed, weighted (square) and average (triangle), vehicle category (III) 


\section{CURRICULUM VITAE}

NAME: $\quad$ Yu Xia

ADDRESS:

785 Presidents Blvd

Louisville, KY 40217

DOB:

May 28, 1980

EDUCATION

\& TRAINING: $\quad$ ESRI ArcGIS Spatial Analyst Certificate

B.S., Traffic Engineering

Southeast University

$1998-2002$

M.S., Transportation Planning

Southeast University

$2003-2006$

Ph.D., Civil \& Environmental Engineering

University of Louisville

$2006-2010$

AWARDS: $\quad$ Matthew Cowan Fellowship, University of Louisville 2008, 2009

PROFESSIONAL SOCIETIES:

American Society of Civil Engineers (ASCE) 